\title{
CATÁLOGO DE LAS PLANTAS VASCULARES DE RÁQUIRA (BOYACÁ), FLORA ANDINA EN UN ENCLAVE SECO DE COLOMBIA
}

\author{
Checklist of the vascular plants of Ráquira (Boyacá), a dry locality in the Andean \\ flora of Colombia
}

Palabras clave: composición florística, ecosistema andino, riqueza florística, diversidad de plantas vasculares.

Key words: floristic composition, Andean ecosystem, floristic richness, vascular plants diversity.

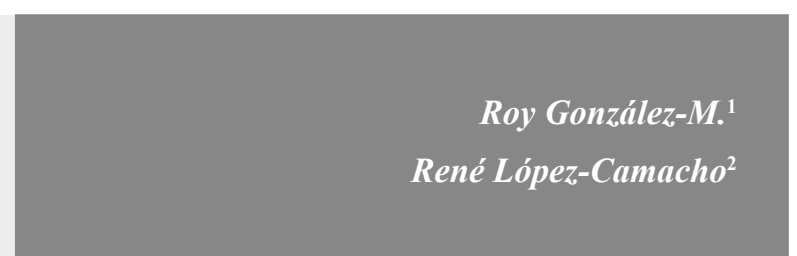

\section{RESUMEN}

La creciente pérdida de ecosistemas andinos y la importancia de su conservación indican la relevancia de efectuar esfuerzos encaminados a la documentación y publicación de la biodiversidad allí presente. Esta investigación provee un listado de las especies de plantas vasculares del municipio de Ráquira (Boyacá), mediante una revisión (consulta directa en herbarios y bases de datos) y levantamientos de información en campo (inventarios y colecciones botánicas), desarrollados durante el 2007 y el 2010. Se encontró un total de 426 especies vasculares, distribuidas en 284 géneros y 99 familias. Desde el punto de vista florístico la familia Asteraceae es la más diversificada con 54 especies distribuidas en 36 géneros, seguida por Fabaceae (33 especies, 21 géneros) y Poaceae (24 especies, 18 géneros). El hábito correspondiente a hierbas fue el más predominante, en términos de riqueza de especies, seguido por los hábitos leñosos (árboles y arbustos). El mayor número de especies se encontró en zonas abiertas y riberas de quebradas. Se registran especies que por su frecuente uso y aprovechamiento han comenzado a extinguirse localmente, como es el caso de Juncus ramboi (esparto) y otras que se encuentran en algún grado de amenaza como Quercus humboldtii (roble). Es importante ampliar el conocimiento sobre la flora vascular de los bosques andinos, en especial, de ecosistemas situados en enclaves secos, puesto que estos se clasifican como zonas de importancia en diversidad de especies de flora en el ámbito mundial.

\section{ABSTRACT}

Increasing Andean ecosystem loss and its conservation priority reinforce the need for documenting Tropical Andean biodiversity. This research provides an updated list of vascular plant species from Ráquira in the Department of Boyacá, based on a database and herbarium review along with field collections between 2007 and 2010. Four hundred and twenty six vascular plant species were found, representing 284 genera and 99 families. Asteraceae was the most diverse family with 54 species and 36 genera, followed by Fabaceae (33 species, 21 genera) and Poaceae (33 species, 21 genera). Herbs were the most common life form followed by woody life forms (trees and shrubs). The greatest number of species was found in open lands and near river margins. Species such as Juncus ramboi were rare because of over harvesting, while other species such as Quercus humboldtii are classified as threatened in Colombia. Improving knowledge of vascular plants in Andean forests is essential, especially in dry ecosystems, which are classified as globally important and diverse biomes.

\footnotetext{
Grupo de investigación Uso y Conservación de la Diversidad Forestal, Universidad Distrital Francisco José de Caldas. rgonzalezm@udistrital. edu.co. Autor para correspondencia.

2 Grupo de investigación Uso y Conservación de la Diversidad Forestal, Universidad Distrital Francisco José de Caldas. rlopezc@udistrital.edu.co
} 


\section{INTRODUCCIÓN}

En el ámbito mundial, uno de los doscientos sectores prioritarios para la conservación de la biodiversidad corresponde a los Andes del norte, los cuales según Myers et al. (2000) son considerados “el epicentro mundial de la biodiversidad". Esta región es una de las zonas con mayor diversidad en especies de flora y fauna en el mundo, pues concentra cerca del $25 \%$ de la biodiversidad del planeta; esto es debido a que se ha identificado como uno de los primeros veinticinco hotspots de la biodiversidad en el mundo (Mittermeier et al., 1999; Myers et al., 2000; Brehm et al., 2008).

Según Cabrera \& Ramírez (2007), los ecosistemas andinos de Colombia ocupan una superficie aproximada de $280000 \mathrm{~km}^{2}$, área catorce veces menor que la cuenca amazónica, no obstante, presenta cantidades similares de especies, incluyendo plantas, aves y reptiles (WWF, 2001), aspecto que ha posicionado a Colombia entre los cinco países más diversos del mundo, designándolo como una zona megadiversa (Chaves \& Arango, 1998; Armenteras et al., 2003).

En relación con estos ecosistemas entre los factores que inciden en las tasas de deforestación se encuentran la migración forzada de la población, las necesidades básicas insatisfechas, el establecimiento de cultivos, los pastizales, los cultivos ilícitos; estos actores inciden permanentemente en la perdida de cobertura (Armenteras et al., 2011). Estos procesos, junto con la búsqueda permanente de conversión de áreas naturales andinas a tierras con fines de producción agrícola y pecuaria (base económica de la región) y los procesos de urbanización han puesto estos ecosistemas en serio peligro, lo que ocasiona una pérdida desproporcionada de biodiversidad e influyen en el número de especies de fauna y flora que se encuentran en riesgo de extinción. Se ha reconocido que esta zona es altamente vulnerable frente a la perdida de esta riqueza biótica (Carrizosa \& Hernández, 1990; Mittermeier et al., 1999; Olson \& Dinerstein, 2002; Feeley \& Silman, 2010).

La intervención sobre la cobertura vegetal en la cordillera de los Andes se encuentra aproximadamente en un 70\% Así, Cabrera \& Ramírez (2007) establecieron que durante el periodo 1985-2005 el área de estos ecosistemas disminuyó en un $14.20 \%$, lo que ha generado una alteración en la diversidad presente en esta región. Actualmente, la población asentada en esta región sustenta varias de sus actividades económicas en el aprovechamiento del bosque, como la ampliación de la frontera agrícola y la conformación de bancos de tierras disponibles para la producción; esta noción ha generado una concepción errada sobre la disponibilidad ilimitada de los recursos biológicos (Rudas et al., 2007), por lo tanto, repercute en el olvido de antiguas prácticas de provisión de alimentos y en el detrimento de estos ecosistemas naturales. Por ejemplo, Rodríguez et al. (2005) establecen que las dinámicas socioeconómicas de los Andes han generado gran fragmentación en los procesos naturales de la región, lo cual está relacionado directamente con la densidad de la población y la actividad económica, factores potencialmente negativos para la diversidad biológica.

Teniendo en cuenta que la región de los andes reúne más del $69 \%$ de la población del país con una densidad que varía entre 1.5 y 2.8 habitantes por hectárea (Garcés \& de la Zerda, 1994; Chávez \& Arango, 1998) y que los ecosistemas andinos son reconocidos en el mundo como un punto estratégico por su extraordinaria riqueza de especies y endemismos y por la necesidad de preservación de variados servicios ecosistemicos que estos sistemas naturales proveen (Myers et al., 2000; Orme et al., 2005), se hace necesario realizar esfuerzos encaminados a documentar y a publicar la información relacionada con la diversidad presente en la región andina de Colombia.

El municipio de Ráquira mejor conocido como "Pueblo de Olleros" se encuentra localizado sobre la cordillera oriental de los Andes colombianos, al norte de Boyacá, formando parte de las zonas áridas xerofíticas, de pisos térmicos fríos, respectivas al enclave seco de Villa de Leyva (Guzmán \& Fajardo, 2000). Este municipio basa su economía en la fabricación de artesanías, lo que ha implicado un alto uso de especies vegetales como insumo 
para el desarrollo de esta actividad (López, 2007; Moncada, 2010). A pesar de la fuerte intervención y alteración de los ecosistemas, el municipio de Ráquira posee importantes remanentes de cobertura vegetal, principalmente de tipo herbáceo y arbustivo, que se distribuyen en áreas geográficas como el desierto de la Candelaria, el páramo de Rabanal, los bosques de Roble de la reserva forestal El Chaute, entre otros, los cuales, a pesar de poseer una estructura y fisionomía propia de cada cobertura, hacen parte de los ecosistemas andinos de zonas áridas y semiáridas descritas por Guzmán \& Fajardo (2000).

Los ecosistemas secos se han estudiado ampliamente en Colombia en el ámbito florístico (Ariza, 1999; Mendoza-C., 1999; Peñaloza, 2001; Albesiano et al., 2003; Albesiano \& Fernández-Alonso, 2006; Figueroa-C \& Galeano, 2007). Sin embargo, los ecosistemas andinos de características xerofíticas presentan pocos estudios que reportan su composición florística (Albesiano \& FernándezAlonso, 2006); por ejemplo, en franjas superiores a los $2000 \mathrm{~m}$ de altitud tan solo se identifican los estudios adelantados por Becerra \& Méndez (1990), Sarmiento \& Cano (1997) y Flores et al. (2010).

Reportes preliminares, relacionados con la vegetación del municipio de Ráquira, incluyen inventarios parciales y estudios de vegetación en sectores aislados como el desierto de la Candelaria, alrededores de la laguna de Fuquene, colecciones en las veredas Resguardo occidente, Roa, Farfán, Firita Peña Abajo, así como de las cuchillas El Chaute, Pan de Azúcar y Confites -estas últimas forman parte del páramo de Rabanal-. Las primeras colecciones botánicas realizadas en este municipio se remontan a 1963 (Becerra \& Méndez, 1990) y fueron adelantadas por Jaramillo, Saravia y Hernández, así como por Cardozo, más adelante en 1965. En 1985, el señor John Orbell, habitante de la región, efectuó una colección de doscientos ejemplares (10 001-10 200), buscando dar inicio a un herbario regional en Ráquira; este trabajo fue la base para las posteriores colectas botánicas adelantadas por Becerra \& Méndez (1990) en su trabajo titulado: Contribución al estudio de la flora del municipio de Ráquira (Boyacá). Estos autores efectuaron colec- tas de 587 exsicados, respectivos a 291 especies, los cuales fueron depositados en el Herbario Nacional Colombiano (COL), bajo la numeración de A. Virginia Méndez (001-287) y Carolina Becerra (001-300), quizás este sea el mayor esfuerzo realizado a la fecha para el conocimiento de la flora de este municipio.

Otros trabajos puntuales han sido adelantados por la Universidad Pedagógica y Tecnológica de Colombia (UPTC), quienes efectuaron aproximaciones sobre la composición florística en algunos sectores del municipio. Flores et al. (2010) elaboraron recientemente el catálogo de plantas útiles del páramo de Rabanal con los principales usos dados a las plantas por los habitantes en esta zona, estudio que junto con los reportes realizados por López et al. (2008) se constituyen como las únicas aproximaciones sobre la investigación etnobotánica en el municipio.

Este estudio tiene como objetivo presentar el listado actual de conocimiento de la flora vascular de Ráquira, contribuyendo con nuevos reportes de la flora existente en esta región, de forma que se constituya en elemento básico para proyectos de restauración y manejo de la vegetación.

\section{MATERIALES Y MÉTODOS}

\section{ÁREA DE ESTUDIO}

El estudio se realizó en Ráquira, localizado al occidente de Boyacá, entre los $5^{\circ} 32^{\prime}$ de latitud norte y $73^{\circ} 38^{\prime}$ longitud oeste, a unos $60 \mathrm{~km}$ de Tunja y 29 km desde Chiquinquirá, el cual posee una extensión de 204 km², limita al norte con Tinjacá y Sutamarchan, al oriente con Sáchica y Samacá, al sur con el municipio de Guachetá (Cundinamarca) y al occidente con San Miguel de Sema y la Laguna de Fuquene (AMR, 2012; Figura 1). Por el municipio cursan varios afluentes hídricos, de los cuales se destacan los ríos Ráquira, La Candelaria, Dulce, Salado, Firita y otros de menor caudal pertenecientes a la cuenca del río Suárez (IGAC, 1980).

El régimen de precipitación es bimodal con dos periodos secos, el primero que abarca enero, fe- 


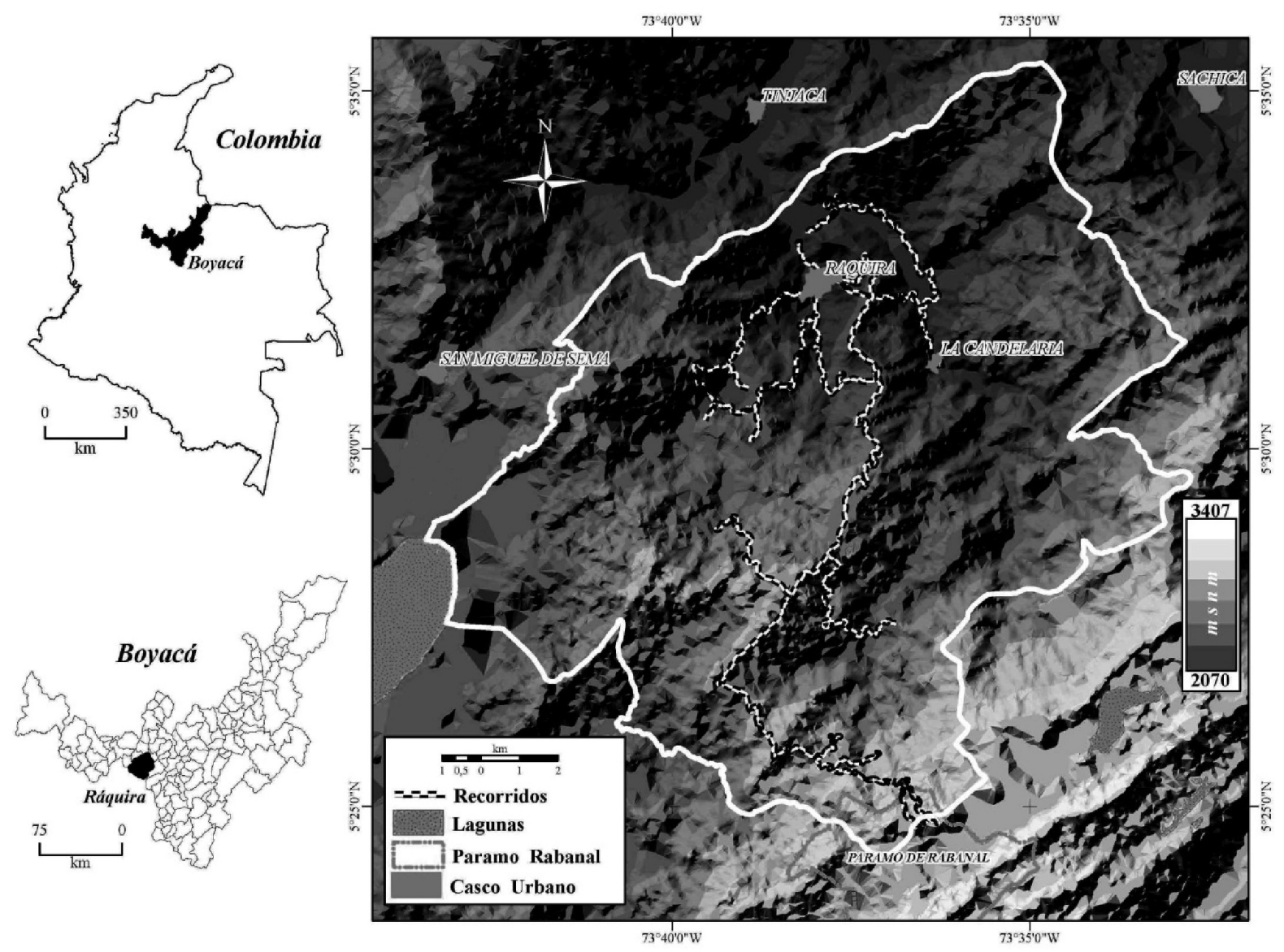

Figura 1. Localización del área de estudio, caminatas y recorridos en el municipio de Ráquira

brero y marzo y el segundo de julio a diciembre, alternándose con dos periodos húmedos. En los periodos secos se registran mínimos frecuentes de $0 \mathrm{~mm}$ y el máximo de precipitación es de $373 \mathrm{~mm}$ en el mes de octubre. La temperatura media es de $17^{\circ} \mathrm{C}$ (Sinning, 2010; AMR, 2011), de acuerdo con la clasificación para zonas de vida propuesta por Holdridge (1987), el área de estudio se define dentro del bh-MB, sin embargo, dado que el municipio se encuentra en un enclave azonal -por ejemplo, condiciones heterogéneas de clima, suelo, topografía, entre otros (Becerra \& Méndez, 1990)-, se puede definir el área dentro de una zona climática árida de matorrales xerofíticos en pisos térmicos fríos, perteneciente al enclave seco de Villa de Leyva (Guzmán \& Fajardo, 2000).

La topografía de la zona varía desde plana a quebrada y esto genera condiciones locales diversas que permiten establecer diferentes tipos de vegetación. Las áreas planas son dedicadas a actividades agropecuarias y se constituyen en el área de mayor productividad agrícola. En las áreas de mayor pendiente se presentan fuertes problemas de erosión. El contraste de paisajes hace que se presenten en el municipio ecosistemas desde páramo como es el caso del páramo El Rabanal a $3210 \mathrm{~m}$ de altitud, el cual es compartido con los municipios de Guachetá y Samacá, hasta zonas desérticas en el sector de la vereda Candelaria. Otro ecosistema de importancia lo constituyen los bosques andinos dominados por roble (Quercus humboldtii), presentes en la reserva natural El Chaute o Robledal, declarada Zona de Reserva Forestal en 1982 (Linares et al., 2007).

La economía principal de Ráquira está constituida en un $75 \%$ por la actividad de las artesanías; esta es un legado indígena y afortunadamente ha prevalecido hasta nuestros días, es famosa en los ámbitos nacional e internacional (Mora de Jaramillo, 1974; Moncada, 2010). La actividad artesanal se desarrolla principalmente bajo técnicas manuales, de rollo, de torno, torno-molde, moldes y colado, 
elaborando objetos de diversa índole que van a ser parte de decoración, jardinería y de uso doméstico. El trabajo en cestería también es importante, en este se emplean especies como Juncus ramboi, J. effusus y J. echinocephalus, las cuales se han vuelto escasas en la región y es necesario adquirirlas en zonas aledañas al municipio.

\section{RECOLECCIÓN DE LA INFORMACIÓN}

La información se obtuvo mediante dos métodos de trabajo, el primero compilando información secundaria y el segundo mediante el levantamiento de información en campo.

\section{Información secundaria}

Se incluyeron las colecciones realizadas por Becerra \& Méndez (1990) y López (2007), adicionalmente se consultaron las colecciones consignadas en los herbarios COL, Herbario Forestal Universidad Distrital (UDBC) y Herbario Federico Medem - Instituto Alexander von Humboldt (FMB). Posteriormente, se actualizaron los nombres científicos de todas las colecciones, con el apoyo de monografías, floras generales, descripciones originales, artículos y las bases de datos disponibles en internet como W3-Trópicos (http:// mobot.mobot.org/), The Internacional Plant Names Index (http://www.ipni.org/), The Plant List (http:// www.theplantlist.org/) y el catálogo de plantas vasculares de Ecuador (Jorgensen \& León-Yánez, 1999).

\section{Levantamiento de información en campo}

Durante el 2007 y el 2010 se hicieron visitas de campo, asimismo, se realizaron recorridos y caminatas transecto con habitantes de la región (Figura 1), por los diferentes tipos de cobertura vegetal presentes en este municipio (ejemplo, paramo de Rabanal, subparamo, bosques, desierto de la Candelaria, áreas antropizadas). En la mayoría de los casos se colectó material vegetal fértil, para hacer más confiable la determinación taxonómica. Cada ejemplar colectado fue numerado bajo los siguientes colectores María Fernanda
Franco (MFF), Roy González (RG), René López (RL), Viviana Pinzón (VP) y Andrea Ramírez (AR). El material fue prensado y alcoholizado (etanol 90\%), para posteriormente ser procesado e incluido en la colección del Herbario UDBC. Se consignaron en una libreta de campo las características específicas que no se conservan con la muestra -colores, olores, material reproductivo si lo hay, características de la corteza, presencia de látex, biotipo-, la información reportada por los habitantes de la región -i.e. nombres comunes, características generales del área de localizacióny los datos espaciales del individuo colectado (coordenadas geográficas y altitud). Adicionalmente se tomó un registro fotográfico de las especies colectadas.

\section{PROCESAMIENTO DEL MATERIAL VEGETAL}

El material colectado fue determinado en el Herbario Forestal Gilberto Emilio Mahecha (UDBC) de la Universidad Distrital Francisco José de Caldas. La organización de las angiospermas se realizó de acuerdo con el sistema de clasificación APG III (Angiosperm Phylogeny Group; Haston et al., 2009; Stevens, 2010), los helechos y afines se agruparon según la propuesta de Tryon \& Tryon (1982) y las gimnospermas siguiendo los criterios establecidos por Judd et al. (2002). Las abreviaturas de los autores en las especies se realizaron de acuerdo con lo establecido por Brummitt \& Powell (1992). En cada familia los géneros y las especies se organizaron en orden alfabético. Con el apoyo de las bases de datos W3-Tropicos, The Internacional Plant Names Index y The Plant List se homologó la información asociada con nombres aceptados de las especies, las abreviaturas de los nombres de los autores de cada taxón y posibles sinónimos taxonómicos. De acuerdo con la clasificación realizada se presenta el catalogo de plantas vasculares del municipio de Ráquira (Anexo 1) como se ilustra en la figura 2.

\section{RESULTADOS}

Se reporta un total de 426 especies de plantas vas- 


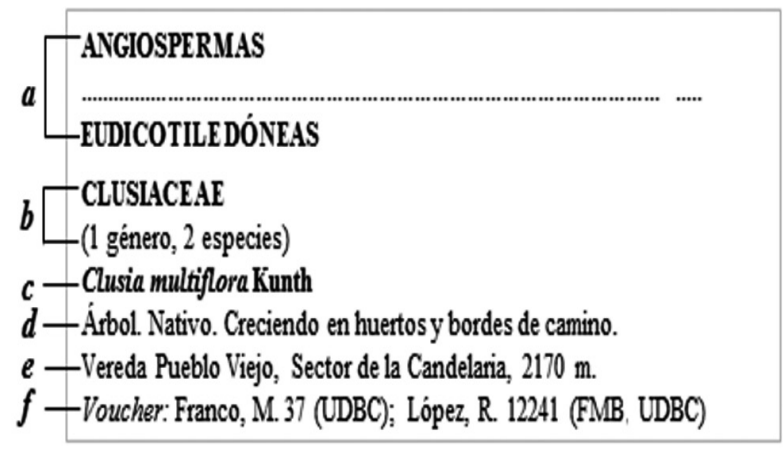

Figura 2. Leyenda explicativa para la interpretación de la información consignada en el catálogo de plantas vasculares de Ráquira (Anexo 1). a. Taxones superiores (grupo y clase, de acuerdo a cada sistema de clasificación). b. Familia y diversidad (número de géneros y especies). c. Nombre científico de la especie y abreviatura del autor. d. biotipo (árbol, arbusto, subarbusto, liana, etc.), origen de la especie - se consideraron dos categorías: nativa e introducida- y descripción general del área donde se registró. e. Lugar donde se registró la especie (indicando la vereda y altitud). f. Colección -indicando denominación del colector, número de colección y herbario donde fue consignada.

culares en Ráquira, distribuidas en 284 géneros y 99 familias. En cuanto a la composición, la cobertura de bosques fue la más representativa abarcando 90 familias, 235 géneros y 355 especies. Las figuras 3 y 4 presentan los diagramas de clasificación de las familias botánicas encontradas en el municipio, basados en las propuestas implementadas para el presente estudio; adicionalmente, se presentan las coberturas de registro para las especies.

El grupo con mayor número de especies fue el de las angiospermas, el cual aportó un total de 412 especies $(96.7 \%)$, el 3.3\% restante comprenden helechos y afines y las gimnospermas. Las angiospermas se encuentran distribuidas en 91 familias, 274 géneros y 412 especies, se encuentran ampliamente representadas por las eudicotiledóneas con el 82.8\% (341 especies), mientras que las monocotiledóneas y las magnólidas aportan el restante $17.2 \%$ de las especies (59 y 12, respectivamente).

De las 412 especies de angiospermas reportadas en el municipio el 51\% (210 especies) se registraron en más de una cobertura (Figura 4); la mayor participación es dada por la cobertura de bosques con 186 especies, seguida de áreas naturales transformadas con 103 especies. El número de especies reportadas únicamente en la cobertura de bosques fue de 158 (38.4\%), para áreas naturales transformadas $29(7 \%)$, desierto $10(2.4 \%)$, páramo $4(1 \%)$ y subpáramo $1(0.2 \%)$. De igual forma, se resalta que la cobertura de bosques en asocio con una o más de una cobertura diferente presentaron un total de 344 especies correspondiente al $83.5 \%$ del total
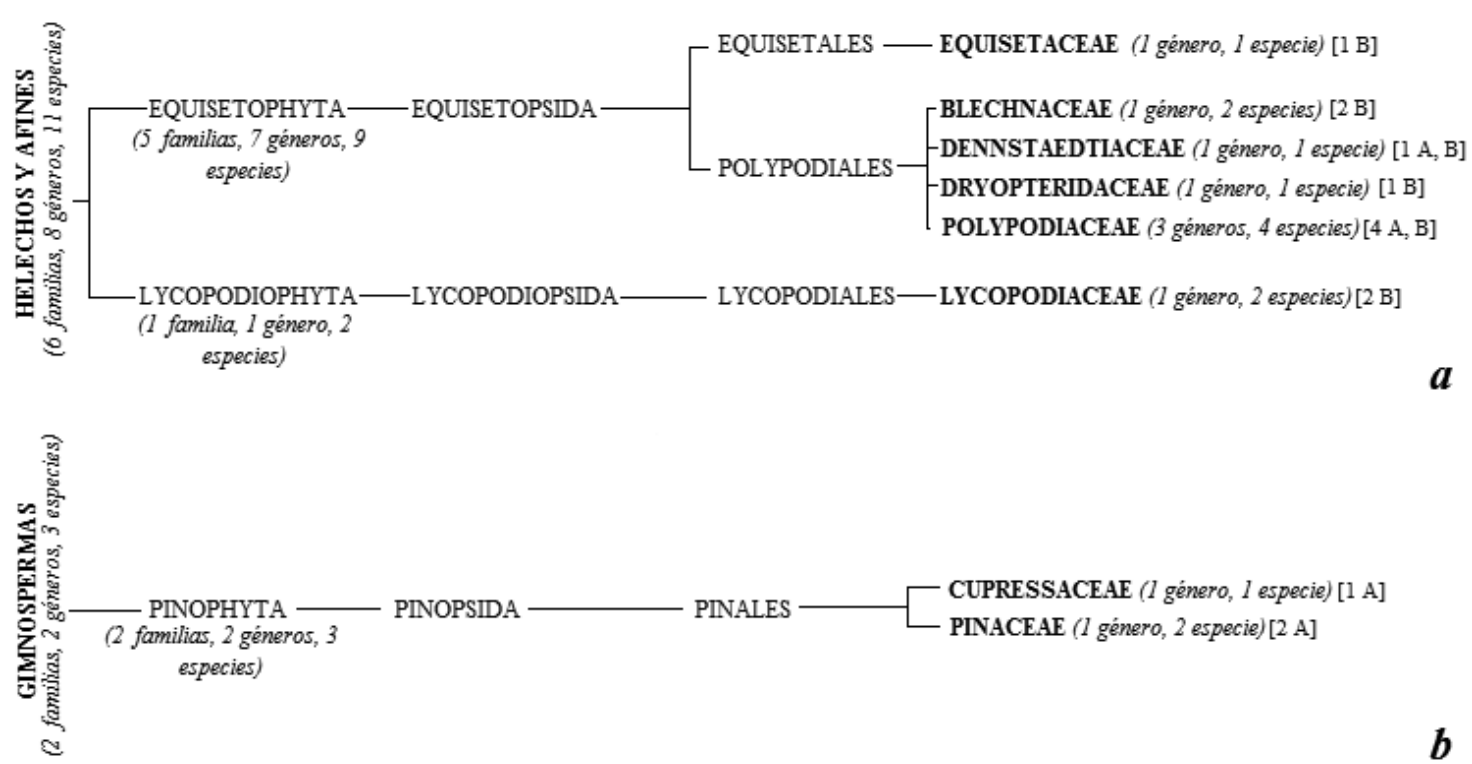

$b$

Figura 3. Clasificación de las familias botánicas en el municipio de Ráquira (Boyacá). a. Helechos y afines, según la propuesta de Tryon \& Tryon (1982). b. Gimnospermas según los criterios establecidos por Judd et al. (2012). Cobertura de registro: Áreas Naturales Transformadas [A] y Bosques [B] 


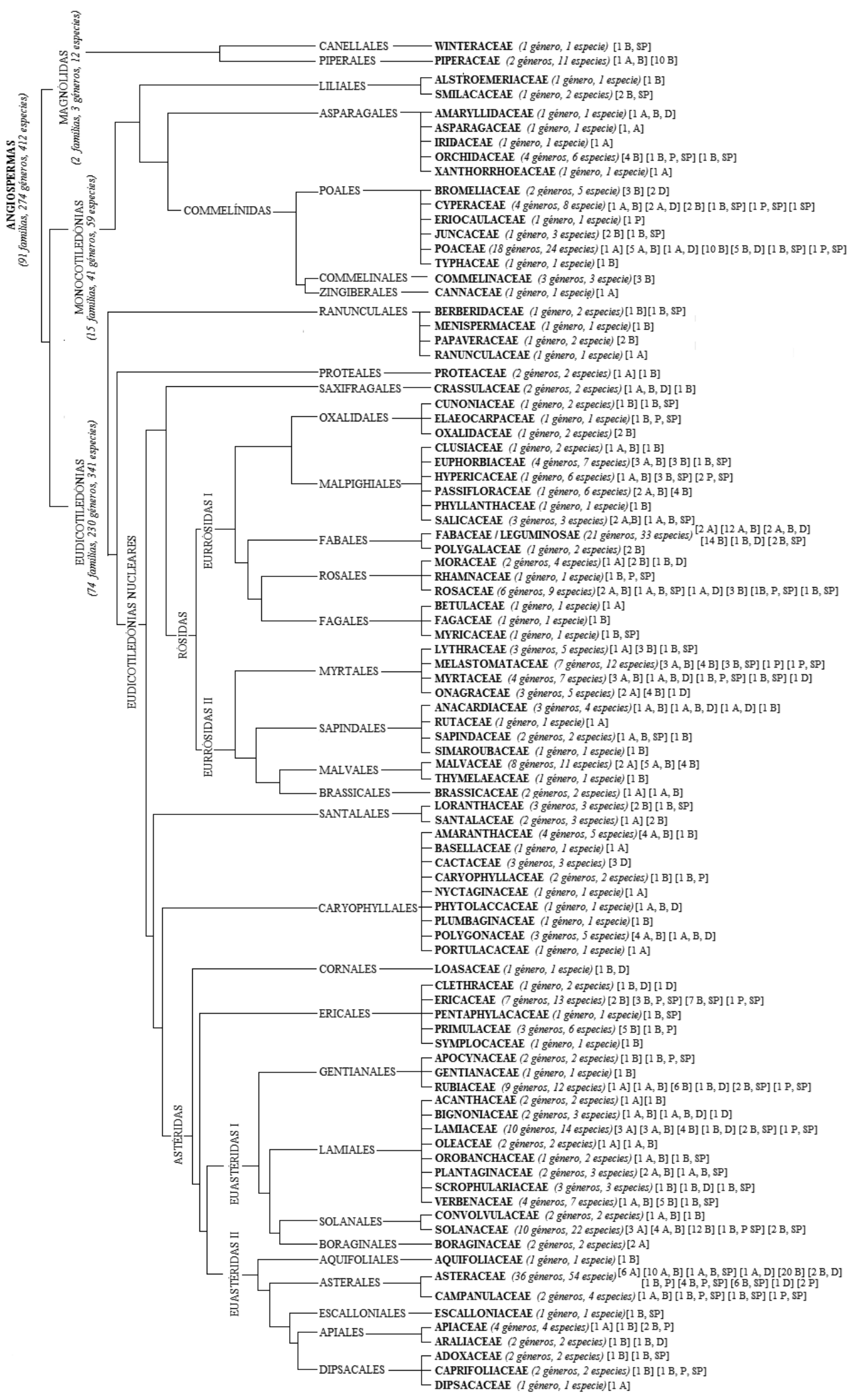

Figura 4. Clasificación de las familias botánicas en el municipio de Ráquira (Boyacá), grupo de las angiospermas basado en la propuesta APG III (Haston et al., 2009; Stevens, 2010). Cobertura de registro: áreas naturales transformadas [A], bosques [B], desierto [D], páramo [P] y subpáramo [SP] 
Tabla 1. Número de especies por tipo de cobertura de las diez familias con mayores valores de riqueza, según el número de especies registradas en Ráquira, correspondientes al grupo de las angiospermas. EUC: número de especies registradas en un tipo de cobertura y EMC: número de especies registradas en más de un tipo de cobertura.

\begin{tabular}{lcccccccc}
\hline \multirow{2}{*}{ Familia } & \multicolumn{7}{c}{ Tipo de cobertura } & \\
\cline { 2 - 7 } & Desierto & Bosque & Páramo & Subpáramo & $\begin{array}{c}\text { Áreas Naturales } \\
\text { Transformadas }\end{array}$ & EUC & EMC & Total \\
\hline Asteraceae & 4 & $\mathbf{4 5}$ & 7 & 11 & 17 & 29 & 25 & 54 \\
Fabaceae/Leguminosae & 3 & $\mathbf{3 1}$ & - & 2 & 16 & 16 & 17 & 33 \\
Poaceae & 6 & $\mathbf{2 1}$ & 1 & 2 & 7 & 11 & 13 & 24 \\
Solanaceae & & $\mathbf{1 9}$ & 1 & 3 & 7 & 15 & 7 & 22 \\
Lamiaceae & 1 & 10 & 1 & 3 & 6 & 7 & 7 & 14 \\
Ericaceae & - & 12 & 4 & 11 & - & 2 & 11 & 13 \\
Melastomataceae & - & 10 & 2 & 4 & 3 & 5 & 7 & 12 \\
Rubiaceae & 1 & 10 & 1 & 3 & 2 & 7 & 5 & 12 \\
Malvaceae & - & 9 & - & - & 7 & 6 & 5 & 11 \\
Piperaceae & - & 11 & - & - & 1 & 10 & 1 & 11 \\
\hline
\end{tabular}

de las angiospermas.

Como se observa en la tabla 1, las familias de angiospermas con mayor número de especies son Asteraceae, Fabaceae/Leguminosae, Solanaceae y Poaceae, las cuales se encuentran mejor representadas en las coberturas de bosque, áreas naturales transformadas y subpáramo. Sin embargo, en cuanto a los géneros, el mayor número de especies se concentran en Solanum (Solanaceae), Hyperi-

Tabla 2. Número de especies por tipo de cobertura de los quince géneros con mayores valores de riqueza, según el número de especies registradas en Ráquira, correspondientes al grupo de las angiospermas. EUC: número de especies registradas en un tipo de cobertura y EMC: número de especies registradas en más de un tipo de cobertura

\begin{tabular}{|c|c|c|c|c|c|c|c|c|}
\hline \multirow[b]{2}{*}{ Género } & \multicolumn{5}{|c|}{ Número de especies por tipo de cobertura } & \multirow[b]{2}{*}{ EUC } & \multirow[b]{2}{*}{ EMC } & \multirow[b]{2}{*}{ Total } \\
\hline & Desierto & Bosque & Páramo & Subpáramo & $\begin{array}{c}\text { Áreas Naturales } \\
\text { Transformadas }\end{array}$ & & & \\
\hline Solanum & - & 10 & - & - & 3 & 7 & 3 & 10 \\
\hline Hypericum & - & 4 & 3 & 6 & 1 & 0 & 6 & 6 \\
\hline Passiflora & - & 6 & - & - & 2 & 4 & 2 & 6 \\
\hline Peperomia & - & 6 & - & - & - & 6 & 0 & 6 \\
\hline Baccharis & - & 5 & - & 1 & - & 4 & 1 & 5 \\
\hline Piper & - & 5 & - & - & 1 & 4 & 1 & 5 \\
\hline Andropogon & 2 & 4 & - & - & 1 & 1 & 3 & 4 \\
\hline Chromolaena & 1 & 4 & - & 1 & - & 2 & 2 & 4 \\
\hline Inga & 1 & 4 & - & - & - & 3 & 1 & 4 \\
\hline Miconia & - & 3 & 1 & - & 1 & 3 & 1 & 4 \\
\hline Myrsine & - & 4 & 1 & - & - & 3 & 1 & 4 \\
\hline Pentacalia & - & 4 & 1 & 1 & - & 2 & 2 & 4 \\
\hline Salvia & 1 & 2 & 1 & 2 & 1 & 1 & 3 & 4 \\
\hline Acacia & 2 & 3 & - & - & 2 & 1 & 2 & 3 \\
\hline Cestrum & - & 3 & - & - & - & 3 & 0 & 3 \\
\hline
\end{tabular}


cum (Hypericaceae), Passiflora (Passifloraceae), Peperomia (Piperaceae) y Baccharis (Asteraceae), representados principalmente en la cobertura de bosque (Tabla 2); así, se puede apreciar como algunas familias con baja riqueza de géneros presentan alta riqueza de especies, como es el caso de Piperaceae, Passifloraceaee e Hypericaceae.

El número de pteridofitas listado a la fecha es de once especies, siendo las familias más representativas Polypodiaceae, Blechnaceae y Lycopodiaceae. Los géneros más frecuentes son Blechnum, Polypodium y Lycopodium. El grupo de las gimnospermas se vio representado tan solo por tres especies pertenecientes a dos familias, en las cuales el género más frecuente fue Pinus con dos especies. Estas especies fueron registradas únicamente en áreas naturales transformadas (Figura 3).

Llama la atención que del total de especies registradas en el municipio, 378 (88.7\%) son nativas y tan solo 48 especies son introducidas. Dentro de las especies introducidas varias se cultivan en la región y tienen importancia económica, como es el caso de Asparagus officinalis, Salvia tiliifolia, Borago officinalis y Macadamia integrifolia. La mayoría de las especies introducidas presentan habito herbáceo (29 especies), mientras que las especies nativas se caracterizan por ser en su mayoría de hábitos arbustivos y arbóreos (113 y 54 especies, respectivamente).

\section{DISCUSIÓN}

A pesar de no encontrar estudios que expongan la diversidad florística en un área con diferentes tipos de cobertura, como las estudiadas en Ráquira, al evaluar la flora de la cobertura más representativa en términos de diversidad en este estudio (bosques; 90 familias, 235 géneros y 355 especies), los resultados obtenidos con respecto a la riqueza de familias, géneros y especies son levemente inferiores a los reportes realizados recientemente en bosques andinos y subandinos por parte de Medina et al. (2010) y Reina et al. (2010); estos autores encontraron 443 especies (257 géneros y 101 familias) y 409 especies (226 géneros y 105 familias), respectivamente. De manera similar, al evaluar la composición florística, varían sustancialmente las familias, los géneros y las especies representativas, en las que se comparte solo la alta predominancia de la familia Asteraceae. Esta variación se atribuye al cambio de las condiciones climáticas y fisiográficas respectivas a las zonas de los tres estudios, donde pese a la similitud en el rango altitudinal y temperatura, es clara la diferencia frente a la zona climática, o de vida, que ha sido definida en estas áreas (Holdridge, 1987; Cuatrecasas, 1989; Guzmán \& Fajardo, 2000; Medina et al., 2010; Reina et al., 2010), lo cual interviene en el gradiente de distribución de las especies.

La composición florística encontrada en esta investigación, en las familias taxonómicas difiere de los resultados de estudios realizados en bosques andinos y subandinos sobre las diferentes cordilleras del país (Rangel, 1995; Lozano-C et al., 1996; Murillo et al., 2002; Galindo-T et al., 2003). Los autores anteriores coinciden en que en las zonas estudiadas, la predominancia de familias por la riqueza de especies está dada por Melastomataceae, Fabaceae, Polypodiaceae y Rubiaceae -con diferente orden de importancia dependiendo cada estudio-, en un gradiente altitudinal que varía entre los 1150-2800 m de altitud y clasificación climática entre boques húmedos y muy húmedos montanos. Sin embargo, se encuentra alguna coincidencia con los estudios adelantados por Galindo-T. et al. (2003), Cordillera oriental, franja andina (Chontales Alto); Vargas (2011), Cordillera oriental, franja subandina y andina, y Alvear et al. (2010), Cordillera central, franja andina, donde se reporta que la familia más predominante es Asteraceae en un gradiente altitudinal entre $1000-3000 \mathrm{~m}$ de altitud.

No obstante, en los siguientes niveles de predominancia aparecen nuevamente las familias Melastomataceae y Rubiaceae. A partir de lo anterior se puede establecer la importancia de los resultados de esta investigación, puesto que proveen nueva información sobre la composición florística en un ecosistema andino localizado sobre un enclave xerofítico, como ha sido definida el área de estudio por Guzmán \& Fajardo (2000), a la vez que aumenta en más del $40 \%$ los reportes realizados por Becerra \& Méndez (1990) y Flores et al. (2010), reconocidos como los más cercanos al área de es- 
tudio de esta investigación.

Los estudios que relacionan la composición florística de ecosistemas secos en Colombia son limitados, más aún, sobre bosques andinos localizados en enclaves secos de las cordilleras (Albesiano \& Fernández-Alonso, 2006). En los ecosistemas secos, por debajo de los $1200 \mathrm{~m}$ de altitud, se encuentran los estudios de Ariza (1999), Mendoza-C. (1999), Peñaloza (2001), Albesiano et al. (2003), Figueroa-C \& Galeano (2007) y Albesiano \& Fernández-Alonso (2006), mientras que en franjas superiores a los 2000 de altitud solo se identifican los adelantados por Becerra \& Méndez (1990), Sarmiento \& Cano (1997) y Flores et al. (2010). Este aspecto llama la atención, puesto que en aproximaciones florísticas de otras regiones andinas de Latinoamérica con características xerofíticas y altitudes superiores a los $2000 \mathrm{~m}$ se identifica una amplia similitud con los resultados del presente estudio, donde las familias predominantes son Aste- raceae, Poaceae, Solanaceae y Fabaceae (Tabla 3).

Por otra parte, en cuanto a los géneros y las especies también se encuentra coincidencia con estos estudios. Los reportes de Arakaki \& Cano (2003) en Perú muestran que las dos zonas comparten cincuenta y cinco géneros y veintidós especies; con los de Hernández et al. (2003), en Venezuela, se comparten treinta y tres géneros y trece especies; asimismo con los reportes de Rodríguez et al. (2008), en Chile, se comparten cuarenta y cinco géneros y cinco especies.

En el bosque seco andino más cercano al área de estudio, reportado por Sarmiento \& Cano (1997) se identificaron 49 géneros y 33 especies compartidas -valores respectivos al $53 \%$ de los géneros y al $30 \%$ de las especies reportadas en aquella investigación; y el $21 \%$ de los géneros y $9 \%$ de las especies en cobertura de bosques en este estudio-. En este sentido, estos resultados contribuyen con

Tabla 3. Familias predominantes por la riqueza de especies en ecosistemas andinos secos de Latinoamérica. Para este análisis se excluyen las coberturas Áreas Naturales Transformadas y Desierto, reportadas en este estudio

\begin{tabular}{|c|c|c|c|c|c|}
\hline Área de estudio & Descripción ambiental & $\begin{array}{c}\text { Altitud } \\
\text { máxima (m) }\end{array}$ & $\begin{array}{c}\text { Familias predomi- } \\
\text { nantes }\end{array}$ & $\begin{array}{c}\text { Número de } \\
\text { especies }\end{array}$ & Autor \\
\hline Ráquira (Colombia) & $\begin{array}{l}\text { Enclave seco de Villa de } \\
\text { Leyva, cordillera oriental } \\
\text { (Guzmán \& Fajardo, } \\
2000)\end{array}$ & 3210 & $\begin{array}{c}\text { Asteraceae } \\
\text { Fabaceae } \\
\text { Poaceae } \\
\text { Solanaceae }\end{array}$ & $\begin{array}{l}46 \\
31 \\
22 \\
19\end{array}$ & $\begin{array}{l}\text { González \& López } \\
\text { (en este estudio) }\end{array}$ \\
\hline $\begin{array}{l}\text { Mosquera, Mondoñedo } \\
\text { (Colombia) }\end{array}$ & $\begin{array}{c}\text { Montaña seca y paramo } \\
\text { seco de la sabana de Bo- } \\
\text { gotá, cordillera oriental } \\
\text { (Sarmiento \& Cano, } \\
\text { 1997) }\end{array}$ & 2880 & $\begin{array}{c}\text { Asteraceae } \\
\text { Poaceae } \\
\text { Polypodiaceae } \\
\text { Solanaceae } \\
\text { Fabaceae }\end{array}$ & $\begin{array}{c}22 \\
9 \\
9 \\
6 \\
5\end{array}$ & $\begin{array}{l}\text { Sarmiento \& } \\
\text { Cano (1997) }\end{array}$ \\
\hline $\begin{array}{l}\text { Cuenca del río Ilo-Mo- } \\
\text { quegua y Lomas de Ilo } \\
\text { (Perú) }\end{array}$ & $\begin{array}{l}\text { Desierto Perarido } \\
\text { Montano Subtropical - } \\
\text { Montano Templado } \\
\text { Calido (OPE, 2011) }\end{array}$ & 4600 & $\begin{array}{l}\text { Asteraceae } \\
\text { Poaceae } \\
\text { Solanaceae } \\
\text { Fabaceae }\end{array}$ & $\begin{array}{l}60 \\
44 \\
32 \\
26\end{array}$ & $\begin{array}{c}\text { Arakaki \& Cano } \\
\text { (2003) }\end{array}$ \\
\hline $\begin{array}{c}\text { Cuenca media del río } \\
\text { Chama, Mérida (Venezu- } \\
\text { ela) }\end{array}$ & $\begin{array}{l}\text { Zona xerofítica } \\
\text { (Hernández et al., } \\
\text { 2003) }\end{array}$ & 4000 & $\begin{array}{c}\text { Asteraceae } \\
\text { Fabaceae (incluye } \\
\text { Mimosaceae) } \\
\text { Cactaceae } \\
\text { Verbenaceae } \\
\text { Poaceae }\end{array}$ & $\begin{array}{l}35 \\
27 \\
\\
20 \\
15 \\
14\end{array}$ & $\begin{array}{l}\text { Hernández et al. } \\
\qquad(2003)\end{array}$ \\
\hline Nevados de Chillan, Chile & $\begin{array}{l}\text { Ecosistema templado } \\
\text { cálido con una estación } \\
\text { seca (DMC, 2011) }\end{array}$ & 3000 & $\begin{array}{l}\text { Asteraceae } \\
\text { Poaceae } \\
\text { Fabaceae } \\
\text { Cyperaceae }\end{array}$ & $\begin{array}{c}116 \\
58 \\
26 \\
19\end{array}$ & $\begin{array}{l}\text { Rodríguez et al. } \\
\qquad(2008)\end{array}$ \\
\hline
\end{tabular}


nueva información que apoya las predicciones sobre las conexiones florísticas de las formaciones vegetales secas en América del Sur realizadas por Sarmiento (1975).

Teniendo en cuenta que el área de estudio y su composición florística se encuentran inmersas en un enclave seco andino, es importante resaltar los diferentes tipos de cobertura vegetal presentes allí (Figura 8 i, j, k, 1) y la importancia para la conservación derivada de las especies características en cada tipo de cobertura.

En primer lugar se identificaron los relictos de bosques (Figura 8i), los cuales, según Linares et al. (2007) y López (2007), se caracterizan por la alta dominancia de Quercus humboldtii, especie con grado de amenaza en el territorio nacional (vulnerable; Salinas \& Cárdenas, 2007), puesto que fue empleada durante muchos años para la obtención de carbón para hornos de cocción de la actividad de la alfarería -principal actividad económica en esta región-. En consecuencia, a lo largo del tiempo, la cobertura de estos bosques sufrió una excesiva pérdida a través del tiempo.

Por su parte, Moncada (2010) determinó una disminución de estos robledales que se aproxima al $43.43 \%$ en tan solo ocho años (1985-1993). Actualmente, existen figuras administrativas que designan la protección de estos bosques bajos la denominación de la reserva forestal El Robledal o El Chaute; sin embargo, la continuidad del uso extractivo del roble -que ahora es ilegal-y otras especies con potencial dendroenergético -Alnus acuminata, Baccharis tricuneata, Caesalpinia spinosa, Clethra fimbriata, Clusia sp., Mauria heterophylla, Myrsine guianensis, Viburnum tinoides; López \& Cavelier, 2007; Moncada, 2010; reportadas en este estudio- por parte de los habitantes locales sigue siendo persistente en estos bosques, dada la necesidad del recurso para el continuo funcionamiento de las actividades económicas del municipio (Linares et al., 2007). Este aspecto recaba en la necesidad de iniciar políticas viables tanto en el ámbito ecológico como socioeconómico de este municipio, con el fin de restaurar y preservar este ecosistema.
El estudio de Becerra \& Méndez (1990) reporta la especie Salvia amethystina, que se encuentra en estado de amenaza EN (en peligro; García \& Galeano, 2006). Ahora bien, esta planta no fue posible encontrarla durante las visitas de campo, esto puede ser un indicio de lo mitigada que debe de estar la población de esta especie en la región.

En segundo lugar se encuentra el desierto de la Candelaria (Figura $8 \mathrm{j}$ ), que se constituye un elemento bastante representativo del enclave seco de esta región (Sáenz-Jiménez et al., 2008); Adicionalmente, está la excepcionalidad de la composición florística en este tipo de áreas naturales, puesto que se resalta la relevancia de su restauración y conservación. Según Figueroa-C. \& Galeano (2007), la importancia de las especies vegetales presentes en ecosistemas secos o desérticos está dada por las adaptaciones para resistir las sequías y aprovechar al máximo los periodos de lluvia. Esto se corrobora con las características que presentan algunas de las especies encontradas en este sector como Psidium guianense-Myrtaceae, pierde la mayoría de sus hojas en periodos de sequia; Chízmar (2009)-, Furcraea cabuya -Amaryllidaceae, reduce el potencial osmótico de las raíces por debajo del que presenta el sustrato para tomar agua del suelo; Casierra-Posada et al. (2006)- y especies de la familia Cactaceae. Todas estas especies fueron reportadas exclusivamente en esta cobertura y se encuentran equipadas con tallos fotosintéticos, duros, gruesos, suculentos y cubiertos de cera, para resistir las condiciones ambientales desérticas (Gómez, 2004). Otro elemento que resalta la importancia de esta cobertura vegetal basada en su composición florística, de acuerdo con los relatos de habitantes locales, es la pérdida de las poblaciones de especies de cactos, pertenecientes al género Melocactus y que fueron comercializadas durante varios años a turistas y visitantes y hoy en día solo se encuentran algunos individuos en estado doméstico (obs. pers.).

En tercer lugar se encuentra el páramo de Rabanal (Figura 8k), un ecosistema indispensable para la regulación y el suministro hídrico de los embalses La Esmeralda y Teatinos (Ortiz \& Reyes, 2009), donde se localizan especies vegetales clave para la acumulación de la biomasa formante del sustrato (suelo de paramo), como es el caso de los fraile- 
jones (Espeletia spp.), las puyas (Puya spp.) y las especies de pajonal (Franco \& Castaño, 2002). Como elemento taxonómico de interés en esta cobertura se menciona Espeletia boyacensis, que pese a ser clasificado como uno de los veintidós frailejones en categoría preocupación menor en Colombia (LC; García et al., 2005) hace parte de las 48 especies que sustentan el grupo de páramos endémicos que forman el patrón de áreas anidadas en Colombia (Miranda-Esquivel et al., 2002), entendidas estas áreas como las zonas que albergan tanto especies de amplia distribución como especies de distribución restringida, son importantes por ser un elemento clave en la identificación de sitios prioritarios para conservación (Morrone, 1994; Cavieres et al., 2001; Méndez, 2004; Ochoa \& Flores, 2006).

Finalmente se identificaron las áreas naturales transformadas (Figura 81), caracterizadas por ser zonas antropizadas para el desarrollo de actividades agrícolas y pecuarias que han fragmentado significativamente los robledales y han reducido el espacio de ocupación del páramo. También se encuentran como la sustitución de áreas desérticas para actividades de pastoreo e inclusive potreros desprovistos de vegetación y erosionados, sin un uso específico, que provienen de la extracción desmedida de leña para la actividad de alfarería $(\mathrm{Ca}-$ brera \& Ramírez, 2007; López, 2007; Sáenz-Jiménez et al., 2008; Moncada, 2010). En estas áreas es evidente la reducción de la composición florística nativa, que se hace notoria cuando las especies con algún tipo de uso por parte de los pobladores comienzan a escasear, como es el caso de Juncus ramboi, J. effusus y J. echinocephalus -implementadas para la cestería- las cuales, en la actualidad, no se consiguen fácilmente en el municipio y deben ser adquiridas en zonas aledañas, Vaccinium meridionale -cosecha en estado silvestre para alimento humano y comercialización-. especie de importancia económica rural que hoy en día se encuentra bastante retirada de las viviendas y toma distancias largas para la realizar cosecha (Comentarios de los habitantes locales agosto 2009).

\section{CONCLUSIONES}

Se presenta un catálogo actualizado de las plantas vasculares en el municipio de Ráquira (Boyacá), el cual expone una composición florística típica de ecosistemas andinos con características xerofíticas en Latinoamérica, resultados que contribuyen con elementos nuevos que apoyan las predicciones sobre las conexiones florísticas de estos ecosistemas en este continente.

El listado de vegetación en este estudio aumenta considerablemente los reportes realizados con anterioridad sobre los diferentes tipos de cobertura vegetal, presentes en Ráquira; adicionalmente, se puede constituir en una fuente básica de consulta para el inicio de investigaciones específicas sobre estructura y función en estos bosques, así como procesos encaminados a la restauración y conservación de los remanentes existentes.

Si se tiene en cuenta que Ráquira es un municipio de tradición artesanal, donde se resalta la alfarería como principal actividad económica, es importante iniciar un monitoreo y unos estudios de caso que relacionen la composición florística, la estructura y la función de estos bosques con el aprovechamiento de especies con potencial dendroenergético, en pro de generar lineamientos para la conservación de este ecosistema, que además de ser bastante diverso cuenta con la importancia adicional de encontrarse en un enclave seco.

Se deben iniciar investigaciones sobre la dinámica ecológica en lo que se refiere a las poblaciones y a la factibilidad económica en especies con alto interés para los habitantes locales, como es el caso de Juncus ramboi, J. effusus y J. echinocephalus, Vaccinium meridionale, entre otros, debido a la potencialidad que presentan como productos forestales no maderables para este municipio, ligado al agravante del actual aprovechamiento desproporcionado y sin regulaciones que se practica en las áreas rurales del municipio.

\section{AGRADECIMIENTOS}

Esta investigación fue adelantada gracias al apoyo del Centro de Investigaciones y Desarrollo Científico de la Universidad Distrital (CIDC), dentro del proyecto titulado Catálogo de plantas útiles de 
Ráquira, código 3-10-189-09, financiado por parte del semillero de investigación Caracterizaciones Ecológicas Iniciales del Bosque Alto Andino (CEIBA). Queremos agradecerles a los integrantes del semillero, en especial a los estudiantes de ingeniería forestal, Francisco Rojas, María Fernanda Franco, Pablo Vargas, Fernanda Álvarez y Andrea Ramírez, a los ingenieros forestales Viviana Pinzón y Diego Pedraza, a la señora Mary, y a los señores Humberto, Samuel y Andrés Páez (habitantes locales), por su colaboración en las actividades de campo y por compartir su conocimiento sobre la flora de esta región. A los profesionales de los herbarios FEM del Instituto Alexander von Humboldt, COL de la Universidad Nacional de Colombia y UDBC de la Universidad Distrital Francisco José de Caldas y en especial al ingeniero Fabio Andrés Ávila por la colaboración en la determinación de varios especímenes. Finalmente, agradecemos a los evaluadores anónimos del manuscrito por sus acertados comentarios y sugerencias.

\section{REFERENCIAS BIBLIOGRÁFICAS}

Albesiano, S., \& Fernández-Alonso, J.L. (2006). Catálogo comentado de la flora vascular de la franja tropical (500-1200m) del cañón del río Chicamocha (Boyacá-Santander, Colombia). Primera parte. Caldasia, 28, 23-44

Albesiano, S., Rangel-Ch., J.O., \& Cadena, A. (2003). La vegetación del cañón del río Chicamocha (Santander, Colombia). Caldasia, 25, 73-99.

Alvear, M., Betancur, J., \& Franco-Rosselli, P. (2010). Diversidad florística y estructura de remanentes de bosque andino en la zona de amortiguación del Parque Nacional Natural los Nevados, Cordillera Central Colombiana. Caldasia, 32, 39-63.

Alcaldía Municipal de Ráquira [AMR]. (2011). Ráquira - Construyendo Futuro con manos de artesano. Recuperado el 20 de diciembre de 2011 de http://raquira-boyaca.gov.co/index.shtml.

Arakaki, M., \& Cano, A. (2003). Composición florística de la cuenca del río llo-Moquegua y Lomas de 1lo, Moquegua. Perú. Revista Peruana de Biología, 10, 5-19.

Ariza, C.L. (1999). Estudio de la diversidad florística del enclave árido del rio Patía (Colombia) (Tesis inédita de pregrado). Bogotá: Universidad Nacional de Colombia. 190 p.

Armenteras, D., Gast, F., \& Villareal, H. (2003). Andean forest fragmentation and the representativeness of protected natural areas in the Eastern Andes, Colombia. Biological Conservation, 113, 245-256.

Armenteras, D., Rodríguez, N., Retana, J., \& Morales, M. (2011). Understanding deforestation in montane and lowland forest of the Colombian Andes. Regional Environmental Change, 11, 693-705.

Brehm, G., Homeier, J., Fiedler, K., Kottke, I., Illig, J., Nösk e, N.M., Werner, F., \& Breckle, S.W. (2008). Mountain rain forests in southern Ecuador as a hotspot of biodiversity - limited knowledge and diverging patterns. En E. Beck, J. Bendix, I. Kottke, F. Makeschin \& R. Mosandl (eds.), Gradients in a tropical mountain ecosystem of Ecuador. Analysis and Synthesis, Vol. 198, (pp. 15-25). Heidelberg: Ecological Studies.

Becerra, C., \& Méndez, A. (1990). Contribución al estudio de la flora del Municipio de Ráquira (Boyacá) (Tesis inédita de pregrado). Bogotá: Departamento de Biología, Universidad Nacional de Colombia. 403 p.

Brummitt, R.K., \& Powell, C.F. (1992). Author of plant names. A list of authors of scientific names of plants, with recommended standard forms of their names, including abbreviations. Kew: Royal Botanic Garden. 732 p.

Cabrera, E., Vargas, D.M., Galindo, G., García, M.C., \& Ordóñez, M.F. (2011). Cuantificación de la tasa de Deforestación para Colombia, Periodo 1990-2000, 2000-2005. Bogotá: Instituto de Hidrología, Meteorología y Estudios Ambientales. 22 p. 
Cabrera, E., \& Ramírez, D.P. (2007). Estado actual y cambio en los ecosistemas de los Andes colombianos: 1985-2005. En D. Armenteras \& N. Rodríguez (eds.), Monitoreo de los ecosistemas andinos 1985-2005. Síntesis y perspectivas (pp. 39-63). Bogotá: Instituto de Investigaciones Alexander von Humboldt.

Carrizosa, J., \& Hernández, J. (1990). Las selvas andinas colombianas: selva y futuro. Bogotá: Inderena - El Sello Editorial. 213 p.

Casierra-Posada, F., Peréz, W., \& Portilla, F. (2006). Relaciones hídricas y distribución de materia seca en especies de fique (Furcraea sp. Vent) cultivadas bajo estrés por $\mathrm{NaCl}$. Agronomia Colombiana, 24, 280-289.

Cavieres, L.A., Mihoc, M., Marticorena, A., Marticorena, C., Matthei, O., \& Squeo, F.A. (2001). Determinación de áreas prioritarias para la conservación: análisis de parsimonia de endemismos (PAE) en la flora de la IV Región de Coquimbo. En F.A. Squeo, G. Arancio \& J.R. Gutiérrez (eds.), Libro rojo de la flora nativa y de los sitios prioritarios para su conservación: región de Coquimbo (pp.159-170). La Serena: Ediciones Universidad de La Serena.

Chaves, M.E., \& Arango, N. (eds.). (1998). Informe nacional sobre el estado de la biodiversidad 1997, Vol. 3. Bogotá: Instituto de Investigación de Recursos Biológicos Alexander von Humboldt - PNUMA - Ministerio del Medio Ambiente. 535 p.

Chízmar, C. (2009). Plantas comestibles de Centroamérica ( $1^{\text {ra }}$ ed.). Santo Domingo de Heredia: Instituto Nacional de Biodiversidad. $360 \mathrm{p}$.

Cuatrecasas, J. (1989). Aspectos de la vegetación natural de Colombia. Pérez-Arbelaezia, 2, 147283.

Dirección Meteorológica de Chile [DMC]. (2011). Región Del BioBio: Descripción Climatológica, Dirección General de Areonautica Civil, BioBio. Recuperado el 20 de noviembre de 2011 de http://www.meteochile.gob.cl/climas/climas_octava_region.html.

Feeley, K.J., \& Silma, M.R. (2010). Land-use and climate change effects on population size and extinction risk of Andean plants. Global Change Biology, 16, 3215-3222.

Figueroa-C., Y., \& Galeano, G. (2007). Lista comentada de las plantas vasculares del enclave seco interandino de la Tatacoa (Huila, Colombia). Caldasia, 29, 263-281.

Flores G., Nuñez, O., Nuñez, M., Ramírez, L., Ramírez, M., \& Zusunaga, J. (2010). 100 plantas útiles del páramo Rabanal: Guía para comunidades rurales. Bogotá: Instituto Alexander von Humboldt - CAR - Corpoboyacá- Corpochivor. $182 \mathrm{p}$.

Franco, L. \& Castaño, C. (2002). Estado y gestión de los páramos de Colombia. En C. Ange, C. Castaño, F. Arjona, J.V. Rodríguez \& C.L. Durán (eds.), Congreso Mundial de Páramos, Tomo 2, (pp. 110-294). Bogotá: Ministerio del Medio Ambiente - Corporación Autónoma Regional de Cundinamarca - Instituto de Hidrología, Meteorología y Estudios Ambientales Conservación Internacional Colombia.

García, N., \& Galeano, G. (eds.). (2006). Libro Rojo de Plantas de Colombia. Volumen 3: Las Bromelias, las Labiadas, y las Pasifloras. Bogotá: Instituto Alexander von Humboldt - Instituto de Ciencias Naturales de la Universidad Nacional de Colombia - Ministerio de Medio Ambiente, Vivienda y Desarrollo Territorial. Serie Libros Rojos de Especies amenazadas de Colombia.

Galindo-T, R., Betancur, J., \& Cadena-M, J.J. (2003). Estructura y composición florística de cuatro bosques andinos del Santuario de Flora y Fauna Guanentá-Alto río Fonce, Cordillera Oriental Colombiana. Caldasia, 25, 313-335.

Garcés D., \& de la Zerda, S. (1994). Gran libro de los parques nacionales de Colombia. Bogotá: Intermedio Editores. 230 p. 
García, N., Calderón, E., \& Galeano, G. (2005). Lista de las especies de la subtribu Espelettinae (tribu Heliantheae, familia Asteraceae) de Colombia y su categoría de riesgo. En E. Calderón, G. Galeano \& N. García (eds.), Libro rojo de plantas de Colombia: Palmas, frailejones y zamias. Serie libros rojos de especies amenazadas de Colombia, Vol. 2, (pp. 243-244). Bogotá: Instituto Alexander von Humboldt - Instituto de Ciencias Naturales de la Universidad Nacional de Colombia - Ministerio de Ambiente, Vivienda y Desarrollo Territorial.

Gómez, B. (2004). Las plantas y su adaptación al ambiente desértico (Documento inédito). Antofagasta: Universidad de Antofagasta, Instituto del Desierto. 9 p.

Guzmán, M.R., \& Fajardo, Z. (eds.). (2000). Primer informe nacional de implementación de la convención de las Naciones Unidas de lucha contra la desertificación y la sequia - CCD. Bogotá: Ministerio del Medio Ambiente, Dirección General de Ecosistemas. 30 p.

Haston, E., Richardson, J.E., Stevens, P.E., Chase, M.W., \& Harris, D.J. (2009). The Linear Angiosperm Phylogeny Group (LAPG) III: a linear sequence of the families in APG (III). Botanical Journal of the Linnean Society, 161, 128-131.

Hernández C., Rondón, J.A., \& Guevara, J.R. (2003). Flora de la zona xerofítica de la Cuenca media del rio Chama, estado Mérida, Venezuela (lista preliminar). Pittieria 32, 39-50.

Holdridge,L.R.(1987).Ecología basada en zonas de vida. San José de Costa Rica: Instituto Interamericano de Cooperación para la Agricultura. 90 p.

Instituto Geográfico Agustín Codazzi [IGAC]. (1980). Esquema de ordenamiento territorial municipio de Ráquira. Ráquira: Alcaldía Municipal de Ráquira. 226 p.

Jorgensen, P.M., \& León-Yánez, S. (1999). Catálogo de las plantas vasculares del Ecuador. Michigan: Missouri Botanical Garden - Herbario QCA - Herbario Nacional - Museo Ecuatoriano de Ciencias Naturales -Department of Systematic Botany, Aarhus University. 1181 p.

Judd, W.S., Campbell, C.S., Kellogg, E.A. \& Stevens, P.F. (2002). Plant systematics, a phylogenetic approach. Sunderland: Sinauer Associates, Inc. 576 p.

Linares, J.R., Díaz, M., \& Rachez, F. (2007). ¿Cuánto vale una reserva forestal?: el caso de El Robledal. Revista Equidad y Desarrollo, 7, 27-40.

López, R. (2007). Documento marco de especies vegetales del municipio de Ráquira, Boyacá (Documento inédito). Bogotá: Instituto de Investigación de Recursos Biológicos Alexander von Humboldt. 66 p.

López, R., \& Cavelier, I. (2007). Productos forestales no maderables en los Andes colombianos: una aproximación a su conocimiento. En D. Armenteras \& N. Rodríguez (eds.), Monitoreo de los ecosistemas andinos 1985-2005. Síntesis y perspectivas (pp. 92-106). Bogotá: Instituto de Investigaciones Alexander von Humboldt.

López, R., Cavelier, I., \& Archila, S. (2008). Plantas útiles del municipio de Ráquira, Boyacá, Colombia. En G.M. Rodríguez, E. Guerra, S. Reyes \& S.K. Banda (eds.), III Congreso Internacional de Ecosistemas Secos: Experiencias y Estrategias para su Conservación y Manejo (pp. 76-77). Santa Marta: Fundación Ecosistemas Secos.

Lozano-C, G., Ruiz, N., González, F.A., \& Murillo, M.T. (1996). Diversidad vegetal del Parque Nacional Natural Munchique, Cauca (Colombia entre 1.800 y $3.050 \mathrm{msnm}$ ). En P. Pinto (ed.), Notas sobre Biodiversidad (pp. 9-64). Bogotá: Instituto de Ciencias Naturales - Museo de Historia Natural - Biblioteca José Jerónimo Triana.

Méndez, M. (2004).La composición de especies de aves en islas y paisajes fragmentados: un análogo ecológico de las muñecas rusas. El Draque, 5, 199-212 
Medina, R., Reina-E., M., Herrera, E., Ávila, F.A., Chaparro, O., \& Cortés, R. (2010). Catálogo preliminar de la flora vascular de los bosques subandinos de la Cuchilla El Fara (Santander-Colombia). Colombia Forestal, $13,55-85$.

Mendoza-C., H. (1999). Estructura y riqueza florística del bosque seco tropical en la región caribe y valle del río Magdalena, Colombia. Caldasia, 21, 70-94.

Miranda-Esquivel, D.R., Rangel-Ch., J.O., \& Roa-Fuentes, L.L. (2002). Endemismo en páramos colombianos con base en la distribución de espermatófitos y el análisis de parsimonia de endemismo (PAE). En C. Ange, C. Castaño, F. Arjona, J.V. Rodríguez \& C.L. Durán (eds.), Congreso Mundial de Páramos, Tomo 1, (pp. 253-266). Bogotá: Ministerio del Medio Ambiente - Corporación Autónoma Regional de Cundinamarca - Instituto de Hidrologia, Metereologia y Estudios Ambientales - Conservación Internacional Colombia.

Mittermeier, R.A., Myers, N., \& Mittermeier, C.G. (1999). Biodiversidad amenazada. Las ecorregiones terrestres prioritarias del mundo. México, D.F.: CEMEX - Conservation International - Agrupación Sierra Madre. 69-85 p.

Moncada, D.M. (2010). Análisis espacio-temporal del cambio en los bosques de roble (Quercus humboldtii Bonpl.) y su relación con la alfarería en Aguabuena, (Ráquira-Boyacá). Colombia Forestal, 13, 275-298.

Mora de Jaramillo, Y. (1974). Cerámica y ceramistas de Ráquira. Bogotá: Banco Popular Museo Arqueológico Casa del Márquez de San Jorge. $90 \mathrm{p}$.

Morrone, J.J. (1994). On the identification of areas of endemism. Systematic Biology, 43, 438-441.

Myers. N., Mittermeier, R.A., Mittermeier, C.G., da Fonseca, G.A.B., \& Kent, J. (2000). Biodiversity hotspots for conservation priorities. Nature, 403, 853-858.
Murillo, J., Betancur, J., Fernández, J., Galeano, G., González, G., Jiménez, L.C., Linares, E., Orozco, C.I., Uribe, J., Suárez, S., Giraldo, D., Parra, C., Dueñas, H., \& Galeano, M. (2002). La flora de San José de Suaita. En O. Rangel, J. Aguirre \& G. Andrada (eds.), Resúmenes Octavo Congreso Latinoamericano y Segundo Colombiano de Botánica (pp. 359). Bogotá: Instituto de Ciencias Naturales-Universidad Nacional de Colombia.

Ochoa, L.M., \& Flores, O.A. (eds). (2006). Áreas de diversidad y endemismo de la herpetofauna mexicana. México, DF: UNAM-CONABIO. $211 \mathrm{p}$.

ONG'D Perú Ecológico [OPE]. (2011). Regiones y zonas ecológicas en el Perú. Recuperado el 20 de octubre de 2011 de http://www.peruecologico.com.pe/regionesyzonasecologicas.pdf.

Olson, D.M., \& Dinerstein, E. (2002). The global 200: priority ecoregions for global conservation. Annals of the Missouri Botanical Garden, 89, 199-224.

Orme, C.D.L., Davies, R.G., Burgess, M., Eigenbrod, F., Pickup, N., Olson, V.A., Webster, A.J., Ding, T., Rasmussen, P.C., Ridgely, R.S., Stattersfield, A.J., Bennett, P.M., Blackburn, T.M., Gaston, K.J., \& Owens, I.P.F. (2005). Global hotspots of species richness are not congruent with endemism or threat. Nature, 436, 1016-1019.

Ortiz, L.A., \& Reyes, M.A. (2009). Páramos en Colombia: un ecosistema vulnerable. Bogotá: Universidad Sergio Arboleda. 9 p.

Peñaloza, G. (2001). Flórula del enclave árido de la región del Chechua (Suesca-Nemocón, Cundinamarca) (Tesis inédita de pregrado). Bogotá: Universidad Nacional de Colombia. 150 p.

Rangel, J.O. (1995). La diversidad florística en el espacio andino de Colombia. En S.P. Churchill, H. Balslev, E. Forero \& J.L. Luteyn (eds.), Biodiversity and conservation of neotropical montane forests (pp. 187-205). New York: The New York Botanical Garden. 
Reina, M., Medina, R., Ávila, F.A., Ángel, S., \& Cortés, R. (2010). Catálogo preliminar de la flora vascular de los bosques subandinos de la Reserva Biológica Cachalú, Satander (Colombia). Colombia Forestal, 13, 27-54.

Rodríguez, N., Rincón, A., Armenteras, D., Mendoza H., Umaña, A.M., Arango, N., \& Baptiste, M.P. (2005). Corredor nororiental de robles: indicadores de estado de la biodiversidad, factores antrópicos asociados y áreas prioritarias de conservación. Serie: Indicadores de seguimiento de la Política de Biodiversidad. Bogotá: Instituto de Investigación de Recursos Biológicos Alexander von Humboldt. 88 p.

Rodríguez, R., Grau, J., Baeza, C., \& Davies, A. (2008). Lista comentada de las plantas vasculares de los nevados de Chillan, Chile. Gayana Botánica, 65, 153-197.

Rudas G., Marcelo, D., Armenteras, D., Rodríguez, N., Morales, M., Delgado, L.C., \& Sarmiento, A. (2007). Biodiversidad y actividad humana: relaciones en ecosistemas de bosque subandino en Colombia. Bogotá: Instituto de Investigación de Recursos Biológicos Alexander von Humboldt. 128 p.

Sáenz-Jiménez, F., Walter, G., \& Solano-Gutiérrez, C. (2008). Los sistemas productivos sostenibles, un enfoque para la conservación de los ecosistemas secos en el corredor Guantiva, La Rusia, Iguaque, Colombia. En G.M. Rodríguez, E. Guerra, S. Reyes \& S.K. Banda (eds.), III Congreso Internacional de Ecosistemas Secos: Experiencias y Estrategias para su Conservación y Manejo (pp: 73-74).Santa Marta: Fundación Ecosistemas Secos.

Salinas, N.R., \& Cárdenas, D. (2007). Roble: Quercus humboldtii Bonpl. En D. Cárdenas \& N.R. Salinas (eds.), Libro rojo de plantas de Colombia: Especies maderables amenazadas, primera parte. Serie libros rojos de especies amenazadas de Colombia, Vol. 4, (pp. 203209). Bogotá: Instituto Amazónico de Investigaciones Científicas SINCHI - Ministerio de Ambiente, Vivienda y Desarrollo Territorial.
Sarmiento, F. \& Cano, M. (1997). Contribución al estudio florístico de la vegetación montana seca de la sabana de Bogotá. Diógenes, 4(2), 137-182.

Sarmiento, G. (1975). The dry plant formations of South America and their floristic connections. Journal of Biogeography, 2, 233-251.

Sinning, A.M. (2010). Relaciones ecológicas urbano-rurales en el municipio de Ráquira (Boyacá) (Tesis inédita de Maestría). Bogotá: Pontificia Universidad Javeriana. 103 p.

Stevens, P.F.(2010). Angiosperm Phylogeny Website. Recuperado el 20 de octubre de 2011 de http:// www.mobot.org/MOBOT/research/APweb/.

Tryon, R.M., \& Tryon, A.F. (1982). Ferns and Allied Plants with Special Reference to Tropical America. New York: Springer-Verlag. 857 p.

Vargas, C.A. (2011). Caracterización florística y fitogeográfica del sector sur de la Serranía de Perijá y áreas adyacentes de la Cordillera Oriental Colombiana. Bogotá: Universidad Nacional de Colombia. 219 p.

World Wildlife Fund [WWF]. (2001). Biodiversity vision for the Northern Andes Ecoregional Complex. Santiago de Cali: Fundación Natura - Fudena -World Wildlife Fund. 80 p. 


\section{ANEXO 1. \\ CATÁlOGO DE PLANTAS VASCULARES DEL MUNICIPIO DE RÁQUIRA (BOYACÁ, COLOMBIA)}

\section{HELECHOS Y AFINES}

\section{BLECHNACEAE}

(1 género, 2 especies).

Blechnum occidentale $\mathrm{L}$.

Hierba nativa, que crece en los bordes de la quebrada.

Vereda Resguardo de Occidente; Quebrada Mutacá (Chillón).

Voucher: López, R. 12187 (UDBC)

Blechnum sp.

Hierba nativa que crece en el sotobosque.

Vereda Resguardo de Occidente; Quebrada Mutacá (Chillón).

Voucher: López, R. 12369 (UDBC).

\section{DENNSTAEDTIACEAE}

(1 género, 1 especie)

\section{Pteridium arachnoideum (Kaulf.) Maxon}

Hierba nativa que crece en áreas de sucesión natural y bordes de camino.

Vereda Resguardo de Occidente, La Chorrera, Vereda Roa, 1800-3200 m.

Voucher: López, R. Observado

\section{DRYOPTERIDACEAE}

(1 género, 1 especie).

Elaphoglossum sp.

Hierba nativa que crece en el sotobosque.

Vereda Resguardo de Occidente; Quebrada Mutacá (Chillón).

Voucher: González, R. 60 (UDBC)

EQUISETACEAE

(1 género, 1 especie).

Equisetum giganteum L. (Figura 5a)

Hierba nativa que crece en el borde de la quebrada en áreas con drenaje deficiente, húmedas.

Vereda Roa. $2200 \mathrm{~m}$.

Voucher: López, R. 12208, 12386, 12396, 13798 (UDBC)

\section{LYCOPODIACEAE}

(1 género, 2 especies).

Lycopodium clavatum $\mathrm{L}$.

Hierba nativa que crece en áreas cercanas a relictos de bosque de Roble.

Vereda Torres -Valero y Mirque, Sector Sur Oriental de Ráquira.
Voucher: López, R. 12218 (FMB, UDBC). Lycopodium thyoides Humb. \& Bonpl. ex. Willd. Hierba nativa que crece al borde de la quebrada. Vereda Resguardo Oriente, cerca a la quebrada la fragua, $2184 \mathrm{~m}$.

Voucher: López, R. 12193 (UDBC).

\section{POLYPODIACEAE}

(3 género, 4 especies).

Cheilanthes myriophylla Desv.

Hierba nativa, ubicada al borde de la carretera.

Carretera Raquira-Tinjaca, a 1 km de Ráquira, 2150.

Voucher: Acosta, A. 252 (COL)

Pleopeltis cf. remota (Desv.) A.R. Sm.

Hierba nativa que crece en el sotobosque.

Vereda Resguardo de Occidente, La Chorrera.

Polypodium sp.

Hierba nativa que crece en los bordes de la quebrada. Vereda Resguardo Oriente, cerca a la quebrada la fragua, $2184 \mathrm{~m}$.

Voucher: López, R. 12212 (UDBC

Polypodium thyssanolepis A. Braun ex Klotzsch

Helecho nativo, crece al borde de la carretera.

Carretera Raquira-Tinjaca, $2150 \mathrm{~m}$.

Voucher: Acosta, A. 253 (COL).

\section{GIMNOSPERMAS}

\section{CUPRESSACEAE}

(1 género, 1 especie)

Cupressus lusitanica Mill. (Figura 5b)

Árbol introducido y cultivado.

Vereda Roa, 2169-2216m

Voucher: López, R. 13820 (UDBC)

PINACEAE

(1 género, 2 especies).

Pinus patula Schiede ex Schltdl. \& Cham.

Árbol introducido y cultivado. Vereda Roa. $2200 \mathrm{~m}$.

Voucher: López, R. Observado

Pinus radiata D.Don

Árbol introducido y cultivado.

Vereda Roa. 2200 m.

Voucher: López, R. Observado. 


\section{ANGIOSPERMAS}

\section{COMPLEJO MAGNÓLIDAS}

\section{PIPERACEAE}

(2 géneros, 11 especies)

Peperomia aff. camargo-collegianum Trel.

Hierba nativa, semirastrera, rupícola, crece en áreas húmedas a orillas de ríos y quebradas.

Vereda Resguardo occidente, carretera RáquiraGuachetá, $2250 \mathrm{~m}$.

Voucher: Becerra, C. 27 (COL)

\section{Peperomia galioides Kunth}

Hierba nativa, rupícola, crece en ambientes húmedos y sombreados.

Vereda Tapias, sector La Despensa, $2680 \mathrm{~m}$.

Voucher: López, R. 12384 (UDBC)

Peperomia ilaloensis Sodiro

Hierba nativa, rupícola, crece en ambientes muy húmedos, a orillas de ríos y quebradas.

Vereda, Resguardo Occidente, quebrada Mutacá, $2200 \mathrm{~m}$.

Voucher: Becerra, C. 26 (COL)

Peperomia inaequalifolia Ruiz \& Pav.

Arbusto nativo, crece en áreas de bosque.

Voucher: Duarte, C. 26 (COL)

\section{Peperomia sp.}

Hierba nativa, crece en relictos de bosque de roble, en áreas degradadas y en bordes de camino.

Vereda Resguardo de Occidente, Torres y Mirque, 2112-2645 m.

Voucher: López, R. 13857 (UDBC)

Peperomia tetraphylla (G.Forst.) Hook. \& Arn.

Hierba nativa, epifita, crece en ambientes muy húmedos.

Vereda Resguardo Occidente, quebrada Mutacá, 2200 $\mathrm{m}$.

Voucher: Becerra, C. 176 (COL)

Piper angustifolium Lam.

Hierba nativa. Crece en áreas de procesos de sucesión. Vereda Resguardo Occidente, afluente de la quebrada Chillón, $2400 \mathrm{~m}$.

Voucher: López, R. 12355 (UDBC)

Piper bogotense C.DC.

Árbol nativo. Crece en áreas de procesos de sucesión de siete años de edad.

Vereda Tapias, sector La Despensa, 2400m.

Voucher: López, R. 12382 (FMB, UDBC)
Piper cf. hostmannianum (Miq.) C.DC.

Árbol nativo. Crece en áreas en procesos de sucesión de siete años de edad.

Vereda Torres y Valero y vereda Mirque, sector suroriental de Ráquira, en la reserva Chaute.

Voucher: López, R. 12252 (FMB, UDBC)

Piper prunifolium J.Jacq.

Árbol nativo. Ocasional, ocupa claros de robledal intervenido y crece a orillas de caminos y carreteras. Vereda Firita, peña abajo, $2700 \mathrm{~m}$.

Voucher: Becerra, C. 247 (COL)

Piper sp.

Arbusto nativo. Crece en relictos de bosque de roble, em áreas degradadas y en bordes de camino.

Vereda Resguardo de Occidente, Torres y Mirque, 2112-2645 m.

Voucher: López, R. 13845 (UDBC)

WINTERACEAE

(1 género, 1 especie).

Drimys granadensis L.f.

Árbol nativo. Escaso, crece en matorrales densos a orillas del camino vía al páramo de Rabanal.

Vereda Firita Alta. 3490 m.

Voucher: González, R. 1023 (UDBC)

\section{MONOCOTILEDÓNEAS}

\section{ALSTROEMERIACEAE}

(1 género, 1 especie).

Bomarea multiflora (L. f.) Mirb.

Trepadora nativa. Crece en los bordes del camino.

Vereda Firita Peña Abajo, 2700 m.

Voucher: Becerra, C. 243 (COL)

AMARYLLIDACEAE

(1 género, 1 especie)

Furcraea cabuya Trel. (Figura 5d)

Hierba nativa. Roseta frecuente en suelos degradados, con erosión avanzada, al borde de carretera y cultivada. Vereda Candelaria Oriente, carretera a Sámaca, 2400 $\mathrm{m}$.

Voucher: Becerra, C. 282 (COL); López, R. 13855 (UDBC).

\section{ASPARAGACEAE}

(1 género, 1 especie)

Asparagus officinalis L.

Hierba introducida. Cultivada en huertos.

Vereda Roa, 2100-2180 m.

Voucher: López, R. 13784 (UDBC). 


\section{BROMELIACEAE}

(2 géneros, 5 especies).

\section{Puya exuta L.B.Sm. \& Read}

Roseta nativa. Crece en áreas degradadas y suelos desérticos.

Vereda La candelaria, sector occidente y oriente.

Voucher: López, R. 13883 (UDBC).

\section{Puya nitida Mez}

Roseta nativa. Crece en inmediaciones de Robledal intervenido, en suelos relativamente húmedos y con algo de materia orgánica.

Voucher: López, R. 13902 (UDBC)-

\section{Tillandsia recurvata (L.) L.}

Roseta epifíta, nativa. Crece sobre el árbol de Myrtaceae. Frecuente, en áreas con alto grado de degradación de suelos.

Vereda Resguardo oriente, sector La Quinta, cerca a la quebrada La Fragua $2248 \mathrm{~m}$.

Voucher: López, R. 12213 (UDBC).

\section{Tillandsia sp.}

Roseta epifíta nativa. Crece en ambientes desérticos y vegetación de estratos herbaceos.

Vereda Candelaria, sector oriente y occidente. Veredas Chinguichaca y Roa, 2180.

Voucher: López, R. 13924 (UDBC).

Tillandsia usneoides (L.) L.

Roseta epifíta, nativa. Crece sobre árboles a lo largo de quebrada y en áreas con alto grado de degradación de suelos.

Vereda Resguardo oriente, sector La Quinta, cerca a la quebrada La Fragua. 2248 m.

Voucher: López, R. 12215 (FMB, UDBC).

\section{CANNACEAE}

(1 género, 1 especie).

Canna coccinea Mill. (Figura 5h)

Arbusto. Crece en huertos y bordes de camino.

Veredas Pueblo Viejo, sector de la Candelaria, 2170 $\mathrm{m}$.

Voucher: Franco, M. 42 (UDBC).

\section{COMMELINACEAE}

(3 géneros, 3 especies).

\section{Commelina diffusa Burm.f.}

Hierba nativa. Postrada escasa, crece en sitios muy húmedos y sombreados.

Vereda Resguardo Occidente, sitio Las Peñas.

Voucher: Orbell, J. 10065.

\section{Tradescantia multiflora Sw.}

Hierba nativa. Trepadora escasa, en sitios húmedos y suelos pobres.

Vereda Resguardo occidente.

Voucher: Orbell, J. 10055.

Tripogandra serrulata (Vahl) Handlos

Arbusto nativo. Crece en el bosque montano seco.

Voucher: Duarte, C. 22 (COL)

CYPERACEAE

(4 géneros, 5 especies).

Bulbostylis junciformis (Kunth) C.B.Clarke

Hierba nativa. Crece en suelos con alta erosión, asociada a gramineas y algunas asteraceas.

Vereda Candelaria oriente, carretera a Samacá, 2400 $\mathrm{m}$.

Voucher: Becerra, C. 279 (COL); Méndez, V. 272 (COL).

Cyperus aggregatus (Willd.) Endl.

Hierba nativa. Crece en sitios húmedos y sombreaddos a orillas de quebradas, junto con gramineas lamiaceas y malvaceas.

Vereda Resguardo occidente, quebrada Mutacá, 2200 $\mathrm{m}$.

Voucher: Becerra, C. 145, 146 (COL).

\section{Cyperus rufus Kunth}

Hierba nativa. Crece en suelos inundados, en alrededores de la laguna, asociada con Juncus y algunas gramineas.

Vereda Firita Peña Abajo, sector confites, borde de la laguna Confites, $2850 \mathrm{~m}$.

Voucher: Becerra, C. 196 (COL).

\section{Cyperus sp.}

Hierba nativa. Crece en ambientes desérticos y vegetación de estratos herbaceos.

Vereda Candelaria, sector oriente y occidente. Veredas Chinguichaca y Roa, 2180.

Voucher: López, R. 13890 (UDBC).

\section{Eleocharis macrostachya Britton}

Hierba nativa. Crece enraizada en pantanos, sobre suelos húmedos en sitios sombreados.

Vereda San cayetano, $2550 \mathrm{~m}$.

Voucher: Méndez, V. 102, 260 (COL).

Rhynchospora aristata Boeckeler (Figura 5f)

Hierba nativa. Crece en áreas de páramo dominado por frailejoes y puyas.

Vereda Firita Alta, páramo de Rabanal, 3490 m.

Voucher: González, R. 1031 (UDBC).

Rhynchospora nervosa (Vahl) Boeckeler

Hierba nativa. Frecuente, crece en pastizales vía al páramo de Rabanal. 
Vereda Firita Alta, 3490 m.

Voucher: Becerra, C. 4 (COL); Méndez, V. 28 (COL).

\section{Rhynchospora sp.}

Hierba nativa. Crece en relictos de bosque de roble, áreas degradadas y bordes de camino.

Vereda Resguardo de occidente.

Voucher: González, R. 57 (UDBC).

\section{ERIOCAULACEAE}

(1 género, 1 especie).

Paepalanthus alpinus Körn. (Figura 5g)

Hierba nativa. Roseta frecuente en páramo de Rabanal, formando pequeños grupos, sobre suelos húmedos, asociada con Espeletia.

Vereda Firita Alta.

Voucher: González, R. 1026 (UDBC).

\section{IRIDACEAE}

(1 género, 1 especie).

Orthosanthus chimboricensis (Kunth) Bakc. (Figura

5e)

Hierba nativa. Esporádica, crece en sitios abiertos, aislada y sobre suelos muy pobres, con escasa humedad; también crece en cercanías a robledales intervenidos.

Vereda Torres y Valero, sector suroriental de Ráquira, en la reserva Chaute.

Voucher: López, R. 12225, 13930 (FMB, UDBC).

JUNCACEAE

(1 género, 3 especies).

Juncus echinocephalus Balslev

Hierba nativa. Crece en pantanos, con raíces fuertemente aferradas.

Vereda Firita Peña Abajo, sector laguna Confites, $2850 \mathrm{~m}$.

Voucher: Becerra, C. 195 (COL).

Juncus effusus L.

Hierba nativa. Crece en pantanos, con raíces fuertemente aferradas.

Vereda Roa 2200 m. Vereda Firita Peña Abajo y Peña Arriba, sector laguna Confites, 2850-3490 m.

Voucher: López, R. 13791, 13898 (UDBC).

Juncus ramboi Barros

Hierba nativa. Crece en pantanos, con raíces fuertemente aferradas.

Vereda Roa 2200 m. Vereda Firita Peña Abajo y Peña Arriba, sector laguna Confites, 2850-3490 m.

Voucher: Franco, M. $31 \mathrm{~b}$ (UDBC).

\section{ORCHIDACEAE}

(4 géneros, 6 especies).

\section{Elleanthus smithii Schltr.}

Hierba nativa. Terrestre, ocasional. Crece en ambientes húmedos y semisombreados, sobre suelos ricos en materia orgánica, con erosión incipiente.

Vereda Farfán, 2650 m.

Voucher: Becerra, C. 259 (COL).

Epidendrum aff. secundum Jacq.

Hierba nativa. Es terrestre y frecuente en matorrales abiertos y sobre suelos secos con erosión moderada a avanzada, algunas veces sobre taludes de carretera, rupícola.

Vereda Firita Peña Abajo, 2820 m.

Voucher: Becerra, C. 241 (COL); García, B. H. 20245

(COL); López, R. 12254, 13853 (UDBC); Méndez, V. 43 (COL).

Epidendrum sp.

Hierba nativa. Crece en áreas de huerto y borde de camino.

Vereda Pueblo Viejo, sector La Candelaria, 2170$2452 \mathrm{~m}$.

Voucher: López, R. 13876 (UDBC).

Maxillaria aurea (Poepp. \& Endl.) L.O.Williams

Hierba nativa. Terrestre ocasional en pequeños matorrales abiertos, pero siempre resguardada del exceso de luz, en bosques de roble intervenidos, en suelos húmedos.

Vereda Resguardo Occidente, $2200 \mathrm{~m}$.

Voucher: Méndez, V. 287 (COL).

Pleurothallis sp. (1)

Hierba nativa y terrestre. Crece en suelos húmedos junto a helechos.

Vereda Torres y Valero, sector suroriental de Ráquira en la Reserva Chaute, $2600 \mathrm{~m}$.

Voucher: López, R. 12239 (FMB, UDBC).

Pleurothallis sp. (2)

Hierba nativa. Crece en zonas de bosque relictual, páramo y bordes de camino.

Vereda Firita Peña Arriba, camino al páramo de Rabanal, 3100-3490 m.

Voucher: López, R. 13895 (UDBC).

POACEAE

(18 géneros, 24 especies).

Agrostis aff. perennans (Walter) Tuck.

Hierba nativa. Frecuente en áreas de matorrales.

Vereda San Cayetano, $2550 \mathrm{~m}$.

Voucher: Méndez, V. 103 (COL).

Andropogon bicornis L.

Hierba nativa. Crece en áreas degradadas. 
Vereda Resguardo de occidente, sector la quinta, cerca a la quebrada la fragua, $2248 \mathrm{~m}$.

Voucher: López, R. 12190 (UDBC).

Andropogon lehmannii Pilg.

Hierba nativa. Frecuente en áreas circundante a los bosques de robles, en suelos secos y erosionados.

Resguardo oriente, sector La Quinta, cerca a la quebrada de La Fragua. $2250 \mathrm{~m}$.

Voucher: López, R. 12211 (FMB, UDBC); Méndez, V. 18 (COL).

Andropogon leucostachyus Kunth.

Hierba nativa. Crece en ambientes desérticos y vegetación de estratos herbáceos.

Vereda Candelaria, sector oriente y occidente. Veredas Chinguichaca y Roa, 2180.

Voucher: Becerra, C. 276 (COL); Cleef, A. 3460 (COL); López, R. 13888 (UDBC).

\section{Andropogon sp.}

Hierba nativa. Crece en huertos y bordes de camino.

Veredas Pueblo Viejo, sector de la Candelaria, 2170

$\mathrm{m}$.

Voucher: López, R. 13863 (UDBC).

\section{Anthoxanthum odoratum $\mathrm{L}$.}

Hierba nativa. Frecuente en áreas de páramo y subpáramo abierto y seco, en suelos pobres, con erosión leve.

Vereda Firita Peña Arriba, 3050 m.

Voucher: Becerra, C. 211 (COL).

Aristida aff. recurvata Kunth

Hierba nativa. Poco frecuente, típico de suelos erosionados y pobres.

Vereda Candelaria Oriente, carretera Samacá, 2400 m.

Voucher: Becerra, C. 277 (COL).

Axonopus compressus (Sw.) P.Beauv.

Hierba nativa. En suelos secos y moderadamente erosionados, en áreas abiertas.

Ráquira, alrededores del casco urbano. $2220 \mathrm{~m}$.

Voucher: Méndez, V. 266 (COL).

Axonopus fissifolius (Raddi) Kuhlm.

Hierba nativa. Frecuente en espacios abiertos, formando matorrales densos, en suelos degradados.

Ráquira, alrededores del casco urbano. $2220 \mathrm{~m}$.

Voucher: Méndez, V. 262 (COL).

Bothriochloa saccharoides (Sw.) Rydb.

Hierba nativa. En bordes de camino.

Entre en casco urbano de Ráquira y La Candelaria, $2300 \mathrm{~m}$.

Voucher: Stancik, D. 2139 (COL).
Calamagrostis intermedia (J. Presl) Steud.

Hierba nativa. Terrestre frecuente en bordes de carretera.

Vereda Resguardo de occidente, sector la quinta, cerca a la quebrada la fragua, $2248 \mathrm{~m}$.

Voucher: López, R. 12214 (UDBC).

\section{Chloris gayana Kunth}

Hierba introducida. Crece en suelos altamente degradados, algunas veces sobre la roca.

Vereda Resguardo oriente, $2190 \mathrm{~m}$.

Voucher: Méndez, V. 247 (COL).

Chusquea scandens Kunth.

Arbusto nativo. Crece en áreas de subpáramo.

Vereda Firita Peña Arriba, 3050 m.

Voucher: López, R. Observado.

Gynerium sagittatum (Aubl.) P.Beauv.

Hierba nativa. Crece en bordes de quebradas y suelos húmedos, en áreas abiertas.

Vereda Roa. $2200 \mathrm{~m}$.

Voucher: López, R. 13825 (UDBC).

Holcus lanatus $\mathrm{L}$.

Hierba introducida. Crece en áreas de subpáramo, formando pajonales junto con otras poaceas.

Vereda Firita Peña Abajo, sector Laguna confites, $2850 \mathrm{~m}$.

Voucher: Becerra, C. 170 (COL).

Melinis minutiflora P. Beauv.

Hierba introducida. Crece en suelos altamente degradados y con deficit hídrico.

Ráquira alrededor del casco urbano, $2220 \mathrm{~m}$.

Voucher: López, R. 12199 (UDBC); Méndez, V. 265

(COL).

Oplismenus burmanni (Retz.) P.Beauv.

Hierba introducida, escasa, crece en suelos húmedos y sombreados.

Vereda Resguardo occidente, quebrada Mutacá, sitio E1 Pedregal, $2200 \mathrm{~m}$.

Voucher: Méndez, V. 282 (COL).

Panicum pilosum Sw.

Hierba nativa. Crece en suelos húmedos y sombreados, poco frecuente.

Vereda Resguardo occidente, quebrada Mutacá, sitio El Pedregal, $2200 \mathrm{~m}$.

Voucher: Becerra, C. 149 (COL).

Paspalum juergensii Hack.

Hierba nativa. Crece en matorrales densos.

Vereda Resguardo de occidente, $2200 \mathrm{~m}$.

Voucher: Méndez, V. 283 (COL). 


\section{Paspalum macrophyllum Kunth}

Hierba nativa. Cespitosa ocacional, en borde de carretera y bosques de recuperación.

Monasterio La Candelaria. Vereda Roa, 2169-2216m.

Voucher: Giraldo, C. 3561 (COL); López, R. 13831 (UDBC).

\section{Paspalum notatum Alain ex Flüggé}

Hierba nativa. Crece en matorrales densos, suelos moderadamente erosionados.

Vereda Roa, sector La Rochela, $2100 \mathrm{~m}$.

Voucher: Méndez, V. 178 (COL).

Pennisetum purpureum Schumach.

Hierba nativa. Crece en áreas desérticas, zonas de bosque y vegetación de estratos herbáceos.

Vereda Candelaria, sector oriente y occidente. Veredas Chinguichaca y Roa, 2180.

Voucher: López, R. 13877 (UDBC).

\section{Polypogon elongatus Kunth}

Hierba nativa. Frecuente en riveras de quebradas, crece en bordes de camino, bosques relictuales y áreas de páramo

Desierto de La Candelaria, 2300 m. Vereda Firita Peña Arriba, camino al páramo de Rabanal, 3100-3490 m.

Voucher: Giraldo, C. 3558 (COL); López, R. 13901 (UDBC).

\section{Setaria parviflora (Poir.) Kerguélen}

Hierba nativa. Frecuente en matorrales densos, sobre suelos moderadamente húmedos.

Vereda Roa, sector La Rochela, $2100 \mathrm{~m}$.

Voucher: Méndez, V. 179 (COL).

\section{SMILACACEAE}

(1 género, 2 especies).

Smilax floribunda Desv. ex Ham.

Liana nativa. Crece en matorrales densos, cerca de bosque de roble intervenido.

Vereda Resguardo occidente, afluente de la quebrada Chillón. $2400 \mathrm{~m}$.

Voucher: López, R. 12356 (UDBC).

Smilax aff. tomentosa Kunth. (Figura 5c)

Liana nativa. Es poco frecuente en matorral denso sobre suelo seco con erosión moderada.

Vereda Resguardo Occidente, $2400 \mathrm{~m}$.

Voucher: González, R. 61 (UDBC).

\section{TYPHACEAE}

(1 género, 1 especie).

Typha angustifolia $\mathrm{L}$.

Hierba nativa y acuática, en áreas inundadas, formando grandes grupos. Crece en áreas de regeneración no intervenida hace quince años.

Vereda Roa, cercanías a la quebrada San Pedro y alto de San Pedro.

Voucher: López, R. 12323 (FMB, UDBC).

\section{XANTHORRHOEACEAE}

(1 género, 1 especie).

Aloe vera (L.) Burm. f.

Hierba nativa. Frecuente, crece en huertos y jardines.

Vereda Roa, sector La Rochela, $2100 \mathrm{~m}$.

Voucher: López, R. Observado

\section{EUDICOTILEDÓNEAS}

\section{ACANTHACEAE}

(2 géneros, 2 especies).

\section{Thunbergia alata Bojer ex Sims}

Hierba nativa. Crece en áreas de huerto y borde de camino.

Vereda Pueblo Viejo, sector La Candelaria, 2170$2452 \mathrm{~m}$.

Voucher: López, R. 13867 (UDBC).

Trichanthera gigantea (Bonpl.) Nees

Árbol nativo, cultivado. Crece en áreas de huertos.

Vereda la Candelaria sector occidente y oriente.

Voucher: López, R. 13879 (UDBC)-

\section{ADOXACEAE}

(2 géneros, 2 especies).

Sambucus nigra $\mathrm{L}$.

Árbol nativo. Cultivado en jardines.

Vereda Roa.

Voucher: López, R. Observado.

Viburnum tinoides L.f. (Figura 8h)

Árbol nativo. Crece en relictos de bosque de roble, áreas degradadas y bordes de camino.

Vereda Resguardo oriente, sector La Quinta, cerca a la quebrada La Fragua. Veredas Mirque, Torres.

Voucher: Franco, M. 36 (UDBC); López, R. 12191 (FMB, UDBC).

\section{AMARANTHACEAE}

(4 géneros, 5 especies).

Amaranthus hybridus L.

Hierba nativa. Crece wn lugares abiertos sobre suelos secos.

Vereda Roa Sector La Rochela $2100 \mathrm{~m}$.

Voucher: Méndez, V. 175 (COL).

Chenopodium ambrosioides $\mathrm{L}$.

Hierba introducida. Escasa, en áreas abiertas, suelos arenosos y en áreas de cultivo. 
Vereda Roa, sector La Rochela, $2100 \mathrm{~m}$.

Voucher: Méndez, V. 217 (COL); López, R. 13792

(UDBC).

\section{Chenopodium paniculatum Hook.}

Hierba nativa. Crece en suelos secos y arenosos.

Vereda Roa, sector La Rochela, $2100 \mathrm{~m}$.

Voucher: López, R. Observado; Mendez, V. 201

(COL).

Iresine diffusa Humb. \& Bonpl. ex Willd.

Hierba nativa y rastrera.

$2250 \mathrm{~m}$

Voucher: Castroviejo, S. 10646, 10561 (COL).

Pfaffia iresinoides (Kunth) Spreng.

Hierba nativa. Frecuente a borde de carretera, en suelos arenosos.

Vereda Roa Sector La Rochela $2100 \mathrm{~m}$.

Voucher: Méndez, V. 172 (COL).

ANACARDIACEAE

(3 géneros, 4 especies).

Mauria heterophylla Kunth (Figura 6p)

Árbol, arbusto, nativo. Crece en huertos y bordes de camino.

Vereda Pueblo Viejo, Sector de la Candelaria, $2170 \mathrm{~m}$. Voucher: Castroviejo, S. 10635 (COL); Franco, M. 40 (UDBC); López, R. 12337, 13889 (FMB, UDBC); Ranghel, G. 62 (COL).

Mauria sp.

Árbol, arbusto. Nativo. Crece en bosques secundarios. Voucher: López, R. 12189 (UDBC).

\section{Schinus molle $\mathrm{L}$.}

Árbol introducido. Cultivado, crece en suelos arenosos, ambientes desérticos y vegetación de estratos herbáceos.

Vereda Candelaria, sector oriente y occidente. Veredas Chinguichaca y Roa, 2180.

Voucher: López, R. 13890A (UDBC).

Toxicodendrum sp.

Árbol nativo. Crece en relictos de bosque de roble, áreas degradadas y bordes de camino.

Vereda Resguardo de occidente, Torres y Mirque, 2112-2645 m.

Voucher: López, R. 13889 (UDBC); Ramírez, A. 36 (FMB).

\section{APIACEAE}

(4 géneros, 4 especies).

\section{Conium maculatum L.}

Hierba introducida. Cultivada.

Vereda Roa, 2010.
Voucher: López, R. Observado.

Coriandrum sativum $\mathrm{L}$.

Hierba nativa. Crece en zonas de bosque relictual, páramos y bordes de camino.

Vereda Firita Peña Arriba, camino al páramo de Rabanal, 3100-3490 m.

Voucher: López, R. 13900 (UDBC).

Daucus montanus Humb. \& Bonpl.

Hierba nativa. Suelos pobres.

Vereda Roa, sector La Rochela, $2100 \mathrm{~m}$.

Voucher: Méndez, V. 181 (COL).

Eryngium humboldtii F. Delaroche

Roseta. Crece en zonas de bosque relictual, páramo. y bordes de camino.

Vereda Firita Peña Arriba, camino al paramo de Rabanal, 3100-3490 m.

Voucher: González, R. 1018 (UDBC).

\section{APOCYNACEAE}

(2 géneros, 2 especies).

Asclepias curassavica L. (Figura 7i)

Liana nativa. Es común en lugares abiertos, suelos pedregosos, matorrales, zonas de bosque relictual, páramo y bordes de camino.

Vereda Roa, sector la Rochela. Vereda Firita Peña Arriba, camino al páramo de Rabanal, 3100-3490 m.

Voucher: López, R. 13926 (UDBC); Méndez, V. 194 (COL).

Ditassa longiloba Benth.

Hierba nativa. Común en matorrales ralos y suelos secos y pobres.

Desierto de La Calendaría, alrededores del monasterio.

Voucher: Becerra, C. 297 (COL).

\section{AQUIFOLIACEAE}

(1 género, 1 especie).

Ilex sessiliflora Triana \& Planch.

Arbusto nativo. Crece en bosques y bordes de caminos. Vereda Torres y Valero. $2600 \mathrm{~m}$.

Voucher: López, R. 12253 (FMB, UDBC).

\section{ARALIACEAE}

(2 géneros, 2 especies).

Oreopanax floribundum (Kunth) Decne \& Planch. (Figura 8g)

Árbol nativo. Crece en bosque ripario y bosque de Quercus humboldtii.

Vereda Torres y Valero $2750 \mathrm{~m}$.

Voucher: López, R. 12237, 13878 (UDBC).

Oreopanax incisus (Will. ex. Schult.) Decne \& Planch. 
Árbol nativo. Crece en ambientes desérticos y vegetación de estratos herbáceos.

Vereda Candelaria, sector oriente y occidente. Veredas Chinguichaca y Roa, 2180.

Voucher: López, R. 13877a (UDBC).

\section{ASTERACEAE}

(36 géneros, 54 especies).

Achyrocline alata (Kunth) DC.

Arbusto nativo. Crece en ambientes desérticos y vegetación de estratos herbáceos.

Vereda Candelaria, sector oriente y occidente. Veredas Chinguichaca y Roa, 2180.

Voucher: López, R. 13935 (UDBC).

\section{Achyrocline sp.}

Hierba nativa. En ladera seca.

Voucher: Castroviejo, S. 10569, 10573 (COL).

Acmella aff. uliginosa Cass

Hierba nativa. En áreas de cultivo.

Vereda Roa Sector La Rochela. 2100 m.

Voucher: Méndez, V. 227 (COL).

Ageratina gracilis (Kunth) R.M. King \& H. Rob.

Hierba nativa. Crece en áreas de vegetación secundaria, matorrales arbustivos, en suelos arcillosos.

Vereda Mirque. $2600 \mathrm{~m}$.

Voucher: Becerra, C. 257 (COL).

Ageratina theaefolia (Benth.) R.M. King \& H. Rob. Arbusto nativo. Crece en laderas secas.

$2650 \mathrm{~m}$.

Voucher: Castroviejo, S. 10603 (COL).

Ageratum conyzoides $\mathbf{L}$.

Hierba nativa. Crece en matorrales y en áreas de cultivo, en suelos húmedos.

Vereda Resguardo occidente. $2200 \mathrm{~m}$.

Voucher: Castroviejo, S. 10642 (COL).

Ambrosia peruviana Willd.

Hierba nativa. Crece en matorrales abiertos y suelos semihúmedos.

Vereda Roa sector La Rochela. $2100 \mathrm{~m}$.

Voucher: Becerra, C. 157 (COL).

Artemisia absinthium $\mathrm{L}$.

Hierba-subarbusto, introducido. Crece en áreas de huerto y borde de camino.

Vereda Roa. $2100 \mathrm{~m}$.

Voucher: López, R. Observado. Ayapana cf. turbacensis (Hieron) R.M.King

Hierba nativa. Crece en suelos secos.

Vereda Roa sector La Rochela. $2100 \mathrm{~m}$.

Voucher: Méndez, V. 213 (COL).
Baccharis macrantha Kunth (Figura 8a)

Arbusto nativo. Crece en sitios abiertos y orillas de carretera, en suelos erosionados.

Vereda Resguardo oriente, sector La Quinta, cerca a la quebrada La Fragua.

Voucher: González, R. 59 (UDBC); López, R. 12181, 12308, 12312 (FMB, UDBC).

Baccharis nitida (Ruiz \& Pav.) Pers.

Hierba nativa. Crece en relictos de bosque de roble, áreas degradadas y bordes de camino.

Vereda Resguardo de occidente, Torres y Mirque, 2112-2645 m

Voucher: López, R. 13856 (UDBC).

\section{Baccharis prunifolia Kunth}

Arbusto nativo. Crece en sitios abiertos y en orillas de carretera, en sector poco erosionado.

Vereda Resguardo oriente, sector La Quinta.

Voucher: Pinzón, V. 728 (UDBC).

Baccharis tricuneata (L.f.) Pers.

Arbusto nativo. Crece en sitios abiertos y orillas de bosque de roble, en suelos con poca erosión.

Vereda Torres y Valero y Vereda Mirque. $2600 \mathrm{~m}$.

Voucher: López, R. 12242 (FMB, UDBC).

Baccharis trinervis Pers.

Arbusto nativo. Crece en matorrales, rastrojos y sitios de pedregal.

Vereda Roa sector La Rochela. $2100 \mathrm{~m}$.

Voucher: Castroviejo, S. 10633 (COL); Méndez, V. 177 (COL).

Barnadesia spinosa L.f. (Figura 8b)

Arbusto nativo. Crece en matorrales, zonas de bosque relictual, páramo y bordes de camino.

Vereda Roa sector La Rochela, 2100 m. Vereda Firita Peña Arriba, camino al páramo de Rabanal, 3100$3490 \mathrm{~m}$

Voucher: González, R. 47 (UDBC); López, R. 13921 (UDBC).

Bidens pilosa $\mathrm{L}$.

Hierba nativa. Crece en áreas de cultivo y de vegetación densa.

Vereda Resguardo occidente, $2200 \mathrm{~m}$.

Voucher: Becerra, C. 159 (COL); Ranghel, G. 114 (COL).

Bidens rubifolia Kunth

Hierba nativa. En áreas cerca de bosques de Quercus humboldtii y matorrales secundarios.

Vereda Firita, $2700 \mathrm{~m}$.

Voucher: Becerra, C. 245 (COL). 


\section{Calea pachensis Hieron}

Hierba nativa. Crece en matorrales, áreas de quebrada y vegetación ruderal.

Vereda San Cayetano, $2670 \mathrm{~m}$.

Voucher: Méndez, V. 034 (COL).

Calea peruviana (Kunth) Benth. ex Blake

Hierba nativa. Crece en áreas abiertas, suelos arenosos y erosionados.

Área urbana de Ráquira $2200 \mathrm{~m}$.

Voucher: Castroviejo, S. 10575 (COL); Méndez, V. 237 (COL).

\section{Calendula officinalis $\mathbf{L}$.}

Hierba introducida y cultivada en huertos y jardines.

Vereda Roa. 2100 m.

Voucher: López, R. Observado.

Chromolaena bullata (Klatt.) R.M. King \& H. Rob.

Arbusto nativo. Crece en suelos secos con erosión moderada.

Vereda Resguardo occidente. $2600 \mathrm{~m}$.

Voucher: Orbell, J. 10132; Ranghel, G. 89 (COL).

Chromolaena leivensis (Hieron.) R.M. King \& H.

Rob.

Arbusto nativo. Crece en suelos secos con erosión moderada, áreas de matorrales.

Vereda Roa sector La Rochela. $2100 \mathrm{~m}$.

Voucher: González, R. 31 (UDBC).

Chromolaena scabra (L.f.) R.M. King \& H. Rob.

Arbusto nativo. Crece en suelos secos. Frecuente a borde de carretera y caminos.

Vereda San Cayetano. 2550 m.

Voucher: Méndez, V. 106 (COL).

Chromolaena cf. tacotana (Klatt) R.M. King R. H.Rob.

Arbusto nativo. Crece en suelos secos con erosión moderada, áreas de matorrales.

Vereda Resguardo oriente, sector La Quinta. 2300 m, cerca de la quebrada La Fragua.

Voucher: López, R. 12205 (UDBC).

Clibadium surinamense $\mathrm{L}$.

Arbusto nativo. Crece en suelos secos con erosión moderada, áreas de matorrales.

Vereda Resguardo oriente, sector La Quinta. 2300 m, cerca de la quebrada La Fragua.

Voucher: López, R. 12170 (FMB, UDBC); Ramírez, A. 2 (FMB).

Cotula australis (Sieber ex Spreng.) Hook. f.

Hierba rasante.

Cuneta.
Voucher: Castroviejo, S. 10558 (COL).

Cotula mexicana (DC.) Cabrera

Hierba nativa. Enraizada en fango, asociada a Juncus effusus.

Vereda Firita Peña Abajo, sector confites, $2850 \mathrm{~m}$.

Voucher: Becerra, C. 194 (COL).

Dahlia imperialis Roezl ex Ortgies

Hierba nativa. Crece en áreas de huerto.

Vereda Roa. $2100 \mathrm{~m}$.

Voucher: López, R. Observado.

Diplostephium rosmarinifolius (Benth.) Wedd.

Arbusto nativo. Crece en suelos secos con erosión moderada, áreas de matorrales.

Vereda Tapias, sector La Despensa y Vereda Firita Alta vía al páramo Rabanal 2550-3490 m. Vereda Firita Peña Arriba, camino al páramo de Rabanal, 3100-3490 m.

Voucher: González, R. 1024 (UDBC); López, R. 12387, 13925 (UDBC).

Espeletia boyacensis Cuatrec.

Roseta nativa. Crece en áreas abiertas junto con elementos de páramo y subpáramo.

Vereda Firita Peña Abajo, carretera Ráquira-Guachetá. $2940 \mathrm{~m}$.

Voucher: Becerra, C. 127 (COL); Castroviejo, S. 10610 (COL).

Espeletia aff. corymbosa (Bonpl.) Cuatrec. (Figura $8 \mathrm{c})$

Roseta nativa. Frecuente en áreas abiertas junto con elementos de páramo y subpáramo.

Vereda Firita Peña Abajo, Laguna Confites, 2900 m. Vereda Firita Peña Arriba, camino al páramo de Rabanal, 3100-3490 m.

Voucher: González, F. 3792 (COL); López, R. 13904, 13922 (UDBC).

\section{Galinsoga parviflora Cav.}

Hierba nativa. En áreas de cultivos.

Vereda Resguardo occidente. $2500 \mathrm{~m}$.

Voucher: Orbell, J. 10161.

Heterospermum pinnatum Cav.

Hierba nativa. Escasa en suelos pobres y erosionadas. Vereda Resguardo occidente. $2500 \mathrm{~m}$.

Voucher: Orbell, J. 10033.

\section{Hieracium avile Kunth}

Hierba nativa. Ocasional, en algunos cultivos y pastizales en áreas levemente erosionadas.

Vereda Pueblo viejo. $2500 \mathrm{~m}$.

Voucher: Becerra, C. 226 (COL). 
Lepidaploa karstenii (Sch. Bip.) H. Rob.

Arbusto nativo. En áreas de matorral y vegetación de sucesión.

Vereda Roa sector La Rochela. $2100 \mathrm{~m}$.

Voucher: Castroviejo, S. 10570 (COL); González, R. 58 (UDBC); Ranghel, G. 54 (COL).

Lourteigia stoechadifolia (L.f.) R. King \& H. Rob.

Hierba nativa. Restringida a talud de carretera y borde de bosque de roble.

Vereda San Cayetano, $2670 \mathrm{~m}$.

Voucher: Castroviejo, S. 19572 (COL); Méndez, V. 32

(COL).

Lycoseris crocata (Bert.) Blake.

Arbusto nativo. Crece al borde de camino.

Vereda Resguardo occidente, en afluente de la Quebrada Chillón. 2112-2645 m.

Voucher: Castroviejo, S. 10619 (COL); López, R. 12590, 12359, 13859 (FMB, UDBC).

Lycoseris triplinervia Less.

Hierba nativa. Ocasional en matorrales secundarios, sobre suelos arenosos.

Vereda Pueblo Nuevo, cerca al río Salado.

Voucher: Orbell, J. 10104.

Matricaria recutita $\mathbf{L}$.

Hierba introducida y cultivada, en huertos familiares.

Vereda Roa. $2100 \mathrm{~m}$.

Voucher: López, R. 13786, 13842 (UDBC).

Montanoa ovalifolia Deless. ex DC.

Arbusto nativo. Escaso, en áreas de cultivo, cerca al subpáramo y páramo, en suelos secos.

Vereda Carapacho, a borde del río Candelaria.

Voucher: Orbell, J. 10179.

Mutisia clematis L.f. (Figura 8d)

Bejuco nativo. Crece en zonas de bosque relictual, páramo y bordes de camino.

Vereda Firita Peña Arriba, camino al páramo de Rabanal, 3100-3490 m.

Voucher: López, R. 13912 (UDBC).

Noticastrum marginatum (Kunth) Cuatrec.

Hierba nativa. Rizomatosa escasa en bosques de robles y áreas abiertas junto con poaceas, en áreas secas y suelos pedregosos.

Vereda Resguardo occidente, camino a Mirque.

Voucher: Orbell, J. 10057.

Oligactis garcia-barrigae H. Rob.

Hierba nativa. Escandente esporádico, creciendo en bosques densos húmedos.

Vereda San Cayetano, $2550 \mathrm{~m}$.
Voucher: Méndez, V. 104 (COL).

Pentacalia corymbosa (Benth) Cuatrec.

Arbusto nativo. Escandente esporádica, en áreas de matorrales.

Vereda Resguardo occidente, afluente de la Quebrada Chillón. $2400 \mathrm{~m}$.

Voucher: López, R. 12261, 13875 (FMB, UDBC);

Pinzón, V. 739 (UDBC).

Pentacalia ledifolia (Kunth) Cuatrec.

Arbusto nativo. Crece en bordes de camino, bosques relictuales y áreas de páramo

Vereda Firita Peña Arriba, camino al Páramo de Rabanal, 3100-3490 m.

Voucher: López, R. 13906 (UDBC).

Pentacalia aff. pulchella (Kunth) Cuatrec.

Arbusto nativo. Poco frecuente en áreas de roble entresacados y matorrales secundarios.

Vereda Firita Peña Abajo, $2820 \mathrm{~m}$.

Voucher: Becerra, C. 114 (COL).

Pentacalia pulchella subsp. guantivana (Cuatrec.) Cuatrec.

Arbusto nativo. Crece en ladera seca.

Voucher: Castroviejo, S. 10571b (COL).

Pterocaulon virgatum (L.) DC.

Hierba nativa. Frecuente en áreas de cultivos y zonas abiertas, sobre suelos pobres.

Vereda Resguardo occidente, sitio El Pedregal.

Voucher: Orbell, J. 10174.

Smallanthus pyramidalis (Triana) H.Rob.

Árbol nativo. Creciendo en potreros y áreas de regeneración natural.

Vereda Roa. $2100 \mathrm{~m}$.

Voucher: López, R. Observado.

Sonchus oleraceus $\mathbf{L}$.

Hierba introducida. Frecuente en cultivos y huertas.

Vereda Resguardo occidente, $2600 \mathrm{~m}$.

Voucher: Orbell, J. 10130.

Stevia lucida Lag.

Arbusto nativo. Poco frecuente, crece en suelos rocosos y cascajosos, tambien en bosques de regeneración.

Vereda Resguardo oriente, sector la Quinta, cerca a la Quebrada La Fragua, 2300 m. Vereda Roa, 2169$2216 \mathrm{~m}$

Voucher: López, R. 12178, 13830 (UDBC).

Stevia sp.

Hierba nativa. Crece en relictos de bosque de roble, áreas degradadas y bordes de camino.

Vereda Resguardo de Occidente, Torres y Mirque, 
2112-2645 m.

Voucher: López, R. 13847 (UDBC).

Taraxacum officinale F.H. Wigg.

Hierba introducida. Crece al borde de caminos y en potreros.

Vereda Roa, $2200 \mathrm{~m}$.

Voucher: López, R. 13790 (UDBC).

\section{Verbesina centroboyacana S. Díaz}

Arbusto nativo. Poco frecuente, crece al borde de caminos, suelos rocosos y cascajosos.

Vereda Roa, cerca de la quebrada San Pedro, 2200 m. Vereda Pueblo Viejo, sector La Candelaria, 2170$2452 \mathrm{~m}$.

Voucher: López, R. 13868 (UDBC); Ramírez, A. 15 (UDBC).

\section{BASELLACEAE}

(1 género, 1 especie).

\section{Anredera cordifolia (Ten.) Steenis}

Enreadera nativa. Liana frecuente, crece en áreas de huertos.

Vereda Roa, $2216 \mathrm{~m}$.

Voucher: López, R. 13787 (UDBC).

\section{BERBERIDACEAE}

(1 género, 2 especies).

\section{Berberis cf. huertasii L.A. Camargo}

Arbusto nativo. Espinoso en matorrales o arbustales densos de subpáramo.

Vereda Firita Peña Abajo, sector confites. 2850 m.

Voucher: Becerra, C. 203 (COL).

Berberis rigidifolia Kunth ex DC. (Figura 5i)

Arbusto nativo. Espinoso en matorrales y vegetación secundaria en procesos de sucesión.

Vereda Resguardo oriente, sector la Quinta, cerca a la Quebrada La Fragua. 2300 m.

Voucher: González, R. 52 (UDBC).

\section{BETULACEAE}

(1 género, 1 especie).

Alnus acuminata Kunth (Figura 6h)

Árbol nativo. Frecuente al borde de carreteras y en áreas cercanas a cultivos y potreros.

Vereda Torres y Valero y vereda Mirque, sector sur oriental de Ráquira, reserva Chaute. $2600 \mathrm{~m}$.

Voucher: López, R. 12233 (FMB, UDBC).

\section{BIGNONIACEAE}

(2 géneros, 3 especies).

\section{Podranea ricasoliana (Tanfani) Sprague}

Enreadera nativa. Crece en áreas de huerto y borde de camino.
Vereda Pueblo Viejo, sector La Candelaria, 2170$2452 \mathrm{~m}$.

Voucher: López, R. 13873 (UDBC).

Tecoma stans (L.) Juss. ex Kunth

Árbol nativo. Cultivado, en borde de carretera y áreas de potrero.

Vereda Roa, Desierto de La Calendaría, 2200 m.

Voucher: López, R. 13779 (UDBC).

Tecoma stans var. velutina A. DC.

Arbusto nativo.

Vereda Candelaria, Monasterio de la Candelaria.

Voucher: Becerra, C. 292 (COL).

BORAGINACEAE

(2 géneros, 2 especies).

Borago officinalis L.

Hierba introducida. Crece en áreas de huerto.

Vereda Roa. 2100 m.

Voucher: López, R. Observado.

Symphytum officinale L.

Hierba nativa. Cultivado, en huertas.

Vereda Roa. $2200 \mathrm{~m}$.

Voucher: López, R. Observado.

BRASSICACEAE

(2 géneros, 2 especies).

Lepidium bipinnatifidum Donn. Sm.

Hierba nativa. Escasa, en áreas abiertas y terrenos secos.

Vereda Resguardo occidente.

Voucher: López, R. 13801 (UDBC); Orbell, J. 10090.

Raphanus sativus L.

Hierba introducida y cultivada.

Vereda Resguardo occidente.

Voucher: Orbell, J. 10087.

\section{CACTACEAE}

(3 géneros, 3 especies).

\section{Mammilaria colombiana Salm-Dick}

Cacto nativo. Escaso a orillas de camino, en áreas abiertas, sobre suelos arenosos y pedregosos.

Vereda Roa, 2200 m.

Voucher: Méndez, V. 252 (COL).

Opuntia pittieri Britton \& Rose (Figura 7a)

Cacto nativo. Frecuente.

Vereda Carapacho, a borde del río Candelaria. Vereda Roa, 2169-2216m.

Voucher: Calcagno, A. 74, 75 (COL); López, R. 13827

(UDBC).

\section{Rhipsalis baccifera (J.S.Muell.) Stearn}

Cacto nativo. Epífito esporádico, creciendo sobre 
Ficus.

Vereda Candelaria oriente, carretera a Samacá. 2200 $\mathrm{m}$.

Voucher: Becerra, C. 288 (COL).

CAMPANULACEAE

(2 géneros, 4 especies).

Centropogon asclepiadeus E. Wimm. (Figura 8e)

Subarbusto nativo. Escaso, en inmediaciones de robledal intervenido, en suelos arcillosos.

Vereda San Cayetano, $2700 \mathrm{~m}$.

Voucher: Méndez, V. 23 (COL).

Siphocampylus bogotensis E. Wimm.

Subarbusto nativo. Crece en bordes de camino, bosques relictuales y áreas de páramo.

Vereda Firita Peña Arriba, camino al Páramo de Rabanal, 3100-3490 m.

Voucher: López, R. 13914 (UDBC).

Siphocampylus columnae (L.f.) G.Don (Figura 8f)

Subarbusto nativo. En áreas de subpáramo abierto y páramo asociado con Hypericum, zonas de bosque relictual y bordes de camino.

Vereda Firita Peña Arriba, camino al paramo de Rabanal, 3100-3490 m.

Voucher: Becerra, C. 212 (COL); López, R. 13928 (UDBC).

Siphocampylus sp.

Subarbusto nativo. Crece en huertos y bordes de camino.

Vereda La Candelaria de oriente, $2180 \mathrm{~m}$.

Voucher: González, R. 62 (UDBC).

CAPRIFOLIACEAE

(2 géneros, 2 especies).

\section{Valeriana cf. clematitis Kunth}

Hierba, subarbusto. Nativa. Ocasional en bosque de roble degradado, en suelos secos con erosión moderada.

Vereda Farfán, 2900 m.

Voucher: Becerra, C. 265 (COL).

Valeriana laurifolia Kunth.

Hierba nativa. Ocasional en bosque de roble degradado, matorrales densos, sobre suelos secos con erosión moderada y areas de páramo.

Vereda Roa, sector La Rochela, 2100 m. Vereda Firita

Peña Arriba, camino al páramo de Rabanal, 3100$3490 \mathrm{~m}$.

Voucher: Gónzalez, R. 49, 1017 (UDBC).

CARYOPHYLLACEAE

(2 géneros, 2 especies).

\section{Silene gallica $\mathbf{L}$.}

Hierba introducida. En áreas de matorrales densos en suelos con erosión media y con algo de contenido de humedad.

Vereda Resguardo occidente.

Voucher: Orbell, J. 10041.

Spergula arvensis $\mathbf{L}$.

Hierba nativa. Crece en zonas de bosque relictual, paramo y bordes de camino.

Vereda Firita Peña Arriba, camino al paramo de Rabanal, 3100-3490 m. Vereda Pueblo Viejo, sector La Candelaria, 2170-2452 m.

Voucher: López, R. 13917, 13874 (UDBC).

\section{CLETHRACEAE}

(1 género, 2 especies).

Clethra fimbriata Kunth (Figura 7b)

Árbol nativo. Crece en matorrales y en bosques en procesos de sucesión, sobre suelos secos arenososarcillosos.

Vereda Resguardo oriente, sector la Quinta cerca a la quebrada La Fragua. Resguardo Occidente Vereda Torres y Mirque. 2180-2645 m.

Voucher: Becerra, C. 250 (FMB); López, R. 12203, 13861 (UDBC).

Clethra sp.

Árbol nativo. Crece en matorrales y bosques en procesos de sucesión.

Vereda Tapias, sector La Despensa. 2680 m.

Voucher: López, R. 12391 (UDBC).

\section{CLUSIACEAE}

(1 género, 2 especies).

\section{Clusia multiflora Kunth}

Árbol nativo. Crece en huertos y bordes de camino.

Vereda Pueblo Viejo, sector de la Candelaria, $2170 \mathrm{~m}$.

Voucher: Franco, M. 37 (UDBC); López, R. 12241

(FMB, UDBC).

\section{Clusia sp.}

Árbol.Crece en áreas de matorral y bosque en procesos de sucesión.

Vereda Resguardo occidente, afluente de la quebrada Chillon. $2200 \mathrm{~m}$.

Voucher: López, R. 12332 (UDBC).

\section{CONVOLVULACEAE}

(2 géneros, 2 especies).

\section{Evolvulus bogotensis Van. Ostr.}

Hierba nativa. Rastrera sobre suelos secos muy erosionados, en matorrales y bordes de camino.

Vereda resguardo occidente, sitio El Pedregal. 
Voucher: Orbell, J. 10056.

\section{Ipomoea purpurea (L.) Roth}

Liana nativa. En áreas abiertas y húmedas en potreros

y en cultivos.

Vereda Roa y Resguardo Occidente camino a Pueblo Viejo. 2100-2500 m.

Voucher: López, R. 13812 (UDBC).

\section{CRASSULACEAE}

(2 géneros, 2 especies).

Echeveria bicolor (Kunth) Walth. (Figura 5j)

Hierba nativa. Crece en sustratos muy húmedos, sobre barrancos bordeando quebradas.

Vereda resguardo occidente. $2200 \mathrm{~m}$.

Voucher: Becerra, C. 162, 222 (COL); Duarte, C. 23 (COL).

Kalanchoe pinnata (Lam.) Pers.

Hierba introducida. Cultivada en huertos y jardines, algunas veces en matorrales y áreas de regeneración.

Vereda Candelaria, sector oriente y occidente. Veredas Chinguichaca y Roa, 2180.

Voucher: Duarte, C. 7 (COL); Franco, M. 20 (UDBC); López, R. 12320 (FMB, UDBC); Mendez, V. 182 (COL).

\section{CUNONIACEAE}

(1 género, 2 especies).

Weinmannia pubescens var. arcabucoana (Cuatrec.)

\section{Bernardi}

Árbol nativo. Crece en matorral de sucesión secundaria a borde de quebrada y en áreas de procesos sucesional. Vereda resguardo oriente, sector La Quinta, cerca a la Quebrada La Fragua.

Voucher: López, R. 12185 (FMB, UDBC).

Weinmannia tomentosa L.f.

Árbol nativo. Escaso en áreas de vegetación característico de subpáramo, en parches de bosques de robles.

Vereda Firita Peña Abajo y Peña Arriba, 2850-3490 m.

Voucher: Becerra, C. 219 (COL); López, R. 13896 (UDBC).

\section{DIPSACACEAE}

(1 género, 1 especie).

Dipsacus fullonum $\mathrm{L}$.

Hierba introducida. Cultivada en jardines.

Cerca al casco urbano Ráquira.

Voucher: Orbell, J. 10074.

ELAEOCARPACEAE

(1 género, 1 especie).
Vallea stipularis L.f. (Figura 5k)

Árbol nativo. Frecuente al borde de carreteras, en zonas de bosque relictual y páramo.

Vereda Torres y Valero, en la Reserva de Chaute, 2600 m. Vereda Firita Peña Arriba, camino al paramo de Rabanal, 3100-3490 m.

Voucher: López, R. 12227, 12236, 13911 (FMB, UDBC).

\section{ERICACEAE}

(7 géneros, 13 especies).

Bejaria aestuans Mutis ex L.

Árbol nativo. Crece en áreas degradadas sobre suelos pedregosos y matorrales circundantes a Roble.

Vereda San Cayetano, 2670 m.

Voucher: Méndez, V. 012 (FMB, COL).

Bejaria resinosa Mutis ex L.f.

Árbol nativo. Crece en matorrales en proceso de sucesión.

Vereda Resguardo occidente en el sitio denominado La Chorrera, margen izquierdo del Río Ráquira. 2400 $\mathrm{m}$.

Voucher: López, R. 12197, 12327, 12329, 12340, 12346 (FMB, UDBC).

Cavendishia bracteata (Ruiz \& Pav. ex J.St.-Hil.) Hoerold

Arbusto nativo. En matorrales circundantes a bosques de Roble y a borde de camino.

Vereda Torres y Valero y Vereda Mirque, sector sur oriental, $2600 \mathrm{~m}$.

Voucher: López, R. 12229 (FMB, UDBC).

\section{Gaultheria anastomosans (L.f.) Kunth}

Arbusto nativo. Escandente en matorrales abiertos, sobre suelos pedregosos y arenosos.

Vereda Torres y Valero y Vereda Mirque, sector sur oriental, $2600 \mathrm{~m}$

Voucher: López, R. 12217 (FMB, UDBC).

Gaultheria erecta Vent. (Figura 7c)

Hierba nativa. Creciendo en zonas de bosque relictual, paramo y bordes de camino.

Vereda Firita Peña Arriba, camino al paramo de Rabanal, 3100-3490 m.

Voucher: López, R. 13910 (UDBC).

Gaultheria cf. rigida Kunth

Arbusto nativo. Escandente en matorales abiertos y a borde de bosque de roble.

Vereda San Cayetano, $2670 \mathrm{~m}$.

Voucher: Méndez, V. 53 (COL).

Gaylussacia buxifolia Kunth 
Arbusto nativo. Común en subpáramo seco, sobre suelos pedregosos, y en vegetación de matorral bajo. Vereda Firita Peña Abajo, carretera Ráquira-Guachetá. $2940 \mathrm{~m}$.

Voucher: Becerra, C. 128 (COL). Macleania rupestris (Kunth) A.C.Sm.

Arbusto nativo. Escandente en inmediaciones de bosque de roble.

Vereda San Cayetano, $2670 \mathrm{~m}$.

Voucher: Méndez, V. 46 (COL).

Macleania sp.

Arbusto nativo. Escandente creciendo en zonas de bosque relictual, paramo y bordes de camino.

Vereda Firita Peña Arriba, camino al paramo de Rabanal, 3100-3490 m.

Voucher: López, R. 13923 (UDBC).

Pernettya prostrata (Cav.) DC. (Figura 7d)

Arbusto nativo. En matorrales alrededor de bosques de roble y áreas de páramo.

Vereda Torres y Valero, Vereda Mirque, sector sur oriental, $2600 \mathrm{~m}$. Vereda Firita Peña Arriba, camino al páramo de Rabanal, 3100-3490 m.

Voucher: López, R. 12232, 13907 (FMB, UDBC).

Vaccinium corymbodendron Ruiz \& Pav. ex Dunal

Arbusto nativo. En alrededores de bosque de roble y matorrales secundarios en suelos con erosión baja.

Vereda San Cayetano, $2650 \mathrm{~m}$.

Voucher: Méndez, V. 9 (COL).

Vaccinium floribundum Kunth (Figura 7e)

Arbusto nativo. En vegetación secundaria, aledaño a bosques de roble y en subpáramo abierto.

Vereda San Cayetano y páramo de Rabanal. 2670$3200 \mathrm{~m}$.

Voucher: López, R. 13897, 13898, 13931 (UDBC).

Vaccinium meridionale Sw. (Figura 7f)

Arbusto nativo. En matorrales densos aledaño a bosques de robles, en suelos arcillosos.

Vereda Torres y Valero y Vereda Mirque, sector sur oriental, $2600 \mathrm{~m}$.

Voucher: López, R. 12216, 13862 (FMB, UDBC).

ESCALLONIACEAE

(1 género, 1 especie).

Escallonia pendula (Ruiz \& Pav.) Pers.

Árbol nativo. Crece en áreas de huerto y borde de camino.

Vereda Pueblo Viejo, sector La Candelaria, 2170$2452 \mathrm{~m}$.

Voucher: López, R. 13865 (UDBC).

\section{EUPHORBIACEAE}

(4 géneros, 7 especies).

\section{Acalypha padifolia Kunth}

Arbusto nativo. Crece en matorrales de vegetación en proceso de sucesión, huertos y bordes de camino.

Vereda Resguardo occidente, afluente de la Quebrada Chillón, 2200 m. Vereda Pueblo Viejo, Sector de la Candelaria, $2170 \mathrm{~m}$.

Voucher: Franco, M. 39 (UDBC); López, R. 12334 (FMB, UDBC).

\section{Acalypha macrostachya Jacq.}

Arbusto nativo. Escaso en suelos húmedos y áreas sombreadas, en relictos de bosque nativo.

Vereda Pueblo viejo

Voucher: Orbell, J. 10178.

Croton cf. hibiscifolius Kunth ex Spreng.

Árbol nativo. Crece en matorrales densos y a borde de camino.

Vereda Resguardo oriente, sector La Quinta, cerca a la quebrada La Fragua. 2200 m.

Voucher: López, R. 12173 (FMB, UDBC).

\section{Croton pungens Jacq.}

Árbol nativo. Crece en matorrales densos en procesos de sucesión.

Vereda Tapias, sector La Despensa, $2680 \mathrm{~m}$.

Voucher: López, R. 12376 (UDBC).

\section{Euphorbia orbiculata Kunth}

Hierba nativa. Frecuente en suelos húmedos, alrededor de cultivos.

Vereda Firita Peña Abajo, $2820 \mathrm{~m}$.

Voucher: Becerra, C. 121. (COL).

Euphorbia graminea Jacq.

Hierba nativa. Escasa, crecr alrededor de cultivos, en suelos húmedos.

Vereda Resguardo occidente, camino RáquiraResguardo, $2200 \mathrm{~m}$.

Voucher: Becerra, C. 152A (COL).

Ricinus communis L. (Figura 51)

Arbusto introducido. Cultivado, crece al borde de quebradas y carretera.

Vereda Roa y Resguardo oriente, sector La Quinta, cerca a la quebrada La Fragua $2200 \mathrm{~m}$.

Voucher: López, R. 12171, 13821 (FMB, UDBC).

\section{FABACEAE/LEGUMINOSAE}

(21 géneros, 33 especies).

Acacia angustissima (Mill.) Kuntze

Arbusto nativo. Crece al borde de la carretera

Vereda Roa, sector La Rochela. 2010. 
Voucher: Méndez, C. 168 (COL).

Acacia farnesiana (L.) Willd.

Árbol. Esporádico, en suelos arenosos y pedregosos, a borde de caminos.

Vereda Resguardo oriente, sector La Quinta, cerca a la quebrada La Fragua, 2100 m. Vereda Candelaria, sector oriente y occidente. Veredas Chinguichaca y Roa, $2180 \mathrm{~m}$.

Voucher: López, R. 12184, 13834, 13885 (FMB, UDBC); Méndez, C. 173 (COL).

\section{Acacia melanoxylon $\mathrm{R}$. Br.}

Árbol introducido, cultivado. Crece en áreas y suelos degradados, al borde de caminos.

Vereda Resguardo Oriente, sector La Quinta, cerca a la quebrada La Fragua. Resguardo Occidente. Vereda Torres y Mirque. 2100-2645 m. Vereda Roa, 2100$2180 \mathrm{~m}$.

Voucher: López, R. 13834, 13860 (UDBC).

Caesalpinia spinosa (Molina) Kuntze (Figura 6a)

Árbol nativo. Crece en áreas de matorrales, potreros, bosques recuperados y bordes de camino.

Vereda Resguardo oriente, sector La Quinta, cerca a la quebrada La Fragua. 2184 m. Vereda Roa, 2169$2216 \mathrm{~m}$.

Voucher: López, R. 12183, 13818 (FMB, UDBC); Mendez, V. 214 (COL).

\section{Crotalaria incana $\mathrm{L}$.}

Hierba nativa. Crece en áreas cercanas a relictos de bosque de roble.

Veredas Mirque, Torres y Valero, Sector Sur Oriental de Ráquira.

Voucher: Franco, M. 34 (UDBC).

Crotalaria micans Link

Subarbusto nativo. Esporádico en zonas abiertas y rastrojos.

Vereda Roa, sector La Rochela, $2100 \mathrm{~m}$.

Voucher: Méndez, V. 223 (COL).

\section{Dalea boyacana Killip}

Hierba nativa. Crece al borde de carreteras, sobre suelos pobres y en roca.

Vereda Roa, sector La Rochela, $2100 \mathrm{~m}$.

Voucher: Méndez, V. 155 (COL).

Dalea coerulea (L.f.) Schinz \& Thell. (Figura 6b)

Subarbusto nativo. Crece al borde de carreteras, sobre suelos pobres y en roca.

Vereda Resguardo Oriente, sector La Quinta, cerca a la quebrada La Fragua. $2200 \mathrm{~m}$.

Voucher: López, R. 12204, 13808, 13828 (FMB,
UDBC); Méndez, C. 181 (COL).

Desmanthus latus (Britton \& Rose) Standl.

Arbusto nativo. Ocasional en áreas de cultivo abandonados, en proceso sucesional, en suelos enriquecidos con hojarasca y húmedos.

Vereda Roa, sector La Rochela, $2100 \mathrm{~m}$.

Voucher: Méndez, V. 183 (COL),

Desmodium aff. canum Schinz \& Thell.

Hierba nativa. Crece en áreas abiertas y rastrojos, en suelos secos y pedregosos.

Vereda Resguardo Occidente, $2200 \mathrm{~m}$.

Voucher: Becerra, C. 156 (COL).

Desmodium molliculum (Kunth) DC.

Liana nativa. Crece en áreas abiertas sobre suelos arenosos.

Vereda San Cayetano. Vereda Resguardo Oriente, sector La Quinta, cerca a la quebrada La Fragua.2200 $\mathrm{m}$.

Voucher: López, R. 12209 (FMB, UDBC); Méndez, V. 20 (COL).

Erythrina fusca Lour.

Árbol nativo. Crece en relictos de bosque de roble, áreas degradadas y bordes de camino.

Veredas Mirque, Torres y Resguardo de occidente.

Voucher: Franco, M. 33 (UDBC)

Erythrina rubrinervia Kunth

Árbol nativo. Crece al borde de carreteras, esporádico. Vereda Tapias, $2300 \mathrm{~m}$.

Voucher: Becerra, C. 283 (COL); Castroviejo, S. 10645 (COL).

\section{Galactia lindenii Burkart}

Liana nativa. Crece al borde de quebradas, en suelos arcillosos.

Vereda Resguardo occidente.

Voucher: Orbell, J. 10155.

Galactia striata (Jacq.) Urb. (Figura 6c)

Bejuco nativo. Crece en relictos de bosque de roble, áreas degradadas y bordes de camino.

Vereda Resguardo de occidente, Torres y Mirque, 2112-2645 m.

Voucher: López, R. 13841 (UDBC).

Indigofera suffruticosa Mill. (Figura 6d)

Subarbusto nativo. Abundante en áreas abiertas y suelos pedregosos.

Vereda Roa, sector la Rochela. Vereda Resguardo Oriente, sector La Quinta, cerca a la quebrada La Fragua, $2200 \mathrm{~m}$.

Voucher: López, R. 12182, 13796 (UDBC); Méndez, 
V. 154 (COL).

Inga cocleensis Pittier

Árbol nativo. Crece al borde de carreteras y quebradas. Vereda Resguardo oriente, sector La Quinta, cerca a la quebrada La Fragua. $2100 \mathrm{~m}$.

Voucher: González, R. 39 (UDBC); López, R. 13780

(UDBC).

Inga ingoides (Rich.) Willd.

Árbol nativo. Esporádico, en sitios abiertos, a orillas de carretera sobre suelos pobres y secos.

Vereda Roa, sector La Rochela, $2100 \mathrm{~m}$.

Voucher: Méndez, V. 162 (COL).

Inga pseudospuria Britton \& Killip

Árbol nativo. A orillas del río.

Río Ráquira, 2300.

Voucher: Uribe, U. 6942 (COL).

Inga vera Willd.

Árbol nativo. Abundante a lo largo de las cuencas.

Vereda Candelaria, sector oriente y occidente. Veredas Chinguichaca y Roa, sector La Rochela, 2100-2180 $\mathrm{m}$.

Voucher: López, R. 13894 (UDBC); Méndez, V. 219 (COL).

\section{Lathyrus magellanicus Lam.}

Liana nativa. Escasa en suelos relativamente húmedos, alrededor de cultivos.

Vereda Resguardo Occidente, Las Peñas.

Voucher: Orbell, J. 10066.

Lupinus bogotensis Benth.

Arbusto nativo. En sitios con bastante disponibilidad de agua, con erosión moderada.

Vereda Resguardo oriente, sector La Quinta, cerca a la quebrada La Fragua $2200 \mathrm{~m}$.

Voucher: Becerra, C. 230 (COL); González, R. 46 (UDBC).

\section{Macroptilium erythroloma (Mart. ex Benth.)}

Liana nativa. En áreas de cultivo y rastrojos.

Vereda Resguardo occidente.

Voucher: Orbell, J. 10082.

\section{Medicago sp.}

Hierba introducida. Crece en sitios con bastante disponibilidad de agua, con erosión moderada.

Vereda Resguardo oriente, sector La Quinta, cerca a la quebrada La Fragua $2200 \mathrm{~m}$.

Voucher: González, R. 40 (UDBC).

Melilotis alba Medick.

Hierba introducida. Crece al borde de cultivos y algunas quebradas. Vereda Roa, sector La Rochela,
$2100 \mathrm{~m}$

Voucher: Méndez, V. 165 (COL).

Otholobium mexicanum (L. f.) J.W. Grimes

Arbusto nativo.

Vereda Roa, sector la Rochela, 2010 m.

Voucher: Méndez, V. 211 (COL).

Otholobium sp.

Subarbusto nativo. Crece en matorrales densos de procesos de sucesión.

Vereda Resguardo oriente, sector La Quinta, cerca a la quebrada La Fragua. 2200 m.

Voucher: González, R. 45 (UDBC).

Senna hirsuta (L.) H.S. Irwin \& Barneby

Subarbusto nativo. Es escaso, en suelos con humedad alta, asociado a pastizales y vegetación ruderal.

Casco urbano de Raquira. 2200m.

Voucher: López, R. 13788, 13803 (UDBC).

Senna occidentalis (L.) Link

Subarbusto nativo. Es común en sitios húmedos y sombreados.

Alrededor del casco urbano en cercanías al río Ráquira. 2200m.

Voucher: Méndez, V. 256 (COL).

Stylosanthes guianensis (Aubl.) Sw.

Hierba nativa. Crece en formaciones arvenses.

Vereda Resguardo occidente, $2351 \mathrm{~m}$.

Voucher: Ranghel, G. 67 (COL).

Trifolium pratense $\mathrm{L}$.

Hierba introducida. Cultivada, en áreas de potrero. Vereda Firita Peña Abajo, sector Confites. 2850 m. Voucher: Becerra, C. 199 (COL).

\section{Ulex europaeus L.}

Arbusto introducido. Es invasor y crece en areas de sucesión

Vereda La candelaria, sector occidente y oriente.

Voucher: López, R. Observado.

Zornia diphylla (L.) Pers.

Hierba nativa. Crece a orillas de camino.

Vereda Resguardo occidente.

Voucher: Orbell, J. 10138.

\section{FAGACEAE}

(1 género, 1 especie).

Quercus humboldtii Bonpl. (Figura 6i)

Árbol nativo. Crece en bosques, forma asociaciones homogéneas.

Vereda Torres y Valero y Vereda Mirque, sector suroriental, reserva Chaute, $2600 \mathrm{~m}$.

Voucher: López, R. 12240, 12251, 13852 (FMB, 


\section{UDBC).}

\section{GENTIANACEAE}

(1 género, 1 especie).

Halenia asclepiadea (Kunth) G. Don.

Hierba nativa. Poco frecuente.

Vereda La candelaria, sector occidente y oriente.

Voucher: López, R. 13934 (UDBC).

\section{HYPERICACEAE}

(1 género, 6 especies).

Hypericum caracasanum Willd.

Arbusto nativo. Frecuente en roca desnuda, creciendo en vegetación de sucesión con Dodonea viscosa.

Vereda Resguardo oriente, sector La Quinta, cerca a la quebrada La Fragua. $2250 \mathrm{~m}$.

Voucher: López, R. 12206 (UDBC).

\section{Hypericum cuatrecasii Gleason}

Arbusto nativo. Poco frecuente en suelos muy secos y pobres de escasa humedad.

Vereda Resguardo occidente, sitio Pedregal

Voucher: Orbell, J. 10048.

Hypericum juniperinum Kunth (Figura $5 \mathrm{~m}$ )

Arbusto nativo. Frecuente en matorrales cerca de bosques de roble intervenidos, creciendo con Vaccinium meridionale y vegetación de sucesión.

Vereda Torres y Valero, reserva Chaute. $2600 \mathrm{~m}$.

Voucher: Franco, M. 35 (UDBC); González, F. 3793 , 3798, 3796 (COL, FMB); López, R. 12244, 13927

(FMB, UDBC); Méndez, V. 17 (COL)

Hypericum jussiaei Pl. et Lindl. ex Triana \& Planch.

Arbusto. Nativo. Escaso, en sitios húmedos.

Vereda Firita Peña Abajo, sector confites, $2850 \mathrm{~m}$.

Voucher: Becerra, C. 201 (COL)

Hypericum laricifolium Juss.

Arbusto. Nativo. Abundante, en áreas de zonas abiertas muy intervenidas.

Vereda Firita, peña Abajo, sector confites. $2850 \mathrm{~m}$.

Voucher: Becerra, C. 202 (COL)

Hypericum mexicanum $\mathrm{L}$.

Arbusto. Nativo. Frecuente en zona de Páramo de

Rabanal.

Vereda Firita Alta. 3490 m.

Voucher: González, R. 1019 (UDBC)

\section{LAMIACEAE}

(10 géneros, 14 especies)

\section{Clinopodium brownei (Sw.) Kuntze}

Hierba. Nativa. Esporádico en áreas de potrero, en suelos húmedos, creciendo en base de árbol.

Vereda Tapias, sector La Despensa. 2682 m.
Voucher: López, R. 12394 (FMB, UDBC).

Hyptis colombiana Epling

Hierba nativa. Poco frecuente, siempre presente en suelos húmedos y sombreados, ricos en materia orgánica.

Vereda Roa, sector La Rochela, $2100 \mathrm{~m}$.

Voucher: Méndez, V. 161 (COL).

Lepechinia salviaefolia (Kunth) Epling

Subarbusto nativo. Frecuente en áreas de matorrales densos, en suelos arenosos y pedregosos. Vereda Tapias, sector La Despensa. $2682 \mathrm{~m}$.

Voucher: López, R. 12393 (FMB, UDBC).

\section{Lepechinia sp.}

Hierba nativa. Crece en huertos y bordes de camino. Vereda Pueblo Viejo, Sector de la Candelaria, $2170 \mathrm{~m}$. Voucher: López, R. 13871 (UDBC).

\section{Mentha spicata $\mathrm{L}$.}

Hierba introducida. Es cultivada en huertos y jardines. Vereda Roa. $2200 \mathrm{~m}$.

Voucher: López, R. Observado.

Minthostachys mollis (Kunth) Griseb.

Hierba nativa. Crece en potreros y áreas húmedas.

Sector Cordillera Chaute. Vereda Torres y Valero. $2600 \mathrm{~m}$

Voucher: López, R. 12257 (FMB, UDBC).

Ocimum basilicum $\mathrm{L}$.

Hierba introducida (cultivada).

Vereda Roa. 2100 m.

Voucher: López, R. Observado.

\section{Rosmarinus officinalis $\mathbf{L}$.}

Arbusto cultivado, en sitios sombreados y húmedos. Vereda Resguardo occidente, quebrada Mutaca, 2200 $\mathrm{m}$.

Voucher: Becerra, C. 155 (COL).

\section{Salvia amethystina $\mathrm{Sm}$.}

Hierba nativa. Escasa en borde de bosque de roble. Vereda Firita Peña Abajo, sector confites, 2800m.

Voucher: Becerra, C. 179 (COL).

\section{Salvia palifolia Kunth}

Hierba nativa. Escasa, crece en potreros vía al páramo de Rabanal.

Vereda Firita Peña Alta 3490m.

Voucher: González, R. 1028 (UDBC).

\section{Salvia tiliifolia Vahl}

Hierba introducida. Esporádica en sitios muy secos, en suelos pobres con erosión avanzada.

Vereda Resguardo oriente, sector La Quinta, cerca a la quebrada La Fragua.2200 m. 
Voucher: González, R. 44 (UDBC).

\section{Salvia sp.}

Hierba nativa. Crece en paisajes desérticos y zonas de bosques.

Vereda Roa, 2100-2180 m.

Voucher: López, R. 13816 (UDBC).

Scutellaria racemosa Pers.

Hierba nativa. Esporádica en suelos húmedos.

Vereda Firita Peña Abajo, sector Laguna confites, $2850 \mathrm{~m}$.

Voucher: Becerra, C. 200 (COL).

\section{Stachys bogotensis Kunth}

Hierba nativa. Frecuente al borde de caminos y en borde de bosques de roble, en suelos secos.

Vereda Firita Peña Abajo, sector confites, 2800m. Vereda Roa, 2169-2216 m.

Voucher: Becerra, C. 189 (COL); López, R. 13829

(UDBC).

\section{LOASACEAE}

(1 género, 1 especie).

Nassa aff. tryphylla (Juss) Weigend

Hierba nativa. Crece en ambientes desérticos y vegetación de estratos herbáceos.

Vereda Candelaria, sector Oriente y Occidente. Veredas Chinguichaca y Roa, 2180.

Voucher: López, R. 13887 (UDBC)

\section{LORANTHACEAE}

(3 géneros, 3 especies).

Aetanthus colombianus A.C.Sm.

Arbusto nativo. Parásito al borde de bosques de roble entresacado, en áreas donde predominan arbustos bajos.

Vereda Pueblo Viejo, $2500 \mathrm{~m}$.

Voucher: Becerra, C. 223 (COL).

Gaiadendron punctatum (Ruiz \& Pav.) G.Don (Figura 6q)

Arbusto nativo. Parásito creciendo a borde de bosque de roble intervenido. Frecuente.

Vereda Torres y Valero, Vereda Mirque y vereda Firita alta, sector suroriental de Ráquira, en la reserva Chaute. $2600 \mathrm{~m}$.

Voucher: González, R. 1021 (UDBC); López, R. 12231, 13844 (FMB, UDBC).

Orycthanthus botryostachys Eichler

Arbusto nativo. Parásito crece al borde de bosques de roble intervenido. Frecuente.

Vereda Firita Peña Arriba, $2700 \mathrm{~m}$.

Voucher: Becerra, C. 233A (COL).

\section{LYTHRACEAE}

(3 géneros, 5 especies).

Cuphea ciliata Ruiz \& Pav.

Sufrutice nativo. Frecuente, en sitios sombreados y suelos con humedad alta.

Vereda Roa, sector La Rochela, $2100 \mathrm{~m}$.

Voucher: Méndez, V. 157 (COL).

\section{Cuphea hyssopifolia Kunth}

Hierba nativa. Crece en suelos muy húmedos (fangosos), asociados con Poaceas y Cyperaceas, bosques de roble.

Vereda Firita Peña Abajo, sector confites, $2850 \mathrm{~m}$. Veredas Resguardo de Occidente, Torres y Mirque 2112-2645 m.

Voucher: López, R. 13851 (UDBC).

\section{Cuphea ef. micrantha Kunth}

Hierba nativa. En matorrales densos de procesos de sucesión.

Vereda Resguardo Oriente, sector La Quinta, cerca a la quebrada La Fragua $2200 \mathrm{~m}$.

Voucher: González, R. 55 (UDBC).

\section{Lythrum maritimum Kunth}

Hierba nativa. Crece en áreas de sitios húmedos y sombreados, sobre suelos orgánicos.

Vereda Resguardo occidente.

Voucher: Orbell, J. 10112.

Punica granatum L. (Figura 6k)

Árbol introducido (cultivado).

Vereda Roa, 2169-2216 m.

Voucher: López, R. 13826 (UDBC).

\section{MALVACEAE}

(8 géneros, 11 especies).

Abutilon insigne Planch.

Subarbusto nativo. Cultivado en el área urbana del municipio.

Área urbana de Ráquira $2200 \mathrm{~m}$.

Voucher: López, R. Observado.

Anoda cristata (L.) Schltdl.

Hierba nativa. Frecuente en matorrales densos, preferentemente en suelos sombreados por arbustos, sobre suelos húmedos.

Vereda Roa, sector La Rochela, $2100 \mathrm{~m}$.

Voucher: Méndez, V. 180 (COL).

Fuertesimalva limense (L.) Fryxell.

Hierba nativa. Escasa, en suelos secos y en áreas escarpadas.

Vereda Resguardo Occidente.

Voucher: Orbell, J. 10095. 
Malva sylvestris $\mathbf{L}$.

Hierba introducida. Cultivada en huertos.

Vereda Roa, sector La Rochela, $2100 \mathrm{~m}$.

Voucher: López, R. 13802 (UDBC).

Pavonia sepium A.St.-Hil.

Arbusto nativo. Frecuente en sitios relativamente húmedos y de hábitats semisombreados, en suelos con erosión moderada.

Vereda Resguardo occidente, camino a Pueblo Viejo. Vereda Roa, 2169-2216 m.

Voucher: López. R. 13837 (UDBC); Méndez, V. 205, 215 (COL); Orbell, J. 10128.

\section{Pavonia spinifex (L.) Cav.}

Hierba nativa. En suelos secos y pobres.

Vereda Resguardo occidente, camino a Pueblo Viejo.

Voucher: Orbell, J. 10128.

\section{Sida cordifolia $\mathrm{L}$.}

Hierba nativa. Frecuente a borde de caminos y en áreas abiertas en suelos relativamente húmedos.

Vereda Resguardo occidente, quebrada Mutacá, sitio el Pedregal y Vereda Roa. 2200 m.

Voucher: López, R. 13837 (UDBC); Mendez, V. 276

(COL).

Sida martiana A. St.-Hil.

Hierba nativa. Crece en maleza aledaña a un cultivo de maíz.

Vereda Resguardo de occidente, a lo largo de la quebrada Mutacá (Chillón).

Voucher: Becerra, C. 151 (COL); Méndez, V. 151 (COL).

Sida rhombifolia $\mathrm{L}$.

Hierba nativa. Frecuente al borde de caminos y en áreas abiertas en suelos relativamente húmedos.

Vereda Roa, sector La Rochela, $2100 \mathrm{~m}$.

Voucher: Méndez, V. 196 (COL).

Triumfetta bogotensis DC.

Hierba, subarbusto, nativa. Ocasional en matorral denso.

Vereda Roa, sector La Rochela, $2100 \mathrm{~m}$.

Voucher: Méndez, V. 200 (COL).

\section{Waltheria indica $\mathrm{L}$.}

Hierba, subarbusto, nativa. Crece en sitios abiertos, sobre suelos muy secos, fuertemente erosionados.

Vereda Resguardo Oriente, $2300 \mathrm{~m}$.

Voucher: Méndez, V. 258 (COL).

MELASTOMATACEAE

(7 géneros, 12 especies).

Brachyotum strigosum (L. f.) Triana
Arbusto nativo. Es poco frecuente; crece en areas de sotobosque.

Vereda La candelaria, sector occidente y oriente.

Voucher: López, R. 13933 (UDBC).

Bucquetia glutinosa (L. f.) DC.

Arbusto nativo. Es frecuente que crezca en areas de sotobosque y bordes de carretera.

Vereda Torres y Valero, Vereda Mirque, sector sur oriental, 2600 m. Vereda Firita Peña Arriba, camino al Páramo de Rabanal, 3100-3490 m.

Voucher: López, R. 12230 (UDBC).

Chaetolepis microphylla (Bonpl.) Miq.

Arbusto nativo. Rasante.

Voucher: Castroviejo, S. 10585 (COL).

\section{Clidemia capitellata (Bonpl.) D. Don}

Arbusto nativo. Crece en sitios abiertos, sobre suelos pobres y degradados.

Vereda Resguardo occidente, $2200 \mathrm{~m}$.

Voucher: Becerra, C. 139 (COL).

Clidemia ciliata Pav. ex D. Don

Arbusto nativo. Crece en sitios abiertos, sobre suelos pobres y degradados.

Vereda Resguardo occidente, $2200 \mathrm{~m}$.

Voucher: Becerra, C. 137 (COL).

\section{Miconia elaeoides Naudin}

Arbusto nativo. Crece en áreas de páramo dominados por Espeletia spp.

Páramo de Rabanal.

Voucher: González, R. 1015 (UDBC).

Miconia squamulosa (H. Karst. ex Triana) Triana.

Arbusto nativo. Crece en matorrales densos, en procesos de sucesión, áreas con alto grado de degradación y relictos de bosque.

Vereda Resguardo oriente, sector La Quinta, cerca de la quebrada La Fragua. Vereda Torres - Valero y Mirque; sector Cordillera Chaute, sector sur oriental.

Voucher: Becerra, C. 97, 213, 248 (COL); Castroviejo, S. 10590 (COL); López, R. 12198, 12222, 12326, 12367 (FMB, UDBC); Méndez, V. 26 (COL).

\section{Miconia theaezans (Bonpl.) Cogn.}

Arbusto nativo. Crece en matorrales densos en proceso de recuperación de siete años de edad.

Vereda Resguardo occidente, afluente de la quebrada Chillón.

Voucher: Becerra, C. 14 (COL); Franco, M. 23 (UDBC); López, R. 12331 (UDBC).

Miconia cf. versicolor Naudin.

Arbusto nativo. Crece en matorrales densos en áreas 
en recuperación.

Vereda Resguardo oriente, sector La Quinta, cerca de a la quebrada La Fragua, 2200 m. Vereda Pueblo Viejo, sector La Candelaria, 2170-2452 m.

Voucher: Becerra, C. 17 (COL); López, R. 12174, 13872, 13832 (FMB, UDBC); Méndez, V. 222 (COL).

Monochaetum bonplandii (Humb. \& Bonpl.)

Naudin. (Figura 61)

Arbusto nativo. Crece en matorrales densos de procesos de sucesión.

Vereda Resguardo oriente, sector La Quinta, cerca a la quebrada La Fragua y vía Paramo El Rabanal. 2200$3490 \mathrm{~m}$.

Voucher: González, R. 54, 1022 (UDBC).

Monochaetum myrtoideum Naudin.

Arbusto nativo. Crece en matorrales densos, a borde de bosque de roble intervenido.

Vereda Torres y Valero y Vereda Mirque, sector suroriental de Ráquira. $2600 \mathrm{~m}$.

Voucher: González, R. 1022 (UDBC); Castroviejo, S. 10594 (COL); López, R. 12230, 13846 (FMB, UDBC); Méndez, V. 29 (COL).

\section{Tibouchina ciliaris (Vent.) Cogn.}

Arbusto nativo. Escaso en suelos con erosión leve, y húmedos y áreas sombreadas.

Vereda Resguardo occidente, camino a Pueblo Viejo. Voucher: Orbell, J. 10117.

MENISPERMACEAE

(1 género, 1 especie).

Cissampelos pareira $\mathrm{L}$.

Liana nativa. Es escaso, crece en arbustos de Solanum, en áreas sombreadas y húmedas, bajo dosel.

Vereda Roa, sector La Rochela, $2100 \mathrm{~m}$.

Voucher: Méndez, V. 167 (COL).

\section{MORACEAE}

(2 géneros, 4 especies).

\section{Ficus cuatrecasasiana Dugand}

Árbol nativo. Hemiepifíto en matorrales densos, a borde de quebrada.

Vereda Resguardo occidente, afluente de la quebrada chillón, $2400 \mathrm{~m}$.

Voucher: López, R. 12351 (FMB, UDBC).

Ficus tequendamae Dugand

Árbol nativo. Ocasional, sobre terrenos altamente erosionados, en suelos pedregosos y cascajosos.

Vereda Candelaria oriente, Carretera CandelariaSamacá.

Voucher: López, R. 13881 (UDBC).
Ficus velutina Humb.\& Bonpl. ex Willd

Árbol hemiepifito creciendo en matorrales densos, a borde de quebrada.

Vereda Resguardo Occidente, afluente de la quebrada chillón, $2400 \mathrm{~m}$.

Voucher: Ranghel, G. 123 (COL); Ramírez, A. 35 (UDBC).

Morus alba L. (Figura 6e)

Árbol introducido. Cultivado, sobre suelos muy secos y pedregosos.

Vereda Roa. 2100 m

Voucher: López, R. 13789 (UDBC).

MYRICACEAE

(1 género, 1 especie).

Morella parvifolia (Benth) Parra-O. (Figura 6j)

Arbusto nativo. Frecuente en zona de subpáramo en matorrales en procesos de sucesión, sobre suelos arenosos y pedregosos.

Vereda Resguardo oriente, sector La Quinta, cerca de a la quebrada La Fragua y Vereda Resguardo occidente. Voucher: López, R. 12201, 12341, 12363, 13840 (FMB, UDBC).

MYRTACEAE

(4 géneros, 7 especies).

Eucalyptus globulus Labill.

Árbol introducido. Es cultivado al borde de carreteras y en áreas de potreros y cultivos.

Vereda Roa y vereda Torres y Valero y vereda Mirque, sector suroriental, en la Reserva Chaute.

Voucher: López, R. 12243, 13822 (FMB, UDBC).

Myrcianthes leucoxyla (Ortega) Mc.Vaugh

Árbol nativo. Crece en matorrales y en vegetación de subpáramo, sobre suelos secos con erosión moderada. Vereda Resguardo occidente, sitio Las Peñas.

Voucher: López, R. Observado; Orbell, J. 10185

Myrcianthes orthostemon (O. Berg) Grifo

Árbol nativo. Crece en áreas de huerto y borde de caminos.

Vereda Pueblo Viejo, sector La Candelaria, 2170-2452 $\mathrm{m}$. Vereda Candelaria, sector oriente y occidente. Veredas Chinguichaca y Roa, 2180.

Voucher: López, R. 13864, 13884 (UDBC).

Myrcianthes rhopaloides (Kunth) Mc.Vaugh (Figura $6 \mathrm{~m})$

Árbol nativo. Escaso en matorrales y vegetación de subpáramo, sobre suelos secos con erosión moderada. Páramo de Rabanal. Vereda Firita Peña Arriba, 3490 m. 
Voucher: González, R. 1013 (UDBC).

\section{Psidium guajava $\mathrm{L}$.}

Árbol nativo. Cultivado, crece en potreros en y áreas de cultivo.

Vereda Resguardo oriente, sector La Quinta y Vereda Roa, cerca de la quebrada La Fragua. 2200 m.

Voucher: López, R. 12420, 13783 (UDBC).

Psidium guianense Pers. (Figura 6n)

Arbusto nativo. Crece en áreas degradadas, suelos arenosos y pedregosos.

Vereda Resguardo oriente, sector La Quinta microcuenca de la quebrada La Fragua y vereda La Candelaria. 2200 m. Vereda Roa, 2169-2216 m.

Voucher: González, R. 32 (FMB); López, R. 12188, 13836, 13886 (FMB, UDBC).

Syzygium jambos (L.) Alston. (Figura 6ñ)

Árbol introducido, cultivado.

Vereda Resguardo occidente en el sitio denominado La Chorrera, margen izquierda del río Ráquira, cerca de la cuchilla de Loma San Felipe.

Voucher: López, R. 12325, 13892 (FMB, UDBC).

\section{NYCTAGINACEAE}

(1 género, 1 especie).

\section{Mirabilis prostrata (Ruiz \& Pav.) Heimerl}

Hierba nativa. Crece en potreros y algunas veces es cultivada en jardines, en suelos relativamente húmedos.

Vereda Roa, sector La Rochela, $2100 \mathrm{~m}$.

Voucher: Méndez, V. 193 (COL)

\section{OLEACEAE}

(2 géneros, 2 especies).

Olea europaea $\mathbf{L}$.

Árbol, introducido, cultivado.

Vereda Roa. $2200 \mathrm{~m}$.

Voucher: López, R. 13838 (UDBC).

Fraxinus chinensis Roxb.

Árbol introducido. Frecuente a lo largo de borde de caminos y en potreros.

Vereda Roa. 2200 m.

Voucher: López, R. Observada.

ONAGRACEAE

(3 géneros, 5 especies).

Fuchsia boliviana Carrière

Arbusto introducido. Crece en áreas de huerto y borde de camino.

Vereda Roa. 2100 m.

Voucher: López, R. Observado.

Fuchsia venusta Kunth.
Hierba. Crece en sabana; en áreas de regeneración de quince años de edad, dominados por Dodonea viscosa. Vereda Roa, cercanías a la quebrada San Pedro y alto de San Pedro, $2400 \mathrm{~m}$.

Voucher: López, R. 12238 (UDBC)

Ludwigia peruviana (L.) H.Hara (Figura 6o)

Hierba nativa. Escasa, propia de sitios húmedos y pantanosos, por lo general en suelos ricos en materia orgánica.

Vereda Resguardo occidente, vereda Torres y Mirque. Quebrada Mutacá, $2200 \mathrm{~m}$.

Voucher: Becerra, C. 154 (COL); López, R. 13854

(UDBC).

\section{Ludwigia sp.}

Arbusto nativo. Crece en relictos de bosque de roble, áreas degradadas y bordes de camino.

Vereda Resguardo de occidente, Torres y Mirque, 2112-2645 m.

Voucher: López, R. 13843 (UDBC).

Oenothera tetraptera Cav.

Hierba nativa. Escasa, se desarrolla en sitios húmedos y suelos con erosión leve.

Vereda Roa, sector La Rochela, $2100 \mathrm{~m}$.

Voucher: Méndez, V. 169 (COL).

\section{OROBANCHACEAE}

(1 género, 2 especies).

\section{Castilleja fissifolia L. (Figura 71)}

Hierba nativa. Ampliamente dispersa en áreas de subpáramo abierto y en matorrales ralos aislados, sobre suelos secos y pobres.

Vereda Firita Peña Abajo, $2820 \mathrm{~m}$.

Voucher: López, R. 13819 (UDBC).

Castilleja scorzonerifolia Kunth

Hierba nativa. Frecuente en áreas de cultivo y sectores abandonados, sobre suelos secos y con erosión moderada.

Vereda Resguardo occidente.

Voucher: Orbell, J. 10120.

\section{OXALIDACEAE}

(1 género, 2 especies).

Oxalis bisfracta Turcz.

Hierba nativa. Frecuente en sitios sombreados y con buena humedad, en sotobosque de bosque de roble entresacado.

Voucher: Becerra, C. 186 (COL).

Oxalis fendleri Lourteig

Hierba nativa. Escasa, en suelos húmedos y lugares sombreados. 
Vereda San Cayetano, 2670m.

Voucher: Méndez, V. 49 (COL).

PAPAVERACEAE

(1 género, 2 especies).

Bocconia frutescens $\mathrm{L}$.

Arbusto nativo. Crece al borde de quebradas.

Área urbana de Ráquira $2200 \mathrm{~m}$.

Voucher: López, R. Observado.

Bocconia integrifolia Bonpl.

Arbusto nativo. Escaso, cúltivado, crece a lo largo de caminos, en sitios abiertos y sobre suelos secos, con erosión moderada a avanzada.

Vereda Pueblo Viejo.

Voucher: Orbell, J. 10026.

PASSIFLORACEAE

(1 género, 6 especies).

Passiflora adulterina L.f. (Figura 5n)

Bejuco nativo. Esporádico, propio de bosquecillos o matorrales densos al borde de quebradas, en ambientes húmedos y sombreados.

Vereda Pueblo Viejo, 2750 m. Vereda Firita Alta, 3490 $\mathrm{m}$.

Voucher: Becerra, C. 232 (COL); González, R. 1027 (UDBC).

Passiflora aff. alinifolia Kunth.

Enredadera nativa. Crece en relictos de bosque de roble, en áreas degradadas y bordes de camino.

Vereda Resguardo de occidente, Torres y Mirque, 2112-2645 m.

Voucher: Franco, M. 27 (UDBC).

Passiflora bicuspidata (H. Karst.) Mast. (Figura 5ñ) Bejuco. Escaso, en matorral denso, a borde de quebradas, en ambientes húmedos y sombreados.

Vereda San Cayetano y resguardo occidente Vereda Torers y Mirque. $2670 \mathrm{~m}$.

Voucher: López, R. 13858 (UDBC).

Passiflora bogotensis Benth. (Figura 5o)

Bejuco nativo. Esporádico, crece en matorrales densos en proceso sucesional de siete años, paisajes desérticos y zonas de bosques.

Vereda resguardo oriente, sector La Quinta, quebrada La Fragua. Vereda Roa, cercanías a la quebrada San Pedro, 2100-2180 m.

Voucher: González, R. 30 (FMB, UDBC); López, R. 12175 (UDBC).

Passiflora manicata (Juss.) Pers. (Figura 5p)

Bejuco nativo. Frecuente en sitios húmedos, en matorrales densos.
Vereda Roa. $2100 \mathrm{~m}$.

Voucher: González, F. 3800 (FMB); López, R. 13777 (UDBC).

Passiflora mixta L.f.

Bejuco nativo. Crece al borde de caminos, en áreas de cultivo de papá.

Páramo de Rabanal, 3490 m. Vereda Resguardo de occidente, Torres y Mirque, 2112-2645 m.

Voucher: López, R. 13854 (UDBC).

\section{PENTAPHYLACACEAE}

(1 género, 1 especie).

Ternstroemia meridionalis Mutis (Figura 7g)

Árbol nativo. Esporádico, crece en matorrales densos, en áreas de procesos de sucesión y de recuperación, cerca a bosques de roble intervenido.

Vereda Torres y Valero, en la reserva de Chaute, 2400 m. Vereda Firita Peña Arriba, camino al páramo de Rabanal, 3100-3490 m.

Voucher: López, R. 12250, 13909 (FMB, UDBC).

\section{PHYLLANTHACEAE}

(1 género, 1 especie).

Phyllanthus salviifolius Kunth (Figura 5q)

Arbusto nativo. Crece en matorrales densos en procesos de sucesión, esporádico al borde de quebrada. Vereda resguardo Oriente, sector La Quinta, cerca a la quebrada La Fragua 2200 m. Vereda Roa, 2169-2216 $\mathrm{m}$.

Voucher: Castroviejo, S. 10626 (COL); López, R. 12176, 13833 (FMB, UDBC).

\section{PHYTOLACCACEAE}

(1 género, 1 especie).

\section{Phytolacca bogotensis Kunth}

Hierba nativa. Crece en ambientes desérticos y vegetación de estratos herbáceos, al borde de caminos y alrededor de bosques de roble intervenido.

Vereda San Cayetano, 2670 m. Vereda Candelaria, sector oriente y occidente. Veredas Chinguichaca y Roa, 2180.

Voucher: López, R. 13800, 13848, 13878A (UDBC).

\section{PLANTAGINACEAE}

(2 géneros, 3 especies).

Digitalis purpurea $\mathrm{L}$.

Hierba introducida. Abundante al borde de carreteras y en áreas de potreros, en suelos secos y húmedos.

Vereda Farfán, $2850 \mathrm{~m}$.

Voucher: Becerra, C. 258 (COL).

Plantago australis Lam.

Hierba nativa. Propia de matorrales densos, a orillas 
de caminos, en suelos semihúmedos, con erosión moderada.

Vereda Roa, sector La Rochela, $2100 \mathrm{~m}$.

Voucher: Méndez, V. 174 (COL).

Plantago major L. (Figura $7 \mathrm{~m}$ ).

Hierba introducida. Crece a orillas de caminos, en suelos semihúmedos, con erosión moderada.

Vereda Roa, sector La Rochela, $2200 \mathrm{~m}$.

Voucher: López, R. 13797 (UDBC).

\section{PLUMBAGINACEAE}

(1 género, 1 especie).

\section{Plumbago zeylanica $\mathrm{L}$.}

Hierba nativa. Esporadico, propio de matorrales ralos y sitios abiertos, en suelos secos y arenosos.

Vereda Pueblo Viejo.

Voucher: Orbell, J. 10182.

POLYGALACEAE

(1 género, 2 especies).

Monnina aestuans (L. f.) DC.

Arbusto nativo. Crece en relictos de bosques de roble. Vereda Pueblo Viejo, sector de la Candelaria, 2170$2500 \mathrm{~m}$.

Voucher: Becerra, C. 225 (COL); Franco, M. 41 (UDBC).

\section{Monnina cf. angustata Triana \& Planch.}

Hierba nativa. Crece en áreas de procesos de sucesión, creciendo junto con Dodonea viscosa.

Vereda resguardo Oriente, sector La Quinta, cerca a la quebrada La Fragua.

Voucher: López, R. 12192 (FMB, UDBC).

\section{POLYGONACEAE}

(3 géneros, 5 especies).

\section{Muehlenbeckia tamnifolia (Kunth) Meisn.}

Arbusto nativo. Escandente en matorrales secos, ralos a orillas de camino,s en suelos con erosión moderada. Vereda Roa y resguardo Occidente, carretera RáquiraGuachetá, 2100-2250 m.

Voucher: López, R. 13814 (UDBC).

Rumex acetosella $\mathrm{L}$.

Hierba introducida. Frecuente, propia en los estratos bajos de robledal degradado y en áreas de cultivo.

Vereda Mirque, $2600 \mathrm{~m}$.

Voucher: Becerra, C. 255 (COL).

\section{Rumex obtusifolius $\mathbf{L}$.}

Hierba introducida. Crece en potreros y áreas de regeneración natural

Vereda Firita Peña Arriba, 3050 m.

Voucher: López, R. Observado.

\section{Polygonum punctatum Elliot}

Hierba nativa. Escasa, presente en matorrales ralos, sobre suelos secos, con erosión leve.

Vereda Roa, sector La Rochela, $2100 \mathrm{~m}$.

Voucher: Méndez, V. 209 (COL).

\section{Polygonum segetum Kunth}

Hierba nativa. Se encuentra en cultivos abandonados, sobre suelos secos con erosión moderada, crece al borde de caminos y en áreas de pastizales.

Vereda resguardo Occidente.

Voucher: Orbell, J. 10152.

\section{PORTULACACEAE}

(1 género, 1 especie).

\section{Portulaca oleracea L.}

Hierba nativa. Frecuente, en huertas.

Vereda Roa, $2100 \mathrm{~m}$.

Voucher: López, R. 13804 (UDBC).

PRIMULACEAE

(3 géneros, 6 especies).

\section{Anagallis arvensis $\mathbf{L}$.}

Hierba nativa. Rastrera, ocasional en matorrales densos y ambientes húmedos.

Vereda resguardo Occidente, quebrada Mutacá, sitio El Pedregal. $2200 \mathrm{~m}$.

Voucher: Méndez, V. 280 (COL).

Geissanthus aff. bogotensis Mez.

Árbol nativo. Crece en áreas de procesos sucesionales de quince años de edad, matorrales densos con dominancia de Dodonea viscosa.

Vereda Roa, cercanías a la quebrada San Pedro y alto de San Pedro.

Voucher: López, R. 12313 (UDBC).

Myrsine andina (Mez) Pipoly

Árbol nativo. Crece al borde de caminos, en áreas de cultivo de papá.

Páramo de Rabanal, 3490 m.

Voucher: González, R. 1014 (UDBC).

Myrsine coriacea (Sw.) R. Br. ex Roem. \& Schult.

Árbol nativo. En áreas de procesos sucesionales de quince años de edad, matorrales densos con dominancia de Dodonea viscosa

Vereda Roa, cercanías a la quebrada San Pedro y alto de San Pedro

Voucher: López, R. 12310, 12318, 12328, 12344 (FMB, UDBC).

\section{Myrsine guianensis (Aubl.) Kuntze}

Arbusto nativo. Crece en laderas secas.

Voucher: Castroviejo, S.10586 (COL). 
Myrsine latifolia (Ruiz \& Pav.) Spreng (Figura 7h)

Árbol nativo. Crece en áreas de procesos sucesionales de siete años de edad, cerca de quebrada.

Vereda resguardo Oriente, sector La Quinta, cerca de la quebrada La Fragua y páramo de Rabanal. 2300$3490 \mathrm{~m}$.

Voucher: López, R. 12180, 12228, 13778 (FMB, UDBC).

\section{PROTEACEAE}

(2 género, 2 especies).

Macadamia integrifolia Maiden \& Betche

Árbol introducido. Cultivado como ornamental en el area rural del municipio.

Área urbana de Ráquira $2200 \mathrm{~m}$.

Voucher: Franco, M. 30 (UDBC).

Roupala sp.

Árbol nativo. Crece en bosques circundantes a ríos a quebradas, en suelos húmedos y ricos en materia orgánica.

Vereda San Cayetano, $2550 \mathrm{~m}$.

Voucher: Méndez, V. 109 (COL).

\section{RANUNCULACEAE}

(1 género, 1 especie).

\section{Clematis haenkeana C. Presl}

Enreadera nativa. Crece sobre aliso, en áreas de huertos y borde de camino.

Vereda Pueblo Viejo, sector La Candelaria, 2170$2452 \mathrm{~m}$.

Voucher: Franco, M. 38 (UDBC); López, R. 13866 (UDBC).

\section{RHAMNACEAE}

(1 género, 1 especie).

Frangula goudotiana (Triana \& Planch.) Grubov (Figura 6f)

Hierba nativa. Crece en zonas de bosque relictual, páramo y bordes de camino.

Vereda Firita Peña Arriba, camino al paramo de Rabanal, 3100-3490 m.

Voucher: López, R. 13908 (UDBC).

\section{ROSACEAE}

(6 géneros, 9 especies).

Acaena cylindristachya Ruiz \& Pav.

Hierba nativa. Postrada crece en bordes de camino, cultivo de papa, bosques relictuales y páramo.

Vereda Firita Peña Arriba, camino al paramo de Rabanal, 3100-3490 m.

Voucher: González, R. 1016 (UDBC).

Eriobotrya japonica (Thunb.) Lindl. (Figura 6g)
Árbol introducido. Cultivado, a orillas de quebrada y ríos, en suelos húmedos.

Vereda Rua y vereda resguardo Occidente.

Voucher: López, R. 13817 (UDBC).

Hesperomeles goudotiana (Decnec) Killip

Árbol nativo. Crece en matorrales densos (procesos de sucesión vegetal de siete años), áreas de páramo y bosques relictuales.

Vereda Tapias, sector La Despensa. 2400 m. Vereda Firita Peña Arriba, camino al páramo de Rabanal, 3100-3490 m.

Voucher: Becerra, C. 123 (COL); López, R. 12370, 13913 (UDBC); Ranghel, G. 144 (COL).

Hesperomeles obtusifolia (Pers.) Lindl.

Árbol nativo. Crece en matorrales densos, sobre suelos moderadamente erosionados y áreas cercanas a relictos de bosques de roble

Vereda Torres y Valero, sector suroriental de Ráquira, $2400 \mathrm{~m}$

Voucher: López, R. 12226, 12234 (FMB, UDBC).

Malus pumila Mill.

Arbusto nativo.

Vereda resguardo de Occidente, La Lagita, $2403 \mathrm{~m}$.

Voucher: Ranghel, G. 137 (COL).

\section{Rosa sp.}

Hierba nativa. Escandente, crece en áreas de huerto.

Vereda Pueblo Viejo, sector La Candelaria, 2170$2452 \mathrm{~m}$.

Voucher: López, R. 13867 (UDBC).

\section{Rubus bogotensis Kunth}

Arbusto nativo. Común al borde de carreteras y en matorrales densos a lo largo de quebradas.

Vereda San Cayetano y vereda Torres y Mirque. 2100$2670 \mathrm{~m}$

Voucher: López, R. 13870 (UDBC); Méndez, V. 30 (COL).

\section{Rubus guyanensis Focke}

Arbusto nativo. Escandente, creciendo en bosques de roble.

Vereda San Cayetano, $2670 \mathrm{~m}$.

Voucher: Linares, E. 51

Rubus robustus C.Presl.

Arbusto nativo. Presente al borde de carreteras y en caminos, en matorrales densos sobre suelos secos y pobres.

Vereda Resguardo Occidente, camino a pueblo viejo. $2670 \mathrm{~m}$

Voucher: Méndez, V. 051 (COL). 


\section{RUBIACEAE}

(9 géneros, 12 especies).

\section{Arcytophyllum nitidum (Kunth) Schltdl.}

Nativo. Típico de páramo y subpáramo, en matorrales densos y dispersos.

Vereda Firita vía al páramo Rabanal 3490 m.

Voucher: Becerra, C. 122 (COL); Castroviejo, S. 10604 (COL); González, R. 1025 (UDBC).

\section{Borreria anthospermoides DC.}

Hierba nativa. En subpáramo, en áreas de pastizales y matorrales bajos, ralos y dispersos, en suelos secos y pobres, con erosión moderada.

Vereda resguardo Occidente.

Voucher: Orbell, J. 10092.

Borreria capitata (Ruíz \& Pav.) DC.

Hierba nativa. Crece en matorrales bajos, tupidos, en sitios húmedos, en suelos ricos en materia orgánica.

Vereda resguardo Occidente..

Voucher: Mendez, V. 254 (COL); Orbell, J. 10092.

Coccocypselum lanceolatum (Ruiz \& Pav.) Pers.

Arbusto nativo. Crece en suelos pobres y degradados.

Vereda Resguardo Occidente, $2200 \mathrm{~m}$.

Voucher: Becerra, C. 163 (COL).

\section{Coffea arabica $\mathrm{L}$.}

Arbusto introducido. Cultivado en huertos.

Resguardo Occidente. Vereda Torres y Mirque.

Voucher: López, R. 13869 (UDBC).

\section{Declieuxia fruticosa (Willd.) Kuntze}

Hierba nativa. Frecuente en áreas con fuerte erosión, secas y desprovistas de suelos.

Vereda Chinguichanga, vereda Candelaria oriente, carretera a Samacá, $2400 \mathrm{~m}$.

Voucher: Becerra, C. 269 (COL); Ranghel, G. 56 (COL).

Galianthe bogotensis (Kunth) E.L. Cabral \& Bacigalupo

Hierba nativa. Crece en areas de bosque de roble muy intervenidas.

Vereda San Cayetano, $2670 \mathrm{~m}$.

Voucher: Méndez, V. 7 (COL).

\section{Galium canescens Kunth}

Hierba nativa. Crece en potreros arbolados.

Vereda Pauneca, $2486 \mathrm{~m}$.

Voucher: Ranghel, G. 88 (COL).

Galium hypocarpium (L.) Endl. ex Griseb.

Hierba nativa. Rastrera, común en matorrales densos, en sitios húmedos y sombreados, suelos ricos en materia orgánica, con erosión leve.
Vereda San Cayetano. Vereda Firita Peña Abajo, 2850

$\mathrm{m}$.

Voucher: Becerra, C. 206 (COL); Méndez, V. 21

(COL),

Palicourea angustifolia Kunt. (Figura 7j)

Arbusto nativo. Poco frecuente, en matorrales densos a orillas de ríos y quebradas, en suelos húmedos, ricos en materia orgánica.

Vereda Torres y Valero, sector suroriental de Ráquira. $2400 \mathrm{~m}$.

Voucher: González, R. 1017 (UDBC); López, R. 12223, 12374 (FMB, UDBC); Méndez, V. 105 (COL).

\section{Palicourea aff. lineariflora Wernham}

Arbusto nativo. Poco frecuente, en matorrales densos a orillas de ríos y quebradas, en suelos húmedos, ricos en materia orgánica.

Vereda Torres y Valero, sector suroriental de Ráquira. $2400 \mathrm{~m}$

Voucher: Becerra, C. 239, 246 (COL); López, R. 12256 (FMB, UDBC).

Psychotria boqueronensis Wernham.

Arbusto nativo. Escaso, en matorrales ralos aledaños a robledal intervenido, sobre suelos secos y pobre en nutrientes.

Vereda Tapias, sector La Despensa, $2600 \mathrm{~m}$.

Voucher: Becerra, C. 31 (COL); López, R. 12362, 12392 (FMB, UDBC).

\section{RUTACEAE}

(1 género, 1 especie).

Ruta graveolens $\mathbf{L}$.

Arbusto introducido. Cultivado.

Vereda Roa. $2100 \mathrm{~m}$.

Voucher: López, R. Observado.

\section{SALICACEAE}

(3 géneros, 3 especies).

Abatia parviflora Ruiz \& Pav.

Arbusto nativo. Crece en bosques de roble, en suelos moderados.

Vereda Firita Peña Abajo, $2850 \mathrm{~m}$.

Voucher: Becerra, C. 220 (COL).

Salix humboldtiana Willd.

Árbol nativo. Cultivado al borde de carreteras, como cercas vivas y área de regeneración de quince años.

Vereda Roa, en cercanías a la quebrada San Pedro y alto de San Pedro, $2400 \mathrm{~m}$.

Voucher: López, R. 12322, 13824 (FMB, UDBC). Xylosma spiculifera (Tul.) Triana \& Planch (Figura $5 \mathrm{r})$ 
Arbusto nativo. Crece en bosques secundarios y matorrales densos.

Vereda Roa, en cercanías a la quebrada San pedro y alto San Pedro. $2400 \mathrm{~m}$.

Voucher: Becerra, C. 134 (COL); López, R. 12315 (UDBC); Ramírez, A. 6 (FMB).

\section{SANTALACEAE}

(2 géneros, 3 especies).

Dendrophthora clavata (Benth.) Urb.

Epífita nativa. Parásita, crece en áreas de cultivo de papá.

Páramo de Rabanal, 3490 m.

Voucher: González, R. 1029 (UDBC).

Phoradendron sp. (1)

Arbusto parásito. Crece sobre árbol de Clusia, esporádico y en matorrales en proceso de sucesión de siete años de edad.

Vereda resguardo Oriente, sector La Quinta, cerca a la quebrada La Fragua.

Voucher: López, R. 12207 (UDBC).

Phoradendron sp. (2)

Arbusto nativo. Parásito, crece en áreas degradadas.

Vereda Tapias, sector La Despensa, $2680 \mathrm{~m}$.

Voucher: López, R. 12390 (FMB, UDBC).

SAPINDACEAE

(2 géneros, 2 especies).

Dodonaea viscosa Jacq. (Figura 7k)

Arbusto nativo. Muy frecuente en áreas de erosión avanzada, pionero en procesos de sucesión.

Vereda resguardo Oriente, cerca de la quebrada La Fragua sector La Quinta y Resguardo Occidente. 2184 $\mathrm{m}$.

Voucher: Becerra, C. 10 (COL); López, R. 12179, 13839 (FMB, UDBC).

Llagunoa nitida Ruiz \& Pav.

Arbusto nativo. Crece en matorrales densos, en áreas de procesos de sucesión de siete años de edad.

Vereda Tapias, sector La Despensa, $2400 \mathrm{~m}$.

Voucher: Castroviejo, S. 10617 (COL); Pinzón, V. 723 (UDBC).

\section{SCROPHULARIACEAE}

(3 géneros, 3 especies).

\section{Alonsoa meridionalis (L.f.) Kuntze}

Hierba nativa. Crece en sitios húmedos y sombreados en bosque de roble intervenido, en suelos fértiles con erosión leve.

Vereda Firita Peña Abajo, sector confites, $2800 \mathrm{~m}$.

Voucher: Becerra, C. 187 (COL).

\section{Buddleja americana $\mathrm{L}$.}

Arbusto nativo. En áreas abiertas y suelos relativamente húmedos, asociadas con Euphorbiaceas y Solanaceas.

Vereda Candelaria occidente, desierto de la Candelaria. Monasterio de La Candelaria. $2200 \mathrm{~m}$.

Voucher: Becerra, C. 291 (COL).

\section{Gratiola bogotensis Cortés}

Hierba nativa. Acuática enraizada en fango.

Vereda Firita Peña Abajo, Laguna Confites, $2850 \mathrm{~m}$.

Voucher: Becerra, C. 193 (COL).

\section{SIMAROUBACEAE}

(1 género, 1 especie).

Picramnia sphaerocarpa Planch.

Arbusto nativo. Esporádico, en matorrales densos a borde de bosque de roble intervenido.

Vereda tesguardo Occidente, afluente de la Quebrada Chillón. $2400 \mathrm{~m}$.

Voucher: López, R. 12358 (FMB, UDBC).

SOLANACEAE

(10 géneros, 22 especies).

\section{Brugmansia candida Pers.}

Arbusto nativo. Cultivado, poco frecuente, se encuentra como individuo aislado, al borde de carreteras y en jardines y huertos.

Vereda Roa, sector La Rochela, $2100 \mathrm{~m}$.

Voucher: Méndez, V. 171 (COL).

Brugmansia sanguinea (Ruiz \& Pav.) D. Don

Subarbusto nativo. Crece en bordes de camino, bosques relictuales y áreas de páramo.

Vereda Firita Peña Arriba, camino al Páramo de Rabanal, 3100-3490 m.

Voucher: López, R. 13903 (UDBC).

\section{Capsicum sp.}

Arbusto nativo. Crece en zonas de bosque relictual, páramo y bordes de camino.

Vereda Firita Peña Arriba, camino al páramo de Rabanal, 3100-3490 m.

Voucher: López, R. 13916 (UDBC).

Cestrum auriculatum L'Hér. (Figura 7o)

Arbusto nativo. Frecuente en matorral denso sobre suelo seco con erosión moderada.

Vereda Roa $2200 \mathrm{~m}$.

Voucher: López, R. 13795 (UDBC).

\section{Cestrum buxifolium Kunth}

Arbusto nativo. Frecuente en matorral denso sobre suelo seco con erosión moderada.

Vereda resguardo Occidente, $2400 \mathrm{~m}$. 
Voucher: González, R. 50 (UDBC).

Cestrum sp.

Arbusto nativo. Frecuente en matorral denso en proceso de sucesión.

Vereda Torres y Valero y Vereda Mirque, sector suroriental, en el área conocida como reserva de Chaute, $2600 \mathrm{~m}$.

Voucher: López, R. 12262 (FMB, UDBC).

Datura stramonium L. (Figura 7p).

Arbusto nativo. Cultivado, escaso, propio de suelos muy secos.

Ráquira, casco urbano y vereda Roa. $2200 \mathrm{~m}$.

Voucher: López, R. 13806 (UDBC).

Lycianthes lycioides (L.) Hassl.

Arbusto nativo. Ocasional en talud de carretera, sobre suelos muy secos.

Vereda Roa, sector La Rochela, $2100 \mathrm{~m}$.

Voucher: Méndez, V. 176 (COL).

Nicandra physalodes (L.) Gaertn.

Arbusto nativo.

Cuneta.

Voucher: Castroviejo, S. 10557 (COL).

Nicotiana tabacum L. (Figura 7q)

Arbusto nativo. Cultivado, crece en huertos familiares

$\mathrm{y}$ en potreros.

Vereda Roa, sector La Rochela, $2100 \mathrm{~m}$.

Voucher: López, R. 13809 (UDBC).

Nierembergia repens Ruiz \& Pav.

Arbusto nativo. Crece en fango a orillas de Laguna.

Vereda Firita Peña Abajo, sector Laguna Confites, 2850.

Voucher: Becerra, C. 191 (COL).

Physalis peruviana $\mathrm{L}$.

Hierba, subarbusto. Nativa. Cultivado, en suelos húmedos.

Vereda resguardo Occidente.

Voucher: Orbell, J. 10093.

Solanum americanum Mill.

Hierba, arbusto. Nativa.

Vereda Roa. 2200 m.

Voucher: Méndez, V. 170 (COL); López, R. 13794

(UDBC).

Solanum betaceum Cav.

Arbusto nativo. Crece en áreas de huerto.

Vereda Roa. 2100 m.

Voucher: López, R. Observado.

\section{Solanum caripense Dunal}

Hierba nativa. Poco común, propia de matorrales densos a orilla de quebradas, sobre suelos húmedos y ricos en materia orgánica.

Vereda resguardo Occidente, quebrada Mutacá, 2200 $\mathrm{m}$.

Voucher: Becerra, C. 171 (COL); González, F. 3798 (COL).

\section{Solanum dolichosepalum Bitter}

Arbusto nativo. Escaso, propio de sitios abiertos, en suelos altamente erosionados.

Ráquira, casco urbano, $2200 \mathrm{~m}$.

Voucher: Méndez, V. 236 (COL).

\section{Solanum laevigatum Dunal}

Hierba nativa. Crece sobre suelos arcillosos, con arroyos estacionales.

$2250 \mathrm{~m}$

Voucher: Castroviejo, S. 10631 (COL).

Solanum nigrescens M. Martens \& Galeotti

Hierba, subarbusto. Nativa. Escaso, crece en matorrales densos y tupidos, en suelos ligeramente húmedos, con erosión leve.

Vereda Roa, sector La Rochela, $2100 \mathrm{~m}$.

Voucher: Méndez, V. 170 (COL).

Solanum ovalifolium Dunal (Figura $7 \mathrm{r}$ )

Arbusto nativo. Frecuente en matorral denso y a orillas de quebradas, en suelos húmedos con erosión moderada.

Vereda Roa, sector La Rochela y resguardo Occidente, Vereda Torres y Mirque. 2100-2645 m.

Voucher: López, R. 13849 (UDBC).

Solanum sisymbrifolium Lam.

Arbusto nativo. Espinoso frecuente al borde de carreteraa en suelos desnudos, altamente erosionados. Ráquira, casco urbano, $2200 \mathrm{~m}$.

Voucher: Méndez, V. 235 (COL); Ranghel, G. 98.

\section{Solanum stellatiglandulosum Bitter}

Arbusto nativo. Escaso, propio de suelos degradados y secos en matorrales ralos, a orillas de carretera.

Vereda Mirque, 2600.

Voucher: Becerra, C. 251 (COL).

Solanum sp.

Hierba nativa. Crece en áreas cercanas a relictos de bosque de Roble

Veredas Torres-Valero y Mirque; sector cordillera Chaute, sector sur oriental de Ráquira

Voucher: López, R. 12260 (FMB, UDBC).

SYMPLOCACEAE

(1 género, 1 especie).

Symplocos theiformis (L.f.) Oken 
Árbol nativo. Esporádico, crece en matorrales densos, en áreas de procesos de sucesión y de recuperación, cerca a bosques de roble intervenidos.

Vereda Torres y Valero, en la reserva de Chaute, 2400 $\mathrm{m}$.

Voucher: López, R. 12259 (FMB, UDBC).

\section{THYMELAEACEAE}

(1 género, 1 especie).

\section{Daphnopsis caracasana Meisn.}

Árbol, arbusto nativo. Crece wn áreas de matorrales densos, sobre suelos con erosión moderada.

Vereda Tapias, sector La Despensa, $2400 \mathrm{~m}$.

Voucher: López, R. 12368 (UDBC).

\section{VERBENACEAE}

(4 géneros, 7 especies).

\section{Duranta ef. mandonii Moldenke}

Arbusto nativo. Escaso, crece en matorral denso a orillas de ríos y quebradas, algunas veces en robledal entresacado, sobre suelos húmedos, con erosión leve. Vereda Roa, sector La Rochela, $2100 \mathrm{~m}$.

Voucher: Méndez, V. 220 (COL).

Duranta mutisii L.f. (Figura $7 \mathrm{n}$ )

Arbusto nativo. Frecuente a orillas de caminos y carreteras, en suelos secos, con erosión drástica y áreas con alto grado de degradación,

Vereda Roa y resguardo Oriente, sector La Quinta, cerca a la quebrada de La Fragua, $2200 \mathrm{~m}$.

Voucher: Castroviejo, S. 10616 (COL); López, R. 12177, 13825, 13835 (UDBC)
Lantana camara L. (Figura 7ñ)

Hierba, arbusto. Introducida. Cultivado.

Vereda Roa. $2200 \mathrm{~m}$.

Voucher: López, R. 13782 (UDBC).

\section{Lantana rugulosa Kunth}

Arbusto nativo. Frecuente en áreas de rastrojo, crece sobre suelos degradados, secos y cascajosos, resistente a la escasez de agua. En áreas sucesionales de siete años.

Vereda resguardo Oriente, sector La Quinta, cerca a la quebrada La Fragua, $2184 \mathrm{~m}$.

Voucher: Becerra, C. 1 (COL); López, R. 12202 (UDBC).

Lantana urticifolia Mill.

Hierba nativa.

Vereda Chinguichanga, $2360 \mathrm{~m}$.

Voucher: Ranghel, G. 112 (COL).

Lippia hirsuta L.f.

Arbusto nativo. Escaso, en áreas de robledal intervenido, sobre suelos secos y pobres con erosión moderada.

Vereda Tapias, sector La Despensa, $2400 \mathrm{~m}$.

Voucher: López, R. 12377 (UDBC).

\section{Verbena litoralis Kunth}

Hierba nativa. Escasa, crece en matorrales densos a orillas de ríos y quebradas, en hábitat semihúmedos y sombreados, sobre suelos ricos en materia orgánica. Vereda Roa, sector La Rochela, $2100 \mathrm{~m}$.

Voucher: Méndez, V. 203 (COL). 

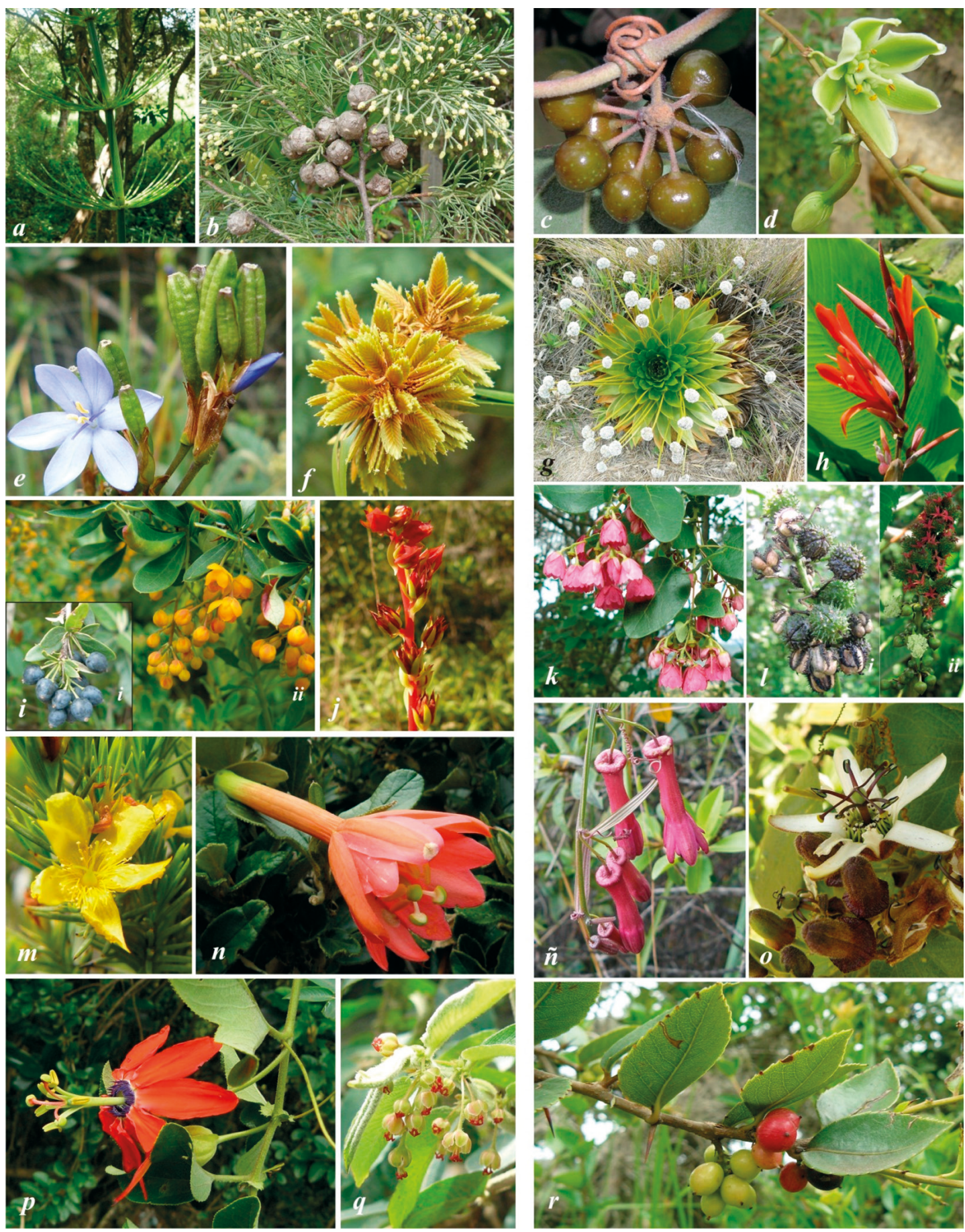

Figura 5. a. EQUISETACEAE. Equisetum giganteum. b. CUPRESSACEAE. Cupressus lusitanica. c. SMILACACEAE. Smilax aff. tomentosa. $\boldsymbol{d}$. AMARYLLIDACEAE. Furcraea cabuya. e. IRIDACEAE. Orthosanthus chimboricensis. $\boldsymbol{f}$. CYPERACEAE. Rhynchospora aristata. $\boldsymbol{g}$. ERIOCAULACEAE. Paepalanthus alpinus. $\boldsymbol{h}$. CANNACEAE. Canna coccinea. $\boldsymbol{i}$. BERBERIDACEAE. Berberis rigidifolia. ( $i$. fruto, ii. flor). $\boldsymbol{j}$. CRASSULACEAE. Echeveria bicolor. $\boldsymbol{k}$. ELAEOCARPACEAE. Vallea stipularis. $\boldsymbol{l}$. EUPHORBIACEAE. Ricinus communis. ( $i$. fruto, ii. flor). $\boldsymbol{m}$. HYPERICACEAE. Hypericum juniperinum. $\boldsymbol{n}$. PASSIFLORACEAE. Passiflora adulterina. $\tilde{\boldsymbol{n}}$. PASSIFLORACEAE. Passiflora bicuspidata. o. PASSIFLORACEAE. Passiflora bogotensis. $\boldsymbol{p}$. PASSIFlORACEAE. Passiflora manicata. q. PHYLLANTHACEAE. Phyllanthus salviifolius. $\boldsymbol{r}$. SALICACEAE. Xylosma spiculifera. 

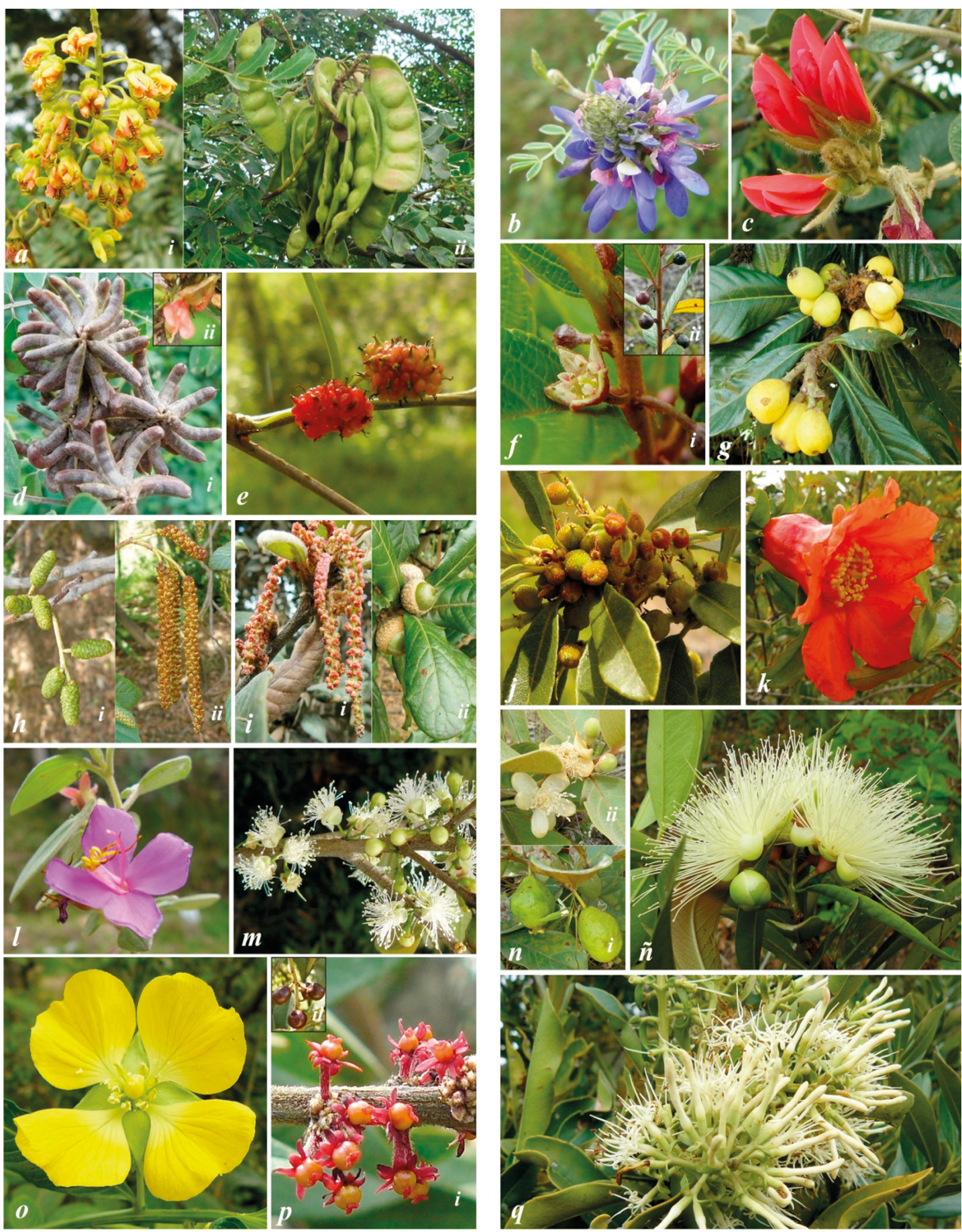

Figura 6. a. FABACEAE / LEGUMINOSAE. Caesalpinia spinosa. (i. flor, ii. fruto). $\boldsymbol{b}$. FABACEAE / LEGUMINOSAE. Dalea coerulea. $c$. FABACEAE / LEGUMINOSAE. Galactia striata. FABACEAE / LEGUMINOSAE. d. Indigofera suffruticosa. (i. fruto, $i$. flor). e. MORACEAE. Morus alba. $f$. RHAMNACEAE. Frangula goudotiana. (i. flor, ii. fruto). g. ROSACEAE. Eriobotrya japonica. $\boldsymbol{h}$. BETULACEAE. Alnus acumina. (i. amento femenino, $i$. amento masculino). $\boldsymbol{i}$. FAGACEAE. Quercus humboldtii. (i. inflorescencia, $i$. fruto). $\boldsymbol{j}$. MYRICACEAE. Morella parvifolia. $\boldsymbol{k}$. LYTHRACEAE. Punica granatum. $\boldsymbol{l}$. MELASTOMATACEAE. Monochaetum bonplandii. $\boldsymbol{m}$. MYRTACEAE. Myrcianthes rhopaloides. $\boldsymbol{n}$. MYRTACEAE. Psidium guianense. (i. fruto, ii. flor). $\tilde{\boldsymbol{n}}$. MYRTACEAE. Syzygium jambos. $\boldsymbol{o}$. ONAGRACEAE. Ludwigia peruviana. p. ANACARDIACEAE. Mauria heterophylla. (i. flor, $i$. fruto). q. LORANTHACEAE. Gaiadendron punctatum. 

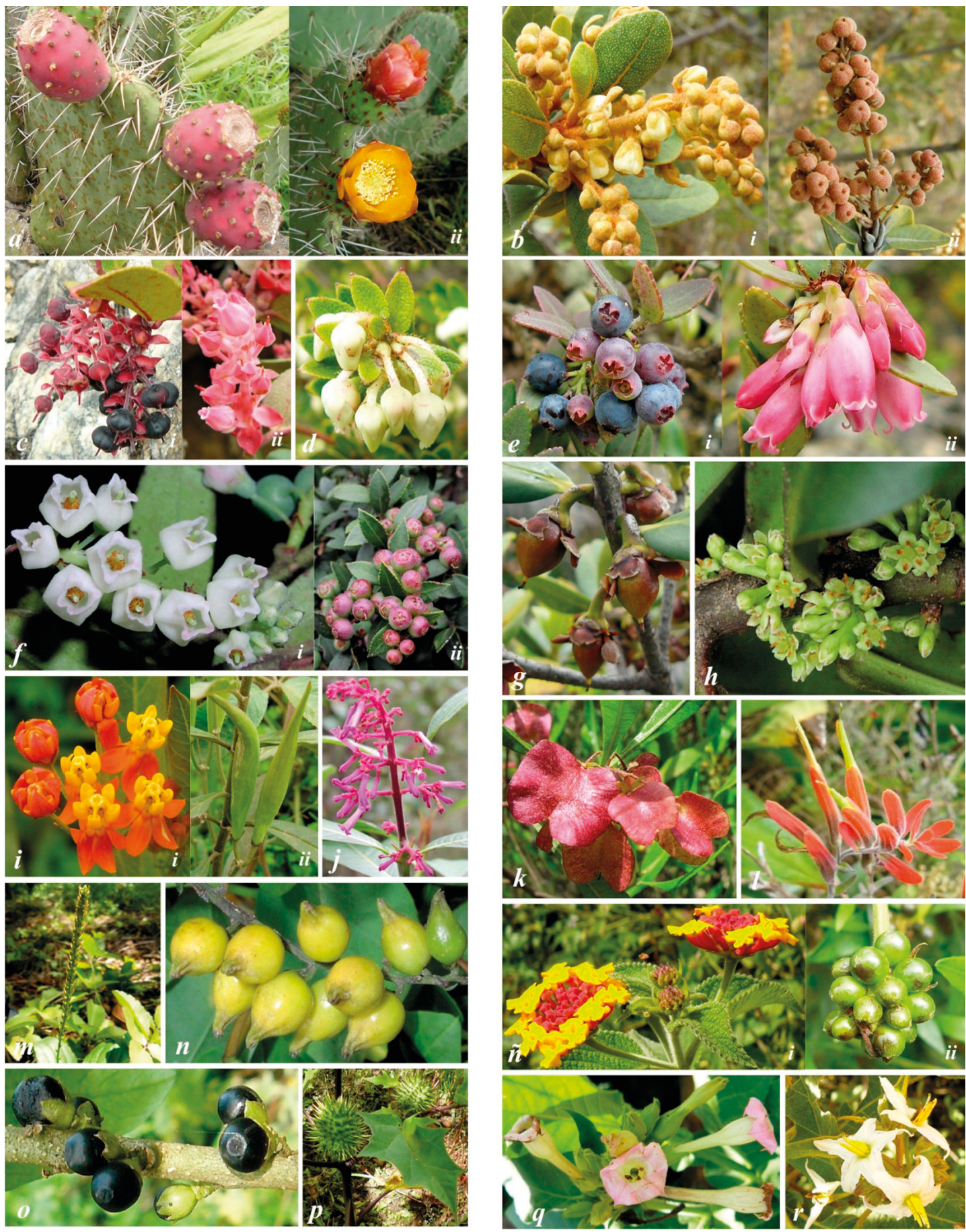

Figura 7. a. CACTACEAE. Opuntia pittieri. ( $i$. fruto, ii. flor). b. CLETHRACEAE. Clethra fimbriata. ( $i$. flor, ii. fruto). $c$. ERICACEAE. Gaultheria erecta. ( $i$. fruto, ii. flor). d. ERICACEAE. Pernettya prostrata. e. ERICACEAE. Vaccinium floribundum. ( $i$. fruto, $i$. flor). $f$. ERICACEAE. Vaccinium meridionale. ( $i$. flor, $i i$. fruto). g. PENTAPHYLACACEAE. Ternstroemia meridionalis. $\boldsymbol{h}$. PRIMULACEAE. Myrsine latifolia. $\boldsymbol{i}$. APOCYNACEAE. Asclepias curassavica. ( $i$. flor, $i$. fruto). j. RUBIACEAE. Palicourea angustifolia. $\boldsymbol{k}$. SAPINDACEAE. Dodonaea viscosa. $\boldsymbol{l}$. OROBANCHACEAE. Castilleja fissifolia. $\boldsymbol{m}$. PLANTAGINACEAE. Plantago major. $\boldsymbol{n}$. VERBENACEAE. Duranta mutisii. $\tilde{\boldsymbol{n}}$. VERBENACEAE. Lantana camara. ( $i$. flor, $i$. fruto). o. SOLANACEAE. Cestrum auriculatum. p. SOLANACEAE. Datura stramonium. $\boldsymbol{q}$. SOLANACEAE. Nicotiana tabacum. $\boldsymbol{r}$. SOLANACEAE. Solanum ovalifolium. 

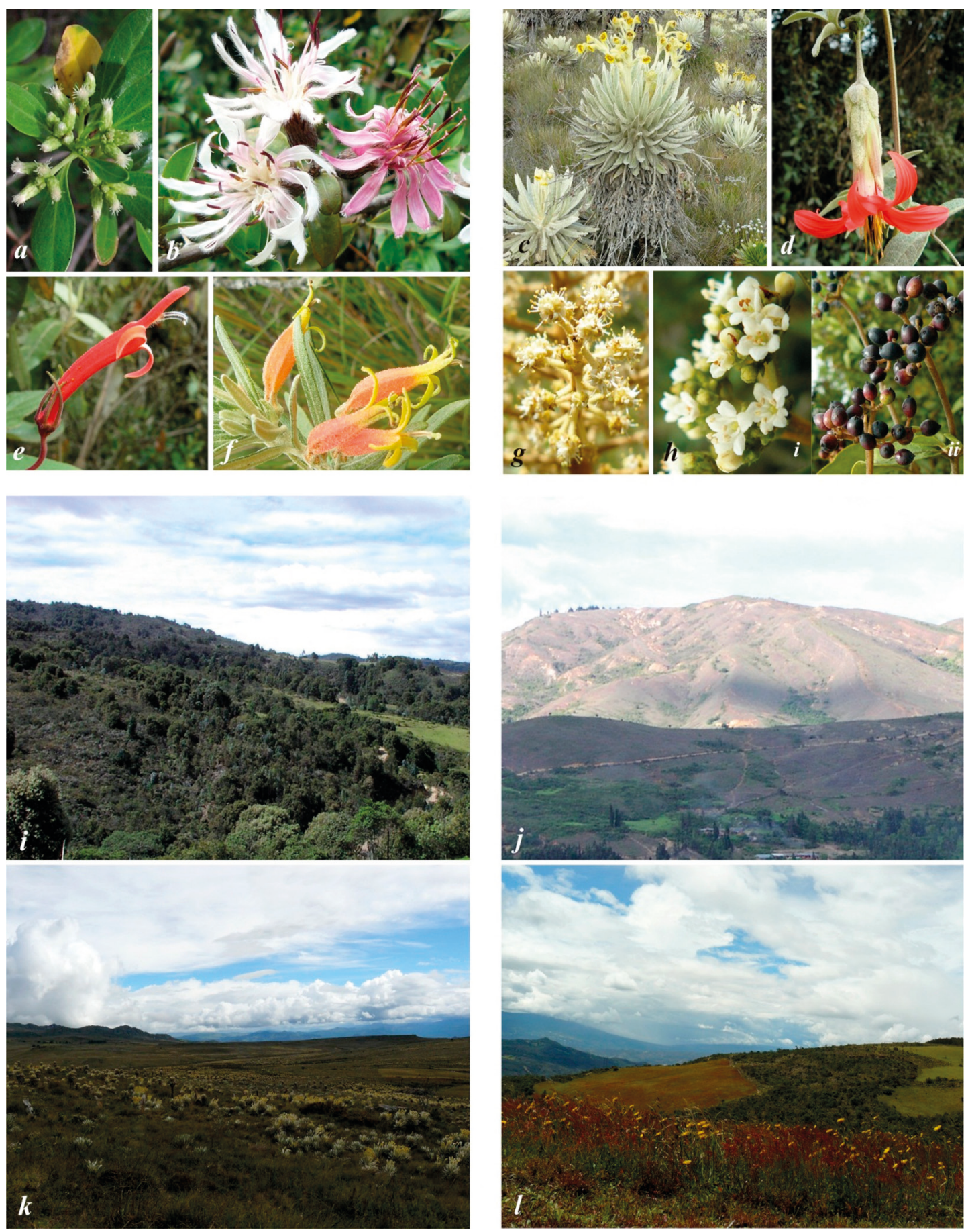

Figura 8. a. ASTERACEAE. Baccharis macrantha. $\boldsymbol{b}$. ASTERACEAE. Barnadesia spinosa. $\boldsymbol{c}$. ASTERACEAE. Espeletia aff. corymbosa. $\boldsymbol{d}$. ASTERACEAE. Mutisia clematis. $\boldsymbol{e}$. CAMPANULACEAE. Centropogon asclepiadeus. $\boldsymbol{f}$. CAMPANULACEAE. Siphocampylus columnae. g. ARALIACEAE. Oreopanax floribundum. $\boldsymbol{h}$. ADOXACEAE. Viburnum tinoides. (i. flor, ii. fruto), $\boldsymbol{i}$. Relicto de Roble -La Chorrera-, $\boldsymbol{j}$. Desierto, -La Candelaria-. $\boldsymbol{k}$. Páramo, -Rabanal-. l. Áreas naturales transformadas, -Firita, Peña Arriba-. 